


\section{DISCLAIMER}

This report was prepared as an account of work sponsored by an agency of the United States Government. Neither the United States Government nor any agency Thereof, nor any of their employees, makes any warranty, express or implied, or assumes any legal liability or responsibility for the accuracy, completeness, or usefulness of any information, apparatus, product, or process disclosed, or represents that its use would not infringe privately owned rights. Reference herein to any specific commercial product, process, or service by trade name, trademark, manufacturer, or otherwise does not necessarily constitute or imply its endorsement, recommendation, or favoring by the United States Government or any agency thereof. The views and opinions of authors expressed herein do not necessarily state or reflect those of the United States Government or any agency thereof. 


\section{DISCLAIMER}

Portions of this document may be illegible in electronic image products. Images are produced from the best available original document. 


\section{DISCLAIMER}

"This book was prepared as an account of work sponsored by an agency of the United States Government. Neither the United States Government nor any agency thereof, nor any of their employees, makes any warranty, express or implied, or assumes any legal liability or responsibility for the accuracy, completeness, or usefulness of any information, apparatus, product, or process disclosed, or represents that its use would not infringe privately owned rights. Reference herein to any specific commercial product, process, or service by trade name, trademark, manufacturer, or otherwise, does not necessarily constitute or imply its endorsement, recommendation, or favoring by the United States Government or any agency thereof. The views and opinions of authors expressed herein do not necessarily state or reflect those of the United States Government or any agency thereof."

This report has been reproduced directly from the best available copy.

Available from the National Technical Information Service, U. S. Department of Commerce, Springfield, Virginia 22161.

Price: Paper Copy $\$ 11.00$

Microfiche $\$ 3.50$ 
SAN-1176-T1(Vol.4)

Distribution Category UC-95f

\section{ENERGY STUDY OF RAILROAD FREIGHT TRANSPORTATION}

Volume 4: Efficiency Improvements and Industry Future

August 1979

Work Performed Under Contract No. EY-76-C-03-1176

Prepared for:

U. S. Department of Energy

Systems Efficiency Branch

Transportation Programs Office

Stanford Research Institute

Menlo Park, California 
0

○ 


\section{PREFACE}

The Energy Research and Development Administration (ERDA)*, recognizing the need for an assessment of energy usage by railroad freight and passenger services and by rail transit systems, has sponsored the Energy Study of Rail Transportation as part of a comprehensive energy conservation program. The objectives of the study were:

- To describe rail transportation systems in terms of physical, operating, and economic charateristics; and to relate energy usage, services rendered, and costs.

- To describe the roles of private and public institutions in ownership, operation, regulation, tariff, and fare determination, and subsidization of rail transportation.

- To describe possible ways to improve efficiency.

- To provide data that the Government may use to determine its future role.

Work was organized in four tasks:

- Description of rail transportation industries

- Regulation, tariff, and institutional relations

- Efficiency improvements

- Industry future and federal role

Results of the study are published in two report series of four volumes each, as follows:

ENERGY STUDY OF RAILROAD FREIGHT TRANSPORTATION:

Executive Summary, Volume I

Industry Description, Volume II

Regulation and Tariff, Volume III

Efficiency Improvements and Industry Future, Volume IV

ENERGY STUDY OF RAIL PASSENGER TRANSPORTATION:

Executive Summary, Volume I

Description of Operating Systems, Volume II

Institutions, Volume III

Efficiency Improvements and Industry Future, Volume IV

* The functions of ERDA have been transferred to the U.S. Department of Energy 
The Energy Study of Rail Transportation was performed by SRI Internationa1, Men1o Park, California, under Contract EY-76-C-03-1176. Ms. Estella Romo and Mr. Richard Alpaugh of ERDA were the contract monitors. Dr. Robert S. Ratner was the project supervisor. Mr. Albert E. Moon was project leader and task leader for freight railroad studies. Mr. Clark Henderson was task leader for passenger rail studies.

This report is Volume IV of the Energy Study of Railroad Freight Transportation. Mr. Moon and Mr. H. Steven Procter were principal authors. Contributions to the text were prepared by Suzelle Ruano and Stephen J. Petracek. Participants in the research included: Randal1 Pozdena, Judith Monaco, David Marimont, Peter Wong, and Marika Garskis.

The Energy Study of Railroad Freight Transportation was completed at an earlier date. It has not been printed prior to this time because of delays in its review and so that it could be released simultaneously with its companion piece, the Energy Study of Railroad Passenger Transportation. While more recent statistics are available for some aspects of the study, the generalized conclusions drawn and recommendations made for energy conservation actions still hold. Technologies and practices are little changed and it is believed the report can be as useful in this form as if it were updated, which could only be accomplished at significant cost. 
CONTENTS

PREFACE . . . . . . . . . . . . . . . . . . . . . . iii

LIST OF ILLUSTRATIONS . . . . . . . . . . . . . . . . . ix

LIST OF TABLES . . . . . . . . . . . . . . . . . . . . . . . $\mathrm{x}$

I INTRODUCTION . . . . . . . . . . . . . . . . . . 1

II SUMMARY

Recommendations . . . . . . . . . . . . . 10

Improve Hardware Technology . . . . . . . . . . 10

Encourage Railroad Operating Companies

to Take Energy Conservation Measures . . . . . . . . . 11

Promote Rail Transportation as an Alternative

to More Energy-Intensive Modes . . . . . . . . . . . . 11

Assure That Regulatory Policies Give Proper

Weight to Energy Conservation . . . . . . . . . 11

III MARKETABILITY OF NEW TECHNOLOGY IN THE RAILROAD INDUSTRY • • 13

Process of Technological Change . . . . . . . . . . . . 13

Factors Influencing Technological Change . . . . . . . . . 14

Industry and Market Structure . . . . . . . . . . 14

Regulation ................. 16

Funds ...................... 17

Labor Regulations . . . . . . . . . . . . . 18

Railway Suppliers ................. 19

Outlook for the Railroad Industry . . . . . . . . . . . 19

Structure of the Railroad Industry . . . . . . . . 20

Future Market for Railroad Freight Transportation . . . 21

Rationalized Freight Transportation System

of the Future . . . . . . . . . . . . . . 23

Imp1ications for Marketing Improved Hardware

and Adopting Improved Operations . . . . . . . . . . 24

IV EFFICIENCY IMPROVEMENTS . . . . . . . . . . . . . . 25

Lighter Equipment Weight . . . . . . . . . . . . 26

Lightweight Freight Cars . . . . . . . . . . . . . 26

Positive Traction Whee1 Slip Control . . . . . . . . 27

Elimination of the Caboose... . . . . . . . . 29

Turbine Locomotives . . . . . . . . . . . . . 29

Operations ..................... . . 31

Circuity . . . . . . . . . . . . . . . 31

Empty Car Mileage Reduction ............. 32 
Fuel Handling . . . . . . . . . . . . . . . . 33

Helper Crew Districts .... . . . . . . . . . 34

Acceleration and Speed Efficiency .......... 35

Locomotive and Equipment Efficiency . . . . . . . . . . . 37

Diesel Waste Heat Recovery . . . . . . . . . . . . 37

Adiabatic Diesel ..... . . . . . . . . . . . 43

Improved Maintenance Practices . . . . . . . . . . 43

Consist Load Matching . . . . . . . . . . . . . . . 44

Diesel-Hydraulic Locomotives . . . . . . . . . . . 45

Wheel Bearing and Seal Resistance... . . . . . . . 46

Regeneration ............... . . . . . . 48

Wayside Energy Storage .. . . . . . . . . . . 48

Onboard Energy Systems . . . . . . . . . . . . . 53

Alternative Fuels . . . . . . . . . . . . . . . 55

Petroleum-Derived Fuels... . . . . . . . . . 55

Derived Synfuels ................ 56

Ammonia ................... 57

Hydrogen ..................... 58

Railroad Electrification ............ . 60

$\mathrm{V}$ INTERMODAL SYSTEMS .................... . . 65

Rationale for an Intermodal System . . . . . . . . . . 65

Present Intermodal Systems . . . . . . . . . . . . 66

Development of an Intermodal System . . . . . . . . . 70

Advanced Intermodal Systems . . . . . . . . . . . . 71

VI MODAL SHIFT . . . . . . . . . . . . . . . . 75

Moda1 Competition Between Truck and Railroad . ....... 75

Modal Analysis . . . . . . . . . . . . . . . 75

Economics of Transportation Cost and Performance

in the Production and Distribution Process . . . . . 75

Relative Performance of Truck and Railroad

Transportation ................ 78

Modal Shares of Various Commodities . . . . . . . . . 81

Energy Conservation through Less Energy-Intensive Modes . 82

Improving Railroad Service . . . . . . . . . 85

VII RECOMMENDATIONS FOR RAILROAD ENERGY CONSERVATION

RESEARCH AND DEVELOPMENT . . . . . . . . . . . . . . 89

New Hardware Technology . . . . . . . . . . . . . . 89

Diesel Locomotive Waste Heat Recovery . . . . . . . . 89

Wheel Bearing Sea1 Resistance... . . . . . . . . . 91

Lightweight Freight Cars . . . . . . . . . . . 92

Positive Traction Contro1 . . . . . . . . . . . . 92

Energy Storage . . . . . . . . . . . . . . 92

Track Structure................... 92

Intermodal Systems Analysis . . . . . . . . . . . 92

Alternative Fuels . . . . . . . . . . . . 93

Railroad Operations . . . . . . . . . . . . . 93 
VII RECOMMENDATIONS FOR RAILROAD ENERGY CONSERVATION

RESEARCH AND DEVELOPMENT (Continued)

Improved Timing and Standards of Maintenance . . . . . 93 Speed Reduction and More Nearly Optimal Train Operations .................. . 9 94

Regulatory Policies .................. . 94

Circuity Reduction . . . . . . . . . . . . . 94

Improved Freight Car Utilization . . . . . . . . . 94

Revision of Long-Haul Rates . . . . . . . . . . . 95

Branch-Line Abandonment . . . . . . . . . . . . . 95

Modal Shifts to Railroads ................. 95

APPENDICES

A RAILROAD ENERGY RESEARCH AND JEVELOPMENT . . . . . . . . . . 99

B MODEL NETWORK DESCRIPTION . . . . . . . . . . . 119

REFERENCES ......................... 123

BIBLIOGRAPHY . . . . . . . . . . . . . . . . . . . 127 
-

.




\section{ILLUSTRATIONS}

1 Distribution of Railroad Ton-Miles:

1973 Class I Railroad Freight Service . . . . . . . . . . . 4

2 The Process of Technological Change . . . . . . . . . . . . 14

3 Rankine Bottoming Cycle for Railroad Locomotive Diesel . . . 39

4 Sum of Present Worth Versus Years for

Diese1 Waste Heat Recovery System . . . . . . . . . . . . 41

5 Diese1 Waste Heat Recovery Fuel Saved Versus Payback . . . . . 42

6 Relationship Between Electrification Efforts and Petroleum Savings................ 61

7 Topical Clearance Envelope and Freight Cross Sections . . . . . 69

8 Two Wide-Gage Container Size Limits and Stacking Alternatives . . . . . . . . . . . . . . . 73

9 Manufacture and Distribution of Goods . . . . . . . . . . 76

10 Inventory Cost Components . . . . . . . . . . . . . 77

11 Inventory Level with Uncertain Demand and order Filling Time .78

12 Effect of Transit Time on Stock Leve1 . . . . . . . . . . 79

13 Effect of Changing Variance of Trip Time on Inventory Level . . 80

14 Comparative Rail, TOFC, and Truck Transit Times . . . . . . . . 81

15 Relationship between Reliability and Mean Trip Time . . . . 82

16 Distribution of Intercity Ton-Miles By Means of Transport: 1972 . . . . . . . . . . . . 83

17 Mode Predominance as a Function of Shipment Size and Distance Shipped . . . . . . . . . . . . . 85 
TABLES

1 Estimated Fuel Allocation for All U.S. Class I

Freight Railroad Operations: 1973 . . . . . . . . . . . . 2

2 Sensitivity of Fuel Consumed to Incremental Value of Curvature, Acceleration, and Grade for U.S.

Class I Freight Railroads: 1973 . . . . . . . . . . . . 3

3 Results of Long-Run Average Cost and Energy Model . . . . . . 8

4 Ratings of Energy-Saving Improvements . . . . . . . . . . 9

5 Projections of Economic and Transportation

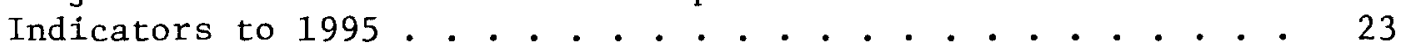

6 Expected Technical and Cost Characteristics of Selected Energy Storage Systems for Use by Electric Utilities . . . . . 49

7 Costs of Proposed Energy Storage Systems . . . . . . . . . . 50

8 Energy Storage Comparison . . . . . . . . . . . . . 54

B-1 Main-Line Variables of the Long-Run Average Cost and Energy Model . . . . . . . . . . . 120

B-2 Assumed Values and Inputs to the Long-Run Average Cost and Energy Model 


\section{INTRODUCTION}

Railroad equipment and operating practices were largely developed in an era during which the price of fuel was a relatively minor part of the cost of railroad operations; however, fuel has now become a scarce and expensive resource. Although many opportunities exist for installing new equipment and operating practices that will result in fuel conservation, cost and market factors can promote or retard the rate at which changes are adopted, and only limited technology may be available for use in conservation applications. The purpose of this report is to identify conservation opportunities and describe potential technological and operational improvements that can be introduced; to analyze the process of introducing new technology in the railroad industry; to assess the future of the railroad industry; and to identify research and development that will contribute to the adoption of energy conservation equipment or processes in the industry.

From the analysis and classification of railroad fuel consumption, we will classify areas of improvement and provide insight into the magnitude of the improvement that might be possible. We will also identify methods by which the improvement might be implemented.

Statistics on consumption of railroad fuel are not collected for all U.S. railroads. Therefore, to estimate components of railroad fuel use, we must allocate the reported fuel consumed by U.S. railroads to: spillage and unaccounted losses; engine idling; traction fuel for overcoming train resistance on level tangent track; and grade, curvature, acceleration, higher-than-nominal speeds, and higher-than-nominal specific fuel consumption ( $\operatorname{spfc})$.

Tables 1 and 2 show the magnitude of fuel consumed by freight movement. Table 1 shows that, in 1973, an estimated 3,325 million gal of fuel or equivalent electric energy were actually input to locomotives on U.S. Class I railroads. Of this amount, 744 million gal (about 23\%) powered idling locomotives. The fuel was used to produce a total of 2,057 million gross ton-miles of traffic which required 1,949 million gal (59\%) of fuel for movement over tangent level track, and an additional 600 million gal $(18 \%)$ to move freight up grade and around curvature, and to overcome higher specific fuel consumption. Table 2 shows a tentative allocation of the $600 \mathrm{million}$ gal. The total of the values shown accounts for approximately the amount of fuel allocated to grade, curvature, acceleration, higher specific fuel consumption, and increased speed in Table 1 . We consider the values for curvature and acceleration to be smaller than those actually encountered. The variation in specific fuel consumption is about $10 \%$ of the accepted figure. An average reduction in grade of $0.01 \%$ per mile (over $0.3 \%$ grade) might 
Table 1

ESTIMATED FUEL ALLOCATION FOR ALL U.S. CLASS I

FREIGHT RAILROAD OPERATIONS: 1973

Reported nationwide fuel consumption (road units)

Equivalent fuel for electrical power used for traction

Fuel allocated to spillage and unaccounted for

Total fuel consumed

Amount

$3,665 \times 10^{6} \mathrm{gal}^{*}$

$7.4 \times 10^{6} \mathrm{gal}^{\dagger}$

$367 \times 10^{6} \mathrm{gal}^{\dagger}$

$3,325 \times 10^{6} \mathrm{gal}$

Allocation of remaining fuel

Idle time, $148.8 \times 10^{6} \mathrm{hr}$

Fuel @ $5 \mathrm{gal} / \mathrm{hr}$

Traction fuel @ $0.06^{\circ} \mathrm{gal} / 100 \mathrm{ft}$-tons

$744 \times 10^{6} \mathrm{gal}^{\S}$

Grade, curvature, acceleration, higher specific

fuel consumption, and increased speed

$1,949 \times 10^{6} \mathrm{gal}^{* *}$

$632 \times 10^{6} \mathrm{gal}^{\ddagger}$

$\star$

Interstate Commerce Commission, Bureau of Accounts, "Eighty-Seventh Annual Report on Transportation Statistics in the United States for the Year Ending December 31, 1973," Interstate Commerce Commission, Washington, D.C.

$+321.5 \times 10^{6} \mathrm{kWh}$ of electrical energy was used for traction in road services. This was converted to gallons of fuel at the rate of 11,700 Btu of central station input per $\mathrm{kWh}$ at the driver, and a fuel heating value of $137,300 \mathrm{Btu}$ per gallon. The resulting factor of $0.085 \mathrm{gal}$ per $\mathrm{kWh}$ converts the electrical energy consumed to 27.4 × $10^{6} \mathrm{gal}$.

SRI estimate.

$\S$

Idling time was taken at twice the operating time estimated for 1ocomotives. Number of locomotives per train was computed at 2.9 from ICC statistics of locomotive unit-miles and train-miles. Reported trainhours in freight service of $25,432,000$ resulted in an idling time of $148.8 \times 10^{6} \mathrm{~h}$.

** Traction fuel was estimated by taking $2,057 \times 10^{9}$ ton-mi at $6 \mathrm{lb} / \mathrm{ton}$ resistance. 
Table 2

SENSITIVITY OF FUEL CONSUMED TO INCREMENTAL VALUES OF CURVATURE, ACCELERATION, AND GRADE FOR U.S. CLASS I

FREIGHT RAILROADS: 1973

\begin{tabular}{|l|l|c|}
\hline \multicolumn{1}{|c|}{$\begin{array}{c}\text { Train Resistance } \\
\text { Source }\end{array}$} & \multicolumn{1}{|c|}{ Increment } & $\begin{array}{c}\text { Fuel Consumed per } \\
\text { Increment }\end{array}$ \\
\hline Curvature & $10^{\circ} / \mathrm{mi}$ & $49 \times 10^{6} \mathrm{gal}$ \\
Acceleration & $\begin{array}{l}\text { One acceleration } \\
\text { to } 30 \mathrm{mph} / 100 \\
\text { train mi }\end{array}$ & $37 \times 10^{6} \mathrm{gal}$ \\
$\begin{array}{l}\text { Grade over } 0.3 \% / \mathrm{mi} \\
\begin{array}{c}\text { Increased specific } \\
\text { fuel consumption }\end{array}\end{array}$ & $\begin{array}{l}0.005 \mathrm{gal} / 1000 \\
\mathrm{ft}-\mathrm{tons}\end{array}$ & $65 \times 10^{6} \mathrm{gal}$ \\
$\begin{array}{c}\text { Increase in train } \\
\text { speed }\end{array}$ & $4 \mathrm{mph}$ & $163 \times 10^{6} \mathrm{gal}$ \\
\hline
\end{tabular}

be considered high as a nationwide average. Table 2 illustrates the sensitivity of fuel consumption to these factors. Consumption is especially sensitive to speed.

Additional insight can be gained by considering the total movement of freight and equipment moved by the railroads. Figure 1 shows the gross ton-miles of movement broken down by net freight, circuity, loaded cars, locomotives, cabooses, and empty car backhaul. By assuming that gross ton-miles can serve as a proxy for actual fuel consumption, we can estimate the potential for national fuel savings for weight- and mileage-related improvements.

Figure 1 and Tables 1 and 2 provide a basis for analyzing components of fuel consumption. For example, if equipment weight were reduced, less fuel would be consumed in moving locomotives and cars, both empty and loaded. If we allocate fuel consumption, exclusive of idle and spillage, to movement of freight and equipment, 1,298 million gal of fuel are consumed in moving equipment. From Figure 1, a total of 1,035 billion ton-miles are involved with moving loaded cars, locomotives, cabooses, and empty cars. This is $50.3 \%$ of the reported 2,053 billion total ton-miles. We therefore assumed that $50.3 \%$ of the 2,581 million gal consumed (1,298 million ga1), exclusive of idle and spillage, was used to move equipment. If all of the equipment weight were eliminated, this figure would be an estimate of the fuel that would not be used. The fuel consumption figure therefore shows a theoretical maximum that could be saved if all of the weight or distance were eliminated. While it is 


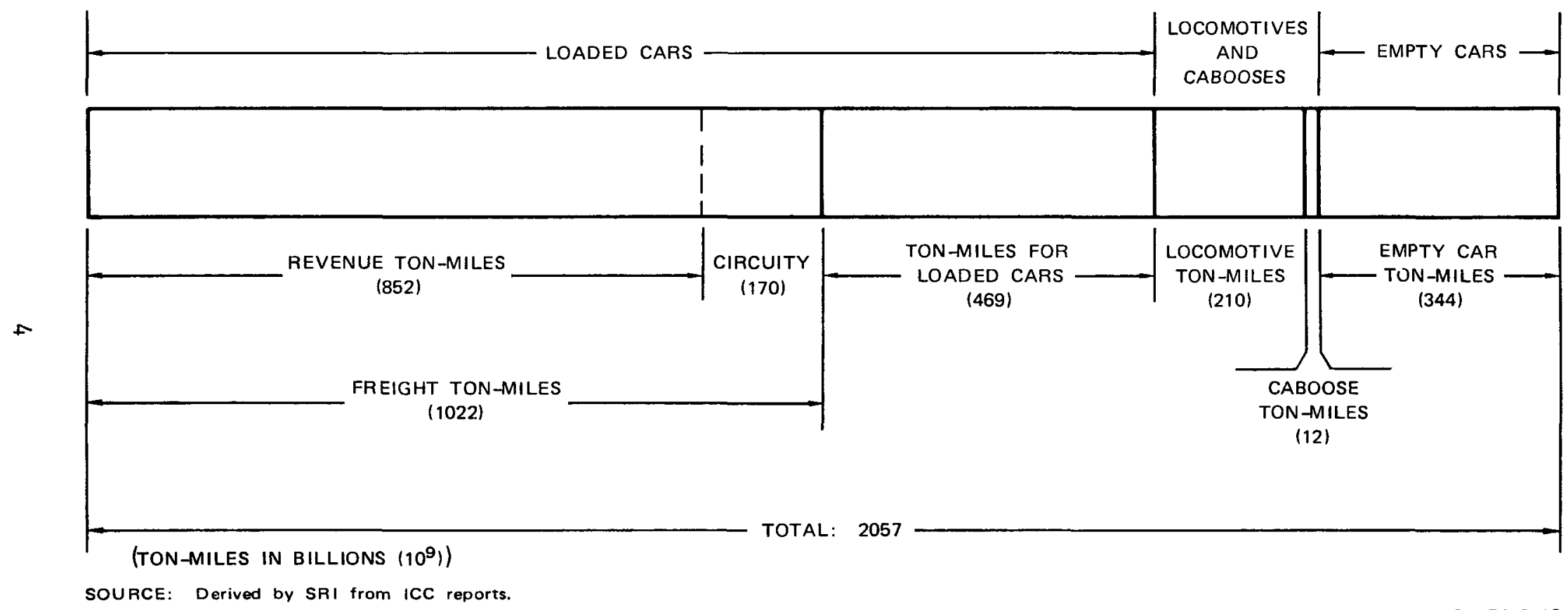

FIGURE 1 DISTRIBUTION OF RAILROAD TON-MILES: 1973 CLASS I RAILROAD FREIGHT SERVICE 
unlikely that the entire amount would ever be eliminated, the analysis indicates where the areas of consumption are, and provides a first approximation to showing the most promising areas to attack.

This analysis indicates the following areas for investigation:

- Lighter weight equipment: 1.3 billion gal used to move equipment

- Operations improvement: 1.5 billion gal used in fuel losses, locomotive idling, and empty car movement

- Locomotive efficiency: 2.5 billion gal used to produce traction work

- Roadbed: 0.6 billion gal used in curves, grades, and braking energy.

In addition to those areas of fuel conservation that can be identified from analysis of Tables 1 and 2 and Figure 1 , other fuel conservation measures are possible. These include fuel substitution, intermodal operations, and moda1 shifts.

Fuel substitution is the replacement of petroleum-derived diesel fuel by synthetic liquid fuels or by other energy sources, such as electrical energy produced from coal or nuclear plants. The characteristics and costs of synthetic fuels are discussed in Section IV. Intermodal operations involve the pickup and delivery of freight at terminal ends of shipments by truck, linehaul carriage by rail, and a system of rapid transfer of freight from one to the other at terminal points. Intermodal operations are discussed in Section V. Finally, shifting of freight shipment from trucks to rails would generally result in a savings in energy. Section VI discusses the shipper's reasons for using trucks, despite their higher costs, and the possibilities for influencing the choice of shipping mode.

The report analyzes the process of innovation in the railroad industry and the implication for marketing; discusses and evaluates potential technological and operational improvements; discusses intermodal operation; analyzes the potential for modal shift; and provides recommendations for energy conservation in railroad freight transportation. 
0

0 


\section{SUMMARY}

The rate at which the railroad industry can absorb technological or operational changes of the magnitude necessary to have an impact on energy conservation is 1imited. The railroad industry and its market structure results in a large number of companies that must simultaneously compete and cooperate to make common use of new ideas and equipment. Limitation of funds, caused by low returns on capital, forces investment in projects with rapid payback. Lenders prefer to lend on rolling stock because it can be repossessed as collateral and has a widespread market if it is of conventional and compatible design. Regulations developed over the years make innovative operations difficult to implement, and a complex web of work rules achieved by years of bargaining with employees provides many restrictions on what can be done. Finally, the supply industry is predominately made of smaller companies that have limited capital for development and demonstration of new technologies.

As services constitute a larger and larger share of the country's gross national product, the railroad industry is growing more slowly than the rest of the economy while trucking accounts for the transportation of the increasingly high-valued manufactured goods. As a result, the railroad industry has limited means by which growth can erase the result of gambles in technology that do not pay off.

The constraints of the industry itself and the outlook for future growth dictate that any technology that is adopted by the railroads must have been demonstrated to meet its performance requirements and must have been demonstrated to be durable and economical. The need for proven technology has forced the attention of the project team toward evaluation and consideration of technologies and operational improvements based primarily on principles that have been extensively proven in other applications; the primary requirement for adoption by the railroads is the demonstration of these principles for a railroad application in a railroad environment. Because of the supply industry structure, government support of the demonstration and development may be necessary.

The project team reviewed and analyzed proposed energy and fuel saving technological and operational changes. Table 3 shows the results of an analysis of certain of these proposals, using the Long-Run Average Cost and Energy Model developed in an earlier task. Table 4 shows several other proposals that were reviewed, but which could not be described well enough for qualitative analysis. Table 3 shows that both energy and cost savings can be achieved through the use of positive 
Table 3

RESULTS OF LONG-RUN AVERAGE COST AND ENERGY MODEL

\begin{tabular}{|c|c|c|c|c|c|c|c|}
\hline & \multirow{2}{*}{$\begin{array}{l}\$ / \text { Net } \\
\text { Ton }\end{array}$} & \multirow{2}{*}{$\begin{array}{l}\text { S/Net } \\
\text { Ton- } \\
\text { Mile }\end{array}$} & \multirow{2}{*}{$\begin{array}{l}\text { Gal or } \\
\text { lb/Net } \\
\text { Ton }\end{array}$} & \multirow{2}{*}{$\begin{array}{c}\text { Btu } \\
\left(\mathrm{x} 10^{6}\right) \\
\text { Btu/ } \\
\text { Net Ton }\end{array}$} & \multicolumn{2}{|c|}{$\begin{array}{c}\text { Percent Increase/ } \\
\text { Decrease from } \\
\text { Base Case } \\
\end{array}$} & \multirow{2}{*}{$\begin{array}{c}\text { Cost-Energy } \\
\text { Ratio } \\
(\$ / B t u \\
\text { Normalized) }\end{array}$} \\
\hline & & & & & Cost $\$$ & Energy & \\
\hline Base Case & 13.4435 & 0.0261 & 1.3243 & 0.1818 & -- & -- & 1 \\
\hline \multicolumn{8}{|l|}{ Equipment weight } \\
\hline - Lightweight freight cars & 13.5269 & 0.0262 & 1.1206 & 0.1538 & $+0.6 \%$ & $-15 \%$ & 1.19 \\
\hline - Positive traction control & 13.3046 & 0.0258 & 1.2410 & 0.1702 & -1 & -6 & 1.06 \\
\hline $\begin{array}{l}\text { - Turbine locomotives } \\
\text { Operations }\end{array}$ & 13.5361 & 0.0262 & 1.4123 & 0.1938 & +0.6 & +7 & 0.94 \\
\hline Empty car management & & & & & & & \\
\hline ( $45 \%$ empty backhaul) & 13.3509 & 0.0259 & 1.2641 & 0.1736 & -1 & -5 & 1.04 \\
\hline ( $42.75 \%$ empty backhau1) & 13.3046 & 0.0258 & 1.2410 & 0.1702 & -1 & -6 & 1.06 \\
\hline Helper crew districts & 13.3972 & 0.0260 & 1.3382 & 0.1836 & -0.3 & +1 & 0.99 \\
\hline \multicolumn{8}{|c|}{ Locomotive and equipment efficiency } \\
\hline - Diesel waste heat recovery & 13.3972 & 0.0260 & 1.2132 & 0.1665 & -0.3 & -8 & 1.12 \\
\hline $\begin{array}{l}\text {. Wheel bearing seal resistance } \\
\text { Regeneration }\end{array}$ & 13.3972 & 0.0260 & 1.2502 & 0.1716 & 0 & -6 & 1.06 \\
\hline $\begin{array}{l}\text { - Wayside storage (including } \\
\text { electrified catenary, etc.) }\end{array}$ & 13.9528 & 0.0270 & -- & 0.1679 & $+1(+4)$ & $-2(-8)$ & 1.01 \\
\hline $\begin{array}{l}\text { Onboard storage } \\
\text { Alternative fuels }\end{array}$ & 13.4435 & 0.0261 & 1.3058 & 0.1795 & 0 & -1 & 1.01 \\
\hline Petroleum-derived fuels & 13.3509 & 0.0259 & 1.2919 & 0.1836 & -1 & +1 & 0.98 \\
\hline Derived synfuels & 13.7365 & 0.0266 & 1.3243 & 0.1818 & +2 & 0 & -- \\
\hline Ammonia (diese1 combination) & 16.8591 & 0.0327 & $10.47741 \mathrm{~b}$ & 0.4605 & +25 & +153 & 0.50 \\
\hline Hydrogen & 14.9765 & 0.0290 & $3.79281 \mathrm{~b}$ & 0.1957 & +11 & +8 & 1.03 \\
\hline Electrification & 13.8139 & 0.0268 & -- & 0.1702 & +3 & -6 & 1.10 \\
\hline
\end{tabular}


traction contro1, reduced empty backhaul, and diesel waste heat recovery. Of these, diesel waste heat recovery systems produce the greatest fuel savings (some $8 \%$ ). A $7.5 \%$ reduction in empty backhaul of freight cars can also produce a fuel savings, but the effort necessary to achieve such a reduction is not known. The greatest overall fuel savings could be achieved through the exclusive use of lightweight freight cars, but the cost would be higher. Our analysis does not include the additional energy used in the manufacture of these cars. It should also be noted that 1 ightweight equipment would not replace existing equipment completely for many years because of the long life of railroad cars. As expected, electrification can produce very large savings in fuel consumed, but at a very high cost.

Other alternative energy sources increase costs and produce either zero or negative fuel savings. Ammonia shows up very poorly as a substitute fuel, and turbine locomotives fail to produce fuel savings despite their lighter weight, and also result in increased costs.

To analyze the relative value of improvements that were not amenable to modeling, we used a procedure containing factors for potential fuel savings, costs, and implementation. The ratings are subjective because these improvements are not easily quantified. A three-part scale plus an unknown indication were used. For example, if an improvement had good potential for fuel savings, we rated it with a plus. A zero indicated no change, while a minus indicated an estimated negative impact. Unknowns were indicated as a blank. The details of the estimates for each improvement are given in the text. For additional background information on each improvement, the reader is referred to the report on Task 3 .

Each improvement rated according to this scheme is shown in Table 4. The improvements are ranked from most effective to least effective to unknown effectiveness.

Table 4

RATINGS OF ENERGY-SAVING IMPROVEMENTS

\begin{tabular}{|c|c|c|c|}
\hline Improvement & $\begin{array}{c}\text { Fue1 } \\
\text { Savings } \\
\end{array}$ & Costs & $\begin{array}{l}\text { Implementation } \\
\text { Difficulty }\end{array}$ \\
\hline Fuel handling & + & + & + \\
\hline Consist 1 oad matching & + & + & 0 \\
\hline Improved maintenance & + & + & - \\
\hline Elimination of cabooses & + & 0 & - \\
\hline Diesel hydraulic locomotives & + & 0 & - \\
\hline Acceleration and speed reduction & + & & - \\
\hline Intermodal systems & + & & - \\
\hline Elimination of circuitry & + & & - \\
\hline Improved track structure & + & & \\
\hline
\end{tabular}


Recommendations

As a result of our analysis, we recommend research activities to:

- Improve hardware technology

- Encourage railroad operating companies to take energy conservation measures

- Assure that regulatory policies give proper weight to energy conservation

- Promote rail transportation as an alternative to more energy-intensive modes

Our specific recommendations are highlighted below.

\section{Improve Hardware Technology}

Recovering waste heat from the exhaust of a diesel locomotive is possible. Research is needed to demonstrate the efficiency, maintainability, and service life of a heat recovery system in railroad service.

From preliminary estimates of cost and performance, it appears that a bottoming cycle unit would be a good investment at today's fuel prices for a locomotive in average service. The attractiveness of this investment would increase with higher fuel prices and for certain applications where high utilization of the locomotive is achieved.

Federal participation in the development program for a bottoming cycle is needed because the cost is higher than a single supplier would wish to undertake, and the market may develop slowly because of the number of relatively new locomotives now in service or to be in service at the time that a unit would become available. A proposed three-phase development program would result in the construction of a laboratory version of the system from which could be gathered design data, a demonstration of serviceability and durability in railroad service, a feasibility study of retrofitting units on existing locomotives, and a prototype demonstration of retrofit hardware. The estimated time for the demonstration program is about three years, and the estimated cost is $\$ 3.5$ million.

Research is underway or planned on improved wheel bearing sea1 resistance, lightweight freight cars, positive traction control, and wayside and onboard energy storage systems. Additional studies are needed to identify the most promising applications and to examine both the feasibility of retrofitting existing units and the overall energy content of some of the systems. Research is also underway on track structure and track train dynamics and on intermodal systems. The primary thrust of this research is improvement of existing systems, but the energy implications of track structure and intermodal systems need to be clearly identified. In all of these areas, a group representing 
energy interests should support contract monitors, and, in some cases, there should be funding of supporting studies.

Encourage Railroad Operating Companies to Take Energy Conservation Measures

Research and analysis that shows the benefits of alternative operating practices will encourage operating companies to adopt these operating practices. Two areas that deserve further study are the timing of maintenance operations and the optimization of individual train performance. Maintenance based on measurements of engine operating parameters could potentially reduce the cost and frequency of maintenance operations and improve locomotive operating efficiency. Identification of suitable measures, development of policies based on the measurements, and evaluation of the alternative procedures should be the subjects of further research. Optimization of individual train performance would identify a pattern of operation for a particular train to minimize fuel consumed, subject to service constraints for the freight in the train and to such other constraints as system power requirements and line capacity needs. Computer programs, locomotive cab displays, and other elements necessary to improve operating practices are available and need to be brought together to demonstrate energy-saving benefits.

Promote Rail Transportation as an Alternative to More Energy-Intensive Modes

Our analysis shows that the lower costs of railroad transportation compared with trucking are offset by longer rail transit times and uncertainty in the amount of time needed to move a shipment by rail. The costs associated with these longer and more unreliable shipping times for many commodities are less than the added cost of truck shipment. Strategies for improving railroad service and for raising the effective cost of truck service need to be studied for their impact on energy savings, additional transportation and distribution costs, and labor and other interest groups.

\section{Assure That Regulatory Policies Give Proper Weight to Energy} Conservation

Issues analyzed in the course of this study include long-haul versus short-haul rate structure, freight car utilization, circuity reduction, and branch-1ine abandonment. A capability of analyzing the energy impace of these issues and presenting them to regulatory agencies is needed. 
-

- 


\section{MARKETABILITY OF NEW TECHNOLOGY IN THE RAILROAD INDUSTRY}

In subsequent sections, we will show technological improvements that could produce energy savings for the railroad industry. However, the introduction of new technology requires adoption by both institutions and individuals who have become comfortable with their current business methods. In this section, we describe the process of and factors influencing technological change in the railroad industry and discuss the outlook for the industry as background for evaluating conservation proposals that have been made or may be made in the future.

\section{Process of Technological Change}

In the context of this report, technological change is defined as any change in the factors of production that alters the cost, quantity, or quality of production output. ${ }^{*}$ In the railroad industry, these factors include materials, equipment, production or operating processes, labor, and organizations. The principal reasons for changing these factors are to improve:

- Capacity

- Capital and labor productivity (reduce production costs)

- Product quality (the quality of freight service)

- Safety and the general working environment.

Technological change should be viewed as a continuous process of interrelated progressive actions (see Figure 2). Although the simplified framework of the process of technological change in Figure 2 is somewhat incomplete because it does not account for the communication or feedback mechanisms between the different stages of the process, it can serve as a basis for a general discussion of technological change:

- Research refers primarily to applied research--that is, to investigations involving the application of known scientific and technological principles and developments to the solution of a problem.

\footnotetext{
* Much of the material on technological change is summarized from another SRI report relating to the introduction of technological change in railroad switchyards [see S. J. Petracek et al., "Railroad Classification Yard Technology: A Survey and Assessment," Final Report No. FRAORD-76/304, pp. 150-174, SRI project No. 3983, Stanford Research Institute, Men1o Park, California 94025 (July 1976)].
} 


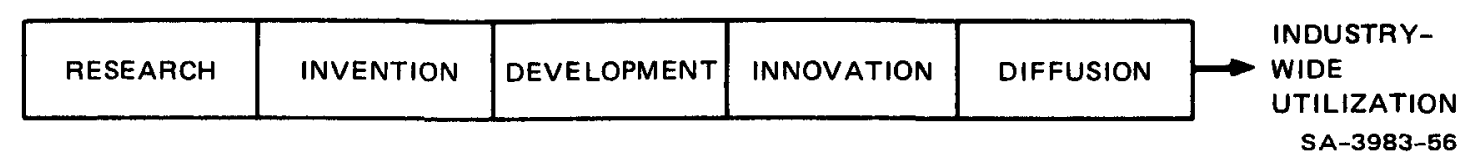

FIGURE 2 THE PROCESS OF TECHNOLOGICAL CHANGE

- Invention is the point at which the concepts, ideas, and information developed during the research stage coalesce into a technically feasible design approach to solving a problem.

- Development is the stage where the basic plan or design is developed into an actual product, process, or technique that can be used as a potential solution to a problem.

- Innovation is the initial adoption of a technology that differs from the current technologies used in an industry. Innovation does not specifically imply a full-scale adoption of a new technology by any individual firm; instead, the term denotes a general pioneering effort in the utilization of a new technology.

- Diffusion is the imitation of the new technology by other firms within the industry, and the degree to which individual firms substitute an innovation for current technology.

Factors Influencing Technological Change

The U.S. railroad system represents the first use of modern transportation technology in the United States. Until recently, railroads dominated intercity freight transportation. However, the development of competing transportation technologies has successfully diverted more than half of the intercity freight traffic (in terms of ton-miles) from the railroads. Although the railroad industry has introduced some technological change, the rate of change has been much slower than that of the competing modes. There is widespread belief, both inside and outside the railroad industry, that U.S. railroad companies are overly reluctant to introduce or adopt new technology. The principal factors that influence, either positively or negatively, the introduction or adoption of new technology in the railroad industry are discussed below.

\section{Industry and Market Structure}

The structure of the U.S. railroad industry significantly influences its process of technological change. Unlike most other large railway systems, the U.S. system is not government owned. It is a conglomeration of several hundred privately owned and operated railroad companies. Some of these companies own and operate extensive rail 
networks that serve large sections of the country, but the majority serve only small regions or local areas.

Because of the conglomerate structure of the U.S. railway system and long-distance freight transportation demand patterns, a large portion of the freight shipped by railroad travels over the lines of more than one company. Efficient handling of such freight requires that individual rail companies use compatible rail technology. A rail system that contains incompatible components, such as track sections of different gages, will waste time and manpower in additional handling of freight during the interchange process.

The necessity of maintaining rail system compatibility can severely constrain the introduction of new technology that is incompatible with existing rail technology. The introduction of incompatible new technology would require large-scale replacement of existing equipment, which would necessitate a massive amount of capital and writeoff of a substantial railroad investment in fixed plant and/or equipment because of the typically long life of railroad equipment.

The relationships among different railroads within the industry are often ambiguous. Although all railroads are elements of a common system and therefore complement the services of one another, different railroads frequently are in competition for rail traffic between certain areas. Because of the regulation of railroad rates, this competition is not based on prices but on quality of service, which includes such factors as reliability, transit time, availability of freight cars, and prevention of damage. Such competition may provide certain incentives for introducing technology that will improve an individual railroad company's quality of service.

Relationships among railroad companies affect the process of technological change in another way. Historic patterns of the introduction of new technology within the industry indicate that some railroads rapidly adopt a new technology, but the majority of railroads delay adoption until the leading railroads have tested and evaluated the new technology.

The speed at which a firm adopts a new technology is directly related to its size and the expected profitability of its investment. Large railroads tend to assume new technology more rapidly than small railroads because of their greater financial resources, experimental facilities, and economically stronger ties with equipment suppliers. However, small railroads may be quicker to utilize a new technology if their expected return on investment is greater. The profitability factor may explain why railroads that lead the industry in introducing one type of technology may be reluctant to introduce other types as rapidly. The trend toward fewer and larger railroad companies is expected to continue or accelerate in the future. This trend can thus be expected to have a mixed, but overall positive, influence on the introduction of new technology. 
The need to expand existing capacity is a primary motivation for technological growth in many industries. The market for railroad transportation can be expected to remain static or, at best, to grow at a very slow rate over the next 20 years. Thus, the addition of new capacity cannot be expected to provide the impetus for technological change.

\section{Regulation}

The railroad energy study examined the relationship between regulation of the railroads and energy consumption. ${ }^{*}$ However, regulation of the railroads also influences the introduction and diffusion of new technology in the industry.

The Association of American Railroads (AAR) was formed in 1934 through the consolidation of other railroad industrial organizations to represent the common interests of the industry in such areas as equipment and safety standards and car movements. Because AAR member railroads operate approximately $95 \%$ of the U.S. railway mileage and carry $99 \%$ of U.S. freight ton-miles, any regulation or standard adopted by the AAR generally becomes an industry standard. Therefore, the AAR significantly influences the process of technological change in the railroad industry through its regulatory and standard-setting activities.

Various federal, state, and local agencies also regulate the industry. Government economic and safety regulatory activities influence technological change most strongly. Other types of government regulation influence technological change to a lesser extent.

The government agency principally responsible for economic regulation of the railroad industry is the Interstate Commerce Commission (ICC), which was established by the Interstate Commerce Act of 1887 and was the first major federal regulatory agency. The charter and powers of the ICC have been modified several times since its establishment. At present, the ICC regulates the railroads primarily in the areas of rates, market entry and exit, and utilization of plants and equipment. Forty-seven states also have established regulatory commissions. However, because the interstate operations of most railways limit the regulatory authority of state commissions, these commissions have less effect on technological change than the ICC has.

Economic regulation can dramatically influence the direction, amount, and rate of technological change in the railroad industry. The highly regulated rate structure of the railroads has been cited as a major barrier to the innovative process within the industry. The current policy of the ICC is heavily committed to maintaining stability within

${ }^{*}$ References are listed at the end of this report. 
the U.S. surface freight transportation system. The Commission is extremely adverse to establishing rates that may foster large reallocation of traffic among competing railroad companies or among railroads and other competing transportation modes.

The ICC also regulates market entry and exit. Although the regulation of market entry probably has little impact on technological change, the regulation of a railroad's desire to exit a market by abandoning its trackage and right-of-way forces the railroad to continue an unprofitable service and thus lessens the availability of capital for investment in new technology. Technological change is also greatly restricted by regulation of intermodal mergers and acquisitions.

The regulation of safety is one of the major constraints on any transportation system. Railroad safety is principally governed by the Federal Railroad Administration (FRA), which has jurisdiction over such areas as track maintenance, inspection standards, locomotives, signals, safety appliances, and power brakes.

Safety regulations have a direct impact on the pattern of technological change within the railroad industry because they force the introduction and diffusion of new equipment throughout the industry. The regulation of railroad operating procedures by the FRA can either encourage or discourage efficient railroad operations while increasing safety.

There are a number of other areas besides economics and safety where the activities of government agencies other than the ICC and FRA can influence the technological change process in the railroad industry. Several laws have been enacted toward regulating railroad investment and capital generation. Because the availability of capital is often vital to the introduction of new technology, regulation of investment and capital generation can play a large role in determining whether new technology will be introduced and how rapidly it will be diffused.

Public concern for the environment has caused the development of numerous regulations that impact the railroad industry. The Environmental Protection Agency (EPA) is the principal regulatory agency in this area. Environmental protection regulations usually specify an acceptable standard level of performance that must be achieved, and the manner of achieving this standard is often the responsibility of the regulated industry. Such regulations provide impetus for the development of alternative and competing technologies because individual hardware items and operating procedures to be used to establish a standard level of performance are not usually specified.

\section{$\underline{\text { Funds }}$}

Relatively long capital turnover times (the ratio of capital to revenues), low earnings on investment, maintenance costs, and inflation 
are placing a squeeze on the railroad industry and its ability to generate necessary operating capital.

The competing demands for funds generated internally and for borrowed money are great. Dividends and expenditures to replace and upgrade plant and equipment are primary demands. Some of the capital expenditures are going for technologically advanced equipment; however, innovative equipment is usually installed only when replacement is required.

Because the demand for capital expenditures exceeds the supply of funds, the railroads must carefully budget their capital resources. Technological changes that could produce more capital and earning power often cannot be made because of capital shortage. New methods of financing or new sources of funds will be required to support the introduction and utilization of new and beneficial technology. Innovations that make existing equipment obsolete are also discouraged by the shortage of capita1.

\section{Labor Regulations}

The reactions of railroad employees to technological change can significantly influence the success or failure of the change. If the labor force resists a certain change, the change will generally not succeed.

The labor force of the U.S. railroad industry is organized into powerful unions. Railroad operating personnel are represented by the United Transportation Union (UTU) and the independent Brotherhood of Locomotive Engineers (BLE). Nonoperating railroad personnel are represented by numerous unions, many of which represent workers in other industries as well.

A major concern of railroad labor unions is the impact of new technology on job security, which has long been considered a critical issue by railroad labor. The railroad labor force decreased from $1,352,000$ in 1947 to 526,000 in 1972, a 61\% dec1ine over a 25-year period. Another factor contributing to labor's concern about job security is that many railway workers have developed unique skills that are not applicable in other industries. It is thus difficult to justify the introduction of any new technology that will decrease the size of the railroad labor force.

Railroad wage rates can also influence or be influenced by the introduction of new technology. If a new technology requires workers to learn new skills, the union often negotiates a wage increase. If a technological change reduces skill requirements, the union generally attempts to maintain the previous wage scale. If a technological change raises efficiency and company earnings, the union often tries to garner a share of the benefits gained through increased wage rates. Despite the $61 \%$ decrease in overall railroad employment between 1947 and 1972 , 
the percentage of operating revenues used for employee compensation has not decreased significantly. Employee compensation accounted for $49.9 \%$ of total operating revenues in 1947 and $47.6 \%$ in 1972 .

\section{Railway Suppliers}

Railroad companies are fundamentally service rather than manufacturing companies and therefore depend heavily on railway suppliers for the development of new equipment technology. The railway suppliers can have a strong impact on the amount and type of technology offered to the railroads. Incentives for railroad suppliers to finance research and development are limited if there is little prospect for large-scale adoption of the developed technology.

\section{Outlook for the Railroad Industry}

The number and size of railroad companies and the market prospects for the industry are factors that influence the adoption of new technology in the railroad industry. The prospects for future changes in the industry and market structure are examined below.

In the early 1970s, there were seven bankruptcies among the approximately 75 Class I railroads in the United States. Among the factors contributing to the bankruptcies were inadequate profits; deteriorating roadbed and track structure; lack of adequate financing; competition; public policies that financed highway and waterway construction and operation on a pay-as-you-go or less than pay-as-you-go basis; antiquated regulations; and a multitude of labor problems. The key role of the railroads in the national economy forced congressional action in the form of the Regional Railroad Reorganization Act (the 3R's Act) of 1973 which provided for planning of a unified railroad company to be made up of the combination of parts of six of the bankruptcies, with provisions for abandoning whatever trackage the planners felt would be unprofitable. Subsequent legislation, the Railroad Revitalization and Regulatory Reform Act (the 4R's Act) of 1976, provided for both federal financing for rehabilitation of track, roadbed, and equipment and limited rate flexibility for the railroads. The act also made the possibility of railroad mergers more likely by limiting the amount of time the ICC could take to act on proposals and by providing that the Secretary of Transportation could initiate merger proposals with the consent of the railroads. These two acts provide an initial direction to the future course of the railroad industry.

The future of the railroad industry is likely to be characterized by increased merger activity resulting in fewer railroad operating companies, fewer miles of railroad, and a shifting market for railroad transportation that will depend on future levels of prosperity. Whatever the future level of national prosperity, the railroads will not increase their traffic by more than a very modest annual rate, and traffic could 
decrease under some circumstances. Further in the future, a rationalized freight system may evolve where three freight services will provide for (1) bulk commodity movement, (2) nonbulk commodity movement over distances shorter than bulk movements, and (3) combined truck-rail intermodal service for nonbulk commodities.

\section{Structure of the Railroad Industry}

Railroads in the United States were built by 6,000 companies without any overall plan for the integration of operations and services they now perform. As a result, consolidations have occurred from the very start of the industry, and, since 1916, railroad mileage has decreased by about $20 \% .^{2}$

Mergers of railroad operating companies are expected to have the following benefits:

- A larger company should have the financial and management resources to overcome short-range adversities and to build a sound company.

- Consolidation of paralle1, competing lines should allow for both the consolidation of traffic on lines that can be operated at densities that have lower costs and the elimination of other duplicate facilities.

- Consolidation of connecting, or end-to-end, lines should eliminate switching at interchange points, provide onecarrier responsibility for a greater part of the shipment, and produce better service.

- A combined railroad might be in a position to solicit traffic for movements that would be unprofitable for individual roads but profitable for the combination.

Whether these benefits can actually be achieved is a matter of some debate. Certainly, examples that on the surface prove the contrary are numerous. The belief that mergers are good still prevails, however, and the industry can look forward to further consolidation.

Public policy has favored mergers since the Transportation Act of 1920, which directed the ICC to prepare a plan for consolidating a11 line-haul railroads into a limited number of systems. The Emergency Transportation Act of 1933 added to the ICC's power to encourage mergers, and the Transportation Act of 1940 again amended the merger provisions of the Interstate Commerce Act and served as the basis for many changes in ownership and control that occurred in the $1950 \mathrm{~s}^{3}$ and 1960s. About 40 mergers, acquisitions, and lease agreements occurred between 1958 and $1973 .{ }^{4}$ 
The intent of the $4 \mathrm{R}^{\prime} \mathrm{s}$ Act is to plan a national railroad system and to promote mergers of companies in such a way that the system would be implemented. The provisions of the act include:

- Classification of railroad lines into those needed for a core network and those that are redundant.

- Studies of the benefits and costs of railroad restructuring.

- Limitations on the time the ICC can take to review merger applications.

- Financing for rehabilitation of lines and equipment on the essential parts of the national railroad network.

The act also enables the Department of Transportation to study and support merger applications.

Although many ideal railroad system configurations have been proposed, 5 including a plan for two railroads, one public and one private as in Canada, and a plan for four, five, or six transcontinental railroads, drastic and large-scale consolidation is probably some years away. Piecemeal mergers and slow progress toward a rational network can be expected. The slow progress will result from resistance to change by many entrenched interests, the lack of clear-cut benefits from largescale consolidation, and the sometimes conflicting public policies that provide assistance in merger analysis while simultaneously encouraging competition between railroads.

\section{Future Market for Railroad Freight Transportation}

The market for railroad freight transportation is determined by the overa11 leve1 and distribution of the nation's economic activity. Railroads offer low-cost, but generally slow and uncertain transportation that is primarily suited for long hauls of bulk commodities and for commodities that move between terminals in a manner similar to that of bulk commodities. Most bulk commodities have low unit value. By contrast, competition from trucks results in the railroad's relatively small market shares in manufactured commodities, which have high unit value. Thus, an economy that produces a relatively large proportion of manufactured goods tends to require more truck transportation relative to railroad transportation than one that consumes a large portion of less highly processed goods.

The economic trend in the United States is toward an increasing fraction of the gross national product (GNP) devoted to services (health care, education, entertainment, and government) rather than to the consumption of goods. The growth in services that require very little, if any, freight transportation does not contribute to the growth of the freight market; hence the total market is growing at a lower rate than the total GNP. Further, the goods used are more highly processed. As personal incomes have risen, an increasing portion of disposable income 
has been devoted to specialty foods, television sets, and so on, rather than to basic foodstuffs and clothing. ${ }^{6}$ These more highly processed goods are usually moved by truck because of their high unit value. Thus, transportation is a smaller proportion of the total cost, and the distribution costs are minimized by using more costly but faster and more reliable truck transportation.

The economy is dependent on many factors, such as the availability of energy and raw materials, the weather, and social and political trends. These factors change over time and can produce changes in the overall level of transportation needed; the distribution of the output affects the kind of transportation demanded. Although these factors are variable, we can postulate two extreme-case scenarios:

- A success scenario, which results from technological and management success in overcoming energy and raw material shortages, a general confidence on the part of the population in the ability of their institutions to succeed in these efforts, and fortuitous weather conditions that provide for abundant harvests.

- A distress secenario, which results from management and technological failure to overcome energy and raw material shortages, a loss of confidence of the population in their institutions, and a steady worsening of the weather.

These scenarios, together with a third that takes into account a shifting of social values, are explored in detail in a recent study of the future of transportation. ${ }^{7}$ Since the sociological transition scenario did not produce results that were significantly different from those produced by the success and distress scenarios, we consider only the latter two.

Table 5 shows the gross national product and railroad and truck transportation for 1975 and for 1995 in both the distress and success scenarios. Freight ton-miles of railroad traffic range from 700 to 1,015 in the success scenario. The lower figure was derived by assuming that the amount of products shippable by rail will be about the same as it was in 1975, but that growth will occur in services and in manufactured goods. The higher figure is an adjustment that includes the addition of coal shipments to the predicted freight traffic. Because the trucking industry is more seriously affected by a depressed economy than the railroad industry, railroad traffic grows at a moderate pace, while the economy is almost stagnant.

The projections in Table 5 were made under the assumption that available fuel will be very expensive in the distress scenario, and thus truck traffic will be discouraged; in the success scenario, the technology and management team will find ways around the fuel shortage (synthetic fuels or other energy sources) to permit the continued use of trucks. Truck productivity is improved by allowing larger units, such as triple tandem 27-ft trailers, on the interstate highways. 
Table 5

PROJECTIONS OF ECONOMIC AND

TRANSPORTATION INDICATORS TO 1995

\begin{tabular}{|c|c|c|c|}
\hline & & \multicolumn{2}{|c|}{1995} \\
\hline Indicator & 1975 & Distress & Success \\
\hline Population (millions) & 213.5 & 235 & 240 \\
\hline $\begin{array}{l}\text { Gross national product } \\
\text { (billions of } 1975 \text { dollars) }\end{array}$ & $\$ 1,516.3$ & $\$ 1,530$ & $\$ 3,000$ \\
\hline Freight ton-miles $\left(10^{9}\right)$ & & & \\
\hline Railroads & 750 & $1,015-1,025$ & $700-1,015$ \\
\hline $\begin{array}{l}\text { Trucks, for hire and } \\
\text { private }\end{array}$ & 440 & 300 & $1,030-1,070$ \\
\hline
\end{tabular}

Source: Reference 7.

Engine improvements and radial tires will limit fuel consumption so that increases in fuel cost will have less than proportional impact.

\section{Rationalized Freight Transportation System of the Future}

The rationalization of the freight transportation system will occur at the network and market levels and in the role that the various carriers play in transportation of freight. It appears that market factors will balance the transportation system by providing services that are attuned to both the characteristics and the length of shipments. Shipments are usually described as either bulk or nonbulk. Bulk commodity shipments are materials that can be pumped, poured, or dumped into and out of railcars or other vehicles. Such materials have low cost per unit of weight relative to processed or manufactured goods. Examples of bulk commodities are coal, sand and gravel, ore, grain, and chemicals. Another characteristic of bulk commodity shipments is that they usually travel in multiple carload lots between terminals located in rural or sparsely populated areas. Nonbulk commodity shipments are usually materials that are manufactured; i.e., canned or processed foods, appliances (white goods), and automobiles. Because some of these commodities may move in multiple carload lots to distribution centers, they have some characteristics of bulk commodities and thus are called "neo-bulk" commodities.

The distance that can be traveled in a day by truck on an interstate highway is critical in the rationalization of freight shipment. A driver can make a round trip of about 200 miles in a day, or he can 
make a run of 400 miles in a day and return the next. For short distances, truck shipment would seem to be most economical for all nonbulk commodity shipments and for a part of the bulk commodity shipments. For long distances, railroads and waterways, where available, would carry the bulk commodities; trucks might carry nonbulk commodities, for example, for perhaps slightly longer distances. An intermodal system, with truck pickup and delivery and rail line-haul, would carry nonbulk commodities for longer distances. With appropriate systems analysis of vehicles, unit loads, and transfer systems, an intermodal system could minimize the overall cost of freight transportation.

Implications for Marketing Improved Hardware and Adopting Improved Operations

The preceding discussion shows that there are significant limitations to the adoption of new technology in the railroad industry and that one of the principal factors in the adoption of conservation techniques is the amount of technological and financial risk undertaken in their adoption. Limited market growth and reduced equipment demand by fewer and larger operating companies mean slow growth in equipment needs and thus limit the opportunity to experiment. Further, limited investment funds available to the railroad companies will probably not be placed in equipment that has not been shown to be as durable and economical as that now in use, and claims for improved durability, economy, and fuel savings will have to be unequivocally demonstrated. On the other side of the counter, the suppliers are not generally in the position to undertake the development necessary to move radical new ideas through the development and demonstration phases.

The discussion of technological opportunites that follows will therefore concentrate on identifying opportunities to apply existing hardware and techniques to railroad problems. Such an approach will minimize the development and demonstration work needed to promote the adoption of conservation measures. 


\section{EFFICIENCY IMPROVEMENTS}

In this section, we discuss potential technological and operational improvements to reduce fuel consumption by the railroads. We expect that the catalogue of improvements presented here will serve as candidates for research and development funding in the future.

A partial listing of research and development projects has been compiled by the project team and is presented in Appendix A. The primary source of the abstracts was the Railroad Research Information Service, so the abstracts tend to concentrate on problems of immediate applicability to the railroad industry. Reference is made to the appendix, where appropriate, to describe existing research programs.

We will analyze these improvements to estimate their cost-energy effectiveness using the Long-Run Average Cost and Energy Model, which is designed to calculate the cost and energy requirements of various freight traffic movements.

In the discussion that follows, results of analysis using the Long-Run Average Cost and Energy Model are reported for those improvements that could be described in adequate detail to permit the analysis. The model was set up to represent the average 1973 freight haul of 516 miles. The characteristics of the corridor and the representative movement are described in Appendix B of this report. For each improvement, the appropriate changes to the main-1ine, branch-1ine, or yard components were made to estimate the percentage of difference from the base case that the improvement could provide. The assumptions and changes to the model inputs are presented with the description and analysis.

Interpretation of the cost comparison from the analysis requires a discussion of the treatment of various cost components in the model. The model produces annual cost estimates by adding a capital cost for invested funds to annual charges for maintenance, operations, and fuel. Thus, the effect of higher investment in equipment is included in the annual costs presented. If the cost index is the same or lower than the base case, we can conclude that savings in annual costs at least offset the effect of higher capital costs at the discount rate (10\%) used in the analysis. Indicated savings will lead to a presumption of higher returns on investment that would make the use of the technology more attractive. On the other hand, if the cost index increases, the economic impact of the indicated energy savings will probably not provide high returns. 
Lighter Equipment Weight

Technological and operational improvements that will reduce equipment weight are discussed below.

\section{Lightweight Freight Cars}

About two-thirds of a train's trailing tonnage is made up of the weight of the freight cars. Thus, the ratio of net trailing tons to gross trailing tons is about 0.35 , and a significant portion of the energy expended in railroad operations is directly related to the transportation of railroad cars rather than the transportation of rail freight. One method for increasing the ratio of net tons to gross tons is to use lightweight freight cars.

The first step toward the production of lightweight cars started about 40 years ago with the introduction of low-alloy, high-tensile steels into the car-building process. The most significant expansion of the use of alloy structural steels has occurred during the last decade, however. Other lightweight materials that have been used in the construction of freight cars for the fabrication of certain freight car components or subassemblies, such as doors, roofs, and hatches, include plywood, laminated hardwoods, fiberglass-reinforced plastics and epoxies, and aluminum.

In recent years, aluminum has been used to construct the bodies of hopper and gondola cars that transport coal in unit trains. In one case, the use of an aluminum-alloy body instead of steel reduced the lightweight of a $3,850-\mathrm{ft}^{3}$ gondola from $63,0001 \mathrm{~b}$ to $47,000 \mathrm{lb}$.

Reducing an individual car's weight increases the load that can be carried by the car without exceeding the allowable total weight placed on the rails. Thus, the capacity of some gondola designs has been increased by 5 to $8 \%$, which in turn allows a 5 to $8 \%$ reduction in the number of cars needed to transport a given amount of coal. For a unit coal train operation, the use of aluminum instead of steel gondola cars would reduce the gross ton-mileage by about 10 to $12 \%$.

A 1968 survey showed that the railroads were using nearly 14,000 aluminum freight cars. ${ }^{8}$ Although this number has undoubtedly increased since 1968, aluminum cars probably account for less than $2 \%$ of the entire car fleet. About 2,500 of these aluminum cars are hoppers or gondolas dedicated to unit train service.

The major disadvantages of using lightweight materials in the construction of rail freight cars are the higher per-pound costs and the increased fabrication and assembly costs associated with some of these materials. These costs often force the railroads to pay a premium price for lightweight cars. For example, aluminum coal cars cost 30 to $40 \%$ more than steel coal cars. As more aluminum cars are built, however, fabrication costs will probably be reduced to a point where the 
total cost difference between aluminum and stee 1 cars is about $25 \%$ (assuming the same relationship between the basic costs of steel and aluminum).

Another disadvantage of aluminum is the amount of energy required for refining and processing. Estimates of the total energy content of rolled steel and aluminum have been made. ${ }^{9}$ It takes $15,455 \mathrm{kWh} / \mathrm{ton}$ to produce rolled steel and $73,400 \mathrm{kWh} /$ ton to produce rolled aluminum. If the steel car weighs 31.5 tons and the aluminum car weighs 23.5 tons, and if each has 10 tons of running gear, the energy content for the remaining structure would be approximately $332 \mathrm{MWh}$ for the steel and 991 WWh for the aluminum car. Although we will not estimate the amount of energy used in the construction of railroad cars, this amount should be considered if extensive conversion to aluminum cars is planned.

The changes required to the inputs to the model are:

$$
\begin{array}{ll}
\text { Average empty car weight (10 ton reduction) } & 15 \text { tons } \\
\text { Car capital costs ( } 25 \% \text { increase) } & \$ 0.630 \text { per car-h } \\
\text { Car load capacity ( } 8 \% \text { increase) } & 65.8 \text { tons } / \text { load }
\end{array}
$$

Analysis of lightweight freight cars with the Long-Run Average Cost and Energy Model indicates that additional costs of about $0.6 \%$ would be incurred if all freight were carried in lightweight freight cars, but that energy savings of about $15 \%$ would be obtained. Therefore, lightweight freight cars should be used only when there is a large amount of empty backhaul and a large number of annual trips. Lightweight freight cars are widely used in unit train service, where these two conditions apply. In contrast to the potential energy savings from using lightweight cars, their manufacture requires substantially more energy that that required for a conventional car. This may negate the operating energy savings, depending on both the annual utilization and the source of the energy used in the manufacture of the car.

The marketability of lightweight freight cars is reduced by the higher initial costs, but this reduction is somewhat offset by the greater availability of funds from financial institutions who are more willing to lend money for cars than they are for other investments, since cars, like locomotives, are easily repossessed, and there are other users available for their disposition.

More widespread use of aluminum in cars requires searching for and examining applications where the utilization patterns of cars justify the higher costs.

\section{Positive Traction Wheel Slip Control}

Since the early 1960s, Canadian National Railways (CN) has been involved in the application of electronics to the problem of locomotive wheel slip control. This effort culminated in the development of the 
Positive Traction Control (PTC) system in 1973. Since that time, PTC has been applied on about 250 four-axle locomotives. Development of a PTC for six-axle locomotives is under way, and a prototype should be in operation in 1977.

Since 1970, CN has conducted many yard and field tests to compare PTC locomoitives with locomotives equipped with a standard wheel slip control system. ${ }^{10}$ From the yard tests, CN concluded that, under adhesion conditions in the 16 to $27 \%$ range, PTC demonstrated an improvement of 15 to $25 \%$ in tractive effort over other wheel slip control systems. As a result, the tonnage rating of a PTC 1ocomotive could be increased by at least $15 \%$ without increasing the risk of stalling. Although field operations indicate that a $15 \%$ increase may be modest, we propose that this figure be used as a conservative estimate in the model.

The PTC will allow higher average speeds on some sections of track. In one road test, $C N$ found that replacing a non-PTC locomotive with a PTC locomotive on the same train over the same grade increased the speed from 9 to $14 \mathrm{mph}$. PTC trains have a consistently better on-time performance because speeds are increased over certain grades and delays caused by stalls and doubling are nonexistent.

Since it is very difficult to estimate the exact effect of PTC on trip times, we will not model this aspect. The increase in traction can be modelled in two ways, either by increasing the tonnage of the trains by $15 \%$ or by decreasing the weight of the locomotive by the same percent. Since in practice the railroads would probably increase the tonnage of the trains to take advantage of PTC, we propose to increase the allowed tonnage by $15 \%$.

The following changes to the model are made for PTC:

$$
\begin{array}{ll}
\text { Cost of locomotives } & \$ 259,000 \\
\text { Maintenance costs } & \$ 0.2004 / \text { gal } \\
\text { Trailing gross tonnage } & 15 \% \text { increase }
\end{array}
$$

The increased cost of locomotives is based on retrofitting old locomotives; the cost for new locomotives is $\$ 6,000$. Maintenance costs are based on CN's experience with PTC systems.

Positive traction control technology is well advanced and is in operation on a limited basis. The analysis shows that a fuel savings of about $6 \%$ can be achieved for an average trip, and cost savings on the order of $1 \%$ might be achieved. The application of the technology to specific runs might produce significantly higher benefits. However, operational or track conditions might make it ineffective on other runs. Careful analyses by the railroads of their track characteristics, speed requirements, and policies for tractive effort and horsepower per ton will be required to gain the maximum advantage from this technology. 
As with other locomotive improvements, the lead time required for new units to be put into service will postpone the benefits to be gained from positive traction control. Determining the costs and benefits of retrofitting would be a worthwhile research project.

\section{Elimination of the Caboose}

Railroads originally required cabooses to carry members of the train crew who were not part of the engine crew because coal-fired steam locomotives did not have room for extra people. In addition, the conductor needed a place to keep records of schedules and cars on board.

With the introduction of the diesel electric locomotive, the need for both a large crew and the caboose has been eliminated. Many bookkeeping functions have been automated and shifted to office clerks, and the conductor no longer needs the large amount of space provided by a caboose.

Railroads have recently been interested in eliminating the caboose. One small railroad, the Florida East Coast, has removed them on most (if not al1) trains. Labor agreements are the major reason for retaining the caboose; management's lack of interest in battling for necessary changes is also contributory.

In Table 4, we showed what effect eliminating cabooses would have on the fuel consumption of the nation's Class I railroads.

\section{Turbine Locomotives}

Gas turbine development for rail use began in 1933 when the Gotawerke Nohab Company of Sweden used a gas turbine traction engine coupled with a reciprocating gas generator to power a $550 \mathrm{hp} 1$ ocomotive.11 One of the largest deployments of gas turbine freight locomotives took place in the United States in the early 1950s. The Union Pacific Railroad used a fleet of 55 gas turbine locomotives for freight service. The turbines in these locomotives, which were adapted from fixed-plant industrial designs by General Electric and Alco, produced $8,500 \mathrm{hp}$ and required a fuel tender. These locomotives have been removed from service.

Present development of gas turbine power exclusively involves the application of aircraft turbines to high-speed passenger service. We agree with Keller's conclusion that "only the gas turbine taken from aircraft engineering development offers genuine space and weight advantages over the diesel engine plant, advantages justifying in certain applications the less favorable efficiency or higher fuel consumption."l For the sake of completeness, we hypothesize a future application of aircraft gas turbines to freight locomotives. The estimated costs and performance of gas-turbine locomotives are given below. 
A turbine locomotive for freight service would need power in the 2,000- to 3,000-hp range. Most, if not all, existing gas turbines with shaft output are below this range; 1,000 to $1,500 \mathrm{hp}$ is typical. Thus, some scaling of existing designs would be required to build turbine locomotives. An alternative approach would be to use two or three existing turbines per locomotive, but this is expensive and more susceptible to reliability problems. The turbine developed could be single- or double-shaft, depending on the engineering analysis.

The reliability of a turbine engine meets or exceeds that of a diesel. In addition, if properly designed, turbines can be repaired modularily, which makes their maintenance quicker and easier than diesel maintenance. To simplify the comparison, we have hypothesized that the locomotive would be turbine electric. However, the use of hydraulic or perhaps even mechanical transmissions might be appropriate. We have not estimated the reliability of these drives. We estimate that there might be a 10 to $20 \%$ decrease in the cost of maintenance and a $5 \%$ increase in locomotive availability with a properly designed turbine.

The turbine faces competition with the diesel engine in fuel consumption. Turbines in the 2,000- to 3,000-hp range consume about 0.4 to $0.5 \mathrm{lb}$ fuel/hp-h. Mr. Warren Bloomfield of Avco-Lycoming* indicated that, with some advanced technologies (especially in the area of blade materials), a turbine of this size might be able to obtain an spfc of about $0.3 \mathrm{lb} / \mathrm{hp}-\mathrm{h}$, which would be somewhat competitive with diesels except at idle. Turbines consume more fuel at idle under almost all foreseeable conditions. Thus, we estimate that an overall $10 \%$ increase in spfc (adjusted for duty cycle) is reasonable. The scaled turbine would naturally be more expensive. Although we have no specific cost estimates available, it is reasonable to assume a 10 to $20 \%$ cost increase for the turbine locomotive over existing diesel electrics. A turbine weighs less than a diesel locomotive. We assume that adhesion limits will allow a $10 \%$ reduction in weight.

Additional advantages of the turbine are that it is easier to burn alternative fuels in turbines than in diesels and turbines are less affected by such chemical contaminants as sulfur. Because we consider these differences secondary effects we have not quantified them. In summary, the turbine locomotive will require the following changes to our model input values:

$\begin{array}{ll}\text { Maintenance cost ( } 15 \% \text { decrease) } & \$ 0.23 / \mathrm{gal} \\ \text { Spfc (10\% increase over diese1) } & 0.0649 \mathrm{gal} / \mathrm{hr}-\mathrm{h} \\ \text { Locomotive availability (5\% } & 8,283.45 \mathrm{~h} / \mathrm{yr} \\ \text { increase) } & \$ 287,500 / \mathrm{unit} \\ \begin{array}{l}\text { Locomotive capital costs ( } 15 \% \\ \text { increase) }\end{array} & \\ \text { Locomotive weight ( } 10 \% \text { decrease) } & 136 \text { tons/unit }\end{array}$

${ }^{*}$ Meeting at SRI, November 1976. 
Despite the potentially lighter weight and lower maintenance costs of turbine locomotives, they did not perform well on the Long-Run Average Cost and Energy Model. The results of the anlysis for an average trip showed an increase of about $7 \%$ in fuel consumption and an increase in average cost of about $0.6 \%$. There may be some applications where the turbine locomotive can be used to take advantage of its restart capability, thus eliminating significant idle fuel consumption, and where multiple units would allow turbine units to be programmed on and off to provide necessary power at peak efficiency. However, similar operations with diesel locomotives are also possible and will improve diesel operation comparably. Research should be directed at finding applications that would make effective use of turbine cost and operational characteristics.

\section{Operations}

Improvements in railroad operations that will reduce the amount of fuel consumed are discussed below.

\section{Circuity}

Circuity is the difference in distance between the most direct route and the route over which a car is actually directed to move. Shippers as well as the railroads themselves are allowed this freedom of routing under the present regulations. Shippers pay for only the short-line distance no matter what the routing. Nevertheless, circuity enables a railroad company to collect more revenue for a shipment. For example, Southern Pacific can collect more revenue by carrying a car, say, from San Francisco across the southern United States to St. Louis (via its subsidiary, the St. Louis and Southwestern Railroad) than by sending it more directly to Salt Lake City and turning it over to another railroad for the remainder of the eastward journey. Southern Pacific can collect the extra direct distance revenue from Salt Lake City to St. Louis as a result of the circuitous routing.

A shipper will specify longer routing for several reasons. He may desire to have the shipment handled by a railroad other than the company with the shortest route. The advantage to the shipper is perceived better service (e.g., less damage and loss and better trip time reliability). Another reason is that shippers sometimes desire to extend a car's transit time. For example, a lumber company in the Northwest is overstocked and will have to pay warehousing costs to store the lumber unless it ships the lumber to a strong market, say, in Illinois. The lumber company at this time may not have sold the lumber (or the delivery date may be several weeks away), so it specifies that the lumber travels a circuitous route across the southern United States. The lumber company can thus use the circuitous routing to reduce its warehouse costs. It can also divert the lumber to another market it it so desires. 
Without a comprehensive network analysis model it is impossible to estimate how much circuity could actually be eliminated and to assess the costs and benefits. The tools for the conduct of a comprehensive network analysis may be available in the next year through the efforts of the Federal Railroad Administration (FRA) to rationalize the U.S. railroad network. The costs and proper regulatory procedures for implementing the results of such an analysis are not well defined and require additional research.

\section{Empty Car Mileage Reduction}

Railroads, shippers, and the government are examining with increasing frequency the problem of empty freight car mileage. Backhaul creates an undesirable operational and energy cost for the railroads. In the previous section we saw that empty cars are responsible for a major portion of the total tonnage hauled by the railroads. In 1975 the transportation of empty cars accounted for a little more than $45 \%$ of the total freight car-miles and nearly $25 \%$ of the gross ton-miles. Despite the economic and energy consumption penaltfes connected with the haulage of empty freight cars, the total nationwide empty car mileage, as a percentage of total car mileage, has increased from $33 \%$ in 1946. The reasons for this increase are more specialized equipment, increased manufacturer ownership, and other factors related to improved service.

The opportunity for fuel savings for U.S. Class I railroads was estimated previously by assuming that there is a direct relation between ton-miles and fuel use. This assumption is probably valid for small decreases in empty car mileage, but it should be noted that a certain amount of energy is expended just in providing service. The Long-Run Average Cost and Energy Model will be useful in estimating this base fuel use. Other operation costs of handling empty cars (e.g., inspection, connecting brake hoses, and switching) as we11 as the investment costs for the cars will also be estimated with the model. Since the model does not specifically account for the relationship between empty backhaul and car utilization, we will not be able to estimate this impact. This complicated relationship has not been fully described and could not be effectively modeled.

Development of a national freight car information or distribution system has often been propsed to reduce the costs associated with empty car mileage and low utilization of freight cars. Proponents of such a system often claim it would lead to increases in utilization of 5 to $10 \%$ and reductions in empty car mileage of a similar magnitude. These proponents claim that such a system would reduce the problem of car shortages and thus be responsbile for increased rail revenues. However, these claims overlook several factors that would severely constrain the capability of car information or distribution systems to improve car utilization, reduce car shortages, or reduce empty car mileage. These factors, which are discussed more thoroughly in the report on regulations and tariff, 12 include geographic and 
seasonal imbalance of rail traffic, ownership of the freight car fleet, specialization of freight cars and service, and effects of government regulation. Even if one overlooks these factors, the question still remains whether a centralized car distribution system could distribute empty freight cars to maximize car utilization and at the same time minimize empty car mileage and car shortages. In a number of cases, these are incompatible goals. For example, unit trains provide good utilization of freight cars although their operation generates more empty car mileage than general service railroad operations. Furthermore, as explained in the Ref. 12 report, there are difficulties associated with reducing both empty car mileage and car shortages. Thus, an empty car distribution system would have to weigh the benefits, probably in terms of costs associated with the goals of increased car utilization, reduced empty car mileage, and reduced car shortages.

Based on the foregoing discussion, it seems unrealistic that a centralized empty car distribution system would reduce overall operating and investment costs by as much as $10 \%$. The Long-Run Average Cost and Energy Model shows that a reduction of $7.5 \%$ (from $50 \%$ ) empty backhaul will result in a cost savings of about $1 \%$ and an energy savings of about $6 \%$. A more modest $5 \%$ reduction would achieve about $5 \%$ energy reduction at a cost of about $1 \%$. Both cost estimates may underestimate the effort required to achieve the reduction.

A number of research projects are underway to improve freight car utilization, some of which are discussed in Appendix A, under the Operations heading.

\section{Fuel Handling}

An estimated 4 to $10 \%$ of the locomotive fue1 used during 1972 and 1973 was wasted. Much of this wastage could be eliminated through better training and operating procedures, better maintenance of fueling equipment, and installation of new equipment.

The technique of filling locomotives by hand without automatic fuel shutoffs can have a large impact on fuel loss. Fuel attendants must take special precautions, which are sometimes difficult, to avoid overfilling. For example, if a multiple-unit consist is being fueled, two or more tanks can become full and overflow at nearly the same time. Even with automatic fuel shutoffs, which are becoming more popular, spillage can occur because of fueling on uneven track. Training and operating procedures can be and are being instituted to reduce spillage.

An obvious step toward reducing spillage due to inattention is the installation of automatic fuel shutoff valves. Other fuel-handling devices are available, such as the recently developed spilled fuel purifier. The $\mathrm{N} \& \mathrm{~W}$ has a fuel separation system capable of recovering 750,000 gal of spilled fuel per year. 
Both manual and newer fuel-handling equipment can potentially improve maintenance. If the estimated $10 \%$ loss is correct, eliminating the loss would result in a savings of 367 million gal annually at the 1973 rate (see Table 4). Steps already taken have probably reduced the loss closer to the $4 \%$ estimate by 1976 .

\section{Helper Crew Districts}

Railroads have used helper crew districts in certain locations for a number of years. The engines and crew assigned to the district help move trains up a grade or series of grades. Several factors affect the economic viability of a helper district. The cost of the helper district crew can easily be close to the cost of the extra locomotives required if the district is not established. If additional locomotives are added to each consist to allow it to climb a ruling grade without helper engines, there is the possibility of running the consist at low and inefficient throttle settings for the major portion of the trip.* Fuel for the extra locomotives might be reduced in this manner below the fuel used by the helper locomotives. Because of these variables, we will not be able to establish national implications for helper districts. Nevertheless, we will attempt to use the Long-Run Average Cost and Energy Model to identify the sensitivities involved.

For a helper district to be productive, sufficient traffic must exist. If the helper crew is idle for long periods of time, the costs of equipment and labor add up quickly. To estimate the traffic requirements for a district, let

$$
\begin{aligned}
& \mathrm{d}=\text { length of grade } \\
& \mathrm{v}_{1}=\text { average speed up the grade } \\
& \mathrm{v}_{2}=\text { average speed of helper locomotives down the grade } \\
& t_{c}=\text { switching coupling/uncoupling time. }
\end{aligned}
$$

Then the time, $t_{s}$, between successive trains must be

$$
t_{s}=\left(d / v_{1}\right)+\left(d / v_{2}\right)+t_{c},
$$

and the maximum number of trains (single track) that can be scheduled per day (assuming all use the helper crew) is $\mathrm{N}=24 / \mathrm{t}_{\mathrm{s}}$. For a 1 -mile grade, $20 \mathrm{~min}$ of average switching coupling/uncoupling time, $10 \mathrm{mph}$

* This may be partially alleviated by consist load matching; see subsequent discussions. 
climbing, and $20 \mathrm{mph}$ down, $\mathrm{N}=50$ trains/day. This is probably a maximum number of trains. In practice, a helper district could probably be justified on longer grades with as few as 15 trains per day.

The number of locomotives in the consist $c$ an be reduced by the number of engines in the helper district (assuming the train can negotiate all other grades on the route). Thus, the actual savings in locomotive requirements is highly dependent on the particular route. For modeling purposes, we assume that one engine could be removed on our typical route and that there are to be two helper districts on the route. Locomotive characteristics and crew costs will be the same for the helper district as they are for the main line. We assume that traffic will be heavy enough to require 30 trains per day (one way). Thus, the helper districts may receive average utilization. The changes required to the model inputs are as follows:

$\begin{array}{ll}\text { Net annual tonnage } & 54.75 \times 10^{6} \text { tons } \\ \text { Cars per train } & 100 \\ \text { Locomotives per helper district } & 1 \\ \text { Number of districts } & 2\end{array}$

On the average route analyzed in the Long-Run Average Cost and Energy Mode1, cost effects were insignificant (saving of $0.3 \%$ ) and the fuel use increased by about $1 \%$. These results are further indications that the use of the helper crew district must be analyzed for individual situations. It also appears that other measures, such as consist load matching or electrification of high-density lines, might be cost-effective alternatives to consider.

\section{Acceleration and Speed Efficiency}

The benefits and costs of some train-hand1ing improvements (including acceleration and speed efficiency) cannot be estimated because of such intangibles as supervisory attention, training, and train-worker response to the improvements. Although we do not analyze the potential fuel savings and costs on a national basis, we summarize the 1iterature. In most articles on improved train handling, such improvements as initial charging of train air brake systems, reduced speed operation, and idling reduction are discussed. We consider below each of these improvements in terms of the potential savings for a single train. The discussion relies heavily on a paper by T. R. Broom. 13 Other members of the Railway Fuel and Operating Officers Association provide similar estimates of savings.

Primary freight train braking is through air brakes; some locomotives have dynamic braking (reversing the traction motors to provide slowing). While a train is being prepared for departure, the air system must be charged. This is accomplished in many cases by using the locomotive air compressor, which is also required to make up for leaks in the air system during periods of idle. Standard practice is to increase the idle speed of the diesel during pump up and when the main 
reservoir air pressure drops below 130 psi. As the pressure drops while the locomotive idles, engineers often increase the idle speed before the 130-psi limit is reached. In the reverse situation, they sometimes fail to reduce the idle speed promptly when the pressure builds beyond this 1imit. A 3,000-hp engine uses 5.5 gal of fuel per hour at normal idle. In throttle notch 4, with the generator unloaded, it burns 14 gal per hour, so up to 10 gal per hour per locomotive could be wasted.

On locomotives equipped with dynamic braking, it is often better, for reasons other than fuel savings, to "stretch" the train by applying the air brakes first and then reducing locomotive power to slow down (with no dynamic braking or coasting). However, on many occasions, the engineer can avoid this type of braking, which uses more fuel. This is especially true if the engineer is conscientious and knows the route being traveled. Tests conducted on the Florida East Coast Railway indicate a savings of 3 gal of fuel in slowing a train without brake application from $60 \mathrm{mph}$ to $30 \mathrm{mph}$ on level track. ${ }^{13}$ On the run from Jacksonville to Miami, where trains can consistently coast or use only dynamic braking, a savings of 40 gal per train is estimated. This savings would not be as great in mountainous areas, where the use of air brakes is absolutely necessary.

Many railroads have established train speeds and policies for horsepower per ton based on general estimates of power requirements and of reasonable speeds to maintain schedules and utilize track and locomotive resources fully. These policies were established for the most part without regard to fuel conservation, and many were based on rough estimates. With the increased need to consider fuel conservation, better planning can and should be done. Using improved computer analysis of trains and routes, Union Pacific (UP) established the best combination of speeds and horsepower/ton ratios that would result in lower fuel consumption and at the same time keep reasonable locomotive fleet requirements. The speed reduction was applied to trains carrying commodities that are not schedule sensitive, such as coal and other bulk commodities; schedules on merchandise trains and trains with trailers and auto parts were maintained. By using these new policies and paying close attention to fuel handling, UP achieved an $8 \%$ reduction in fuel used in the first year and achieved further reductions in subsequent years.

The Soo Line has instituted a maximum speed of $40 \mathrm{mph}$ on its system. Soo personnel believe that the speed restriction not only saves fuel but also provides for more coordinated system operation (especially in yards) and less wear and tear on track. They characterize the operation as being as good as the previous operation and better in many ways.

Research is needed in the area of operations to determine maintenance savings on track and equipment and the savings or additional costs that are incurred in scheduling and yard operations. 
Most of a locomotives' time (up to $50 \%$ and more) is spent idling. Except during repairs and maintenance, past practice has been to leave the engine running because of problems of coolant freezing in cold weather, battery failure on restarting, involved restarting procedures, and increased likelihood of coolant leakage. Recently, railroads have been shutting down locomotives if they will not be used for four hours and the temperature is above $40^{\circ} \mathrm{F}$. As this practice spreads, manufacturers will probably improve the starting properties of locomotives to make it easier to save fuel in this way.

Engine heaters are available that will maintain the temperature of a stopped engine with a smaller expenditure of energy than running the engine. These heaters are electrically powered and require that the locomotive be stopped near a source of power.

Locomotive and Equipment Efficiency

Reasonable improvements in equipment efficiency can have a significant impact on overall fuel use. Improvements in diesel-electric design and rail freight cars are discussed below.

\section{Diesel Waste Heat Recovery}

In diesel engines, significant amounts of waste heat are exhausted and carried away from the combustion areas by the cooling water. There are two general methods for further using this relatively high-

temperature energy: one increases the efficiency of the diesel itself, and the other uses the waste heat to run some other form of heat engine.

The turbocharger, which has been used on diesel engines for some time, increases the efficiency of the diesel by utilizing energy from engine exhaust. Several different arrangements for turbocharging have been tried. The simplest arrangement, which is applied on virtually a11 large diesel-electric locomotives, uses a single turbine at the exhaust of the engine to drive an input compressor. Efficiency is further improved by using an aftercooler to cool the compressed input air charge. Two-stage turbocharging systems have been designed which use two exhaust-compressor systems to successively increase the input air pressure. There is no thermodynamic limit to attainable output provided practical limitations of mechanical and thermal loading can be overcome. ${ }^{14}$ Because of the reliability necessary in locomotives, manufacturers have apparently avoided development of two- and threestage turbochargers. The next best means for recovering the waste heat is to place an additional "separate" recovery system on the exhaust. A simple additional turbine on the exhaust to drive a separate generator (instead of an input air compressor) is not possible because it would increase backpressure on the existing single-stage turbocharger beyond limits. 
Other engines that use external heat sources with the heat transferred to a working fluid are Q-engines or heat engines. Depending on the cycle of changes the working fluid undergoes, several different engines are theoretically possible. Stirling, Ericsson, and Rankine cycle engines have been built. Little work has been accomplished on Ericsson cycle engines since the 1800s. In the 1960s, N. V. Philips Research Laboratories developed a two-piston version of a Stirling cycle engine. Vannevar Bush, an inventor, holds a patent on a modified Stirling cycle engine. The main advantage of Stirling cycle engines over the Rankine cycle engines is that no condenser is needed. However, Stirling cycle engines could not compete economically with Rankine cycle steam engines at the turn of the century, and even now expected production version costs are estimated to be $50 \%$ more than for organic fluid Rankine cycle engines. ${ }^{15}$ Finally, the typical inlet temperature requirement for the Stirling engine is around $1,300^{\circ} \mathrm{F}$, which is too high to use diesel exhaust effectively.

The Space Division of General Electric (GE) has proposed a waste heat recovery system using the Rankine cycle engine with an organic compound as the working fluid. The arrangement is shown schematically in Figure 3. This is a first conceptual estimate of how such a system might be arranged. The fan shaft shown between the diesel and the turbine is coupled through an over-running clutch to the crank shaft of the diesel itself. The clutch prevents the diesel from losing power by driving the turbine. Other possibilities are to have the turbine drive a separate generator with the output simply dumped into the traction motor main bus. GE estimates that a Rankine cycle engine in this application could produce $500 \mathrm{hp}$ when used with a standard, turbocharged, 4,000-hp diesel locomotive. Using GE estimates of fuel consumption for a 3,500-hp diesel and 500-hp Rankine cycle engine combination, we found the spfc for the AAR duty cycle to be $0.041 \mathrm{gal} / \mathrm{hp}-\mathrm{h}$.

Maintenance requirements for this Rankine system are not known. GE personnel indicate that they have only the roughest idea of what these requirements might be. The turbine itself would most likely be the least critical portion of the system. The equipment is quite similar to that found in large refrigeration and air conditioning systems and thus might have similar maintenance requirements and reliability. For an analysis, we assume that the equipment will have no effect on engine availability and that maintenance costs are increased by $5 \%$.

GE estimates that the production cost of the Rankine system (installed) is $\$ 56,500$. As a comparison, Ayres and McKenna estimate $\$ 13 / \mathrm{hp}$ (1970 dollars) as a maximum production cost for similar Rankine cycle engines in automotive sizes. ${ }^{15}$ In the case of automobiles, this includes the cost of burners to provide the external heat source. Allowing for $10 \%$ inflation, this translates to $\$ 21 / \mathrm{hp}$ in 1975 , or $\$ 10,500$ for $500 \mathrm{hp}$. Thus, even if fewer engines would be produced for diese1 locomotives than for automobiles, the GE estimate does not seem too low. We will use the GE estimate in our analysis. 


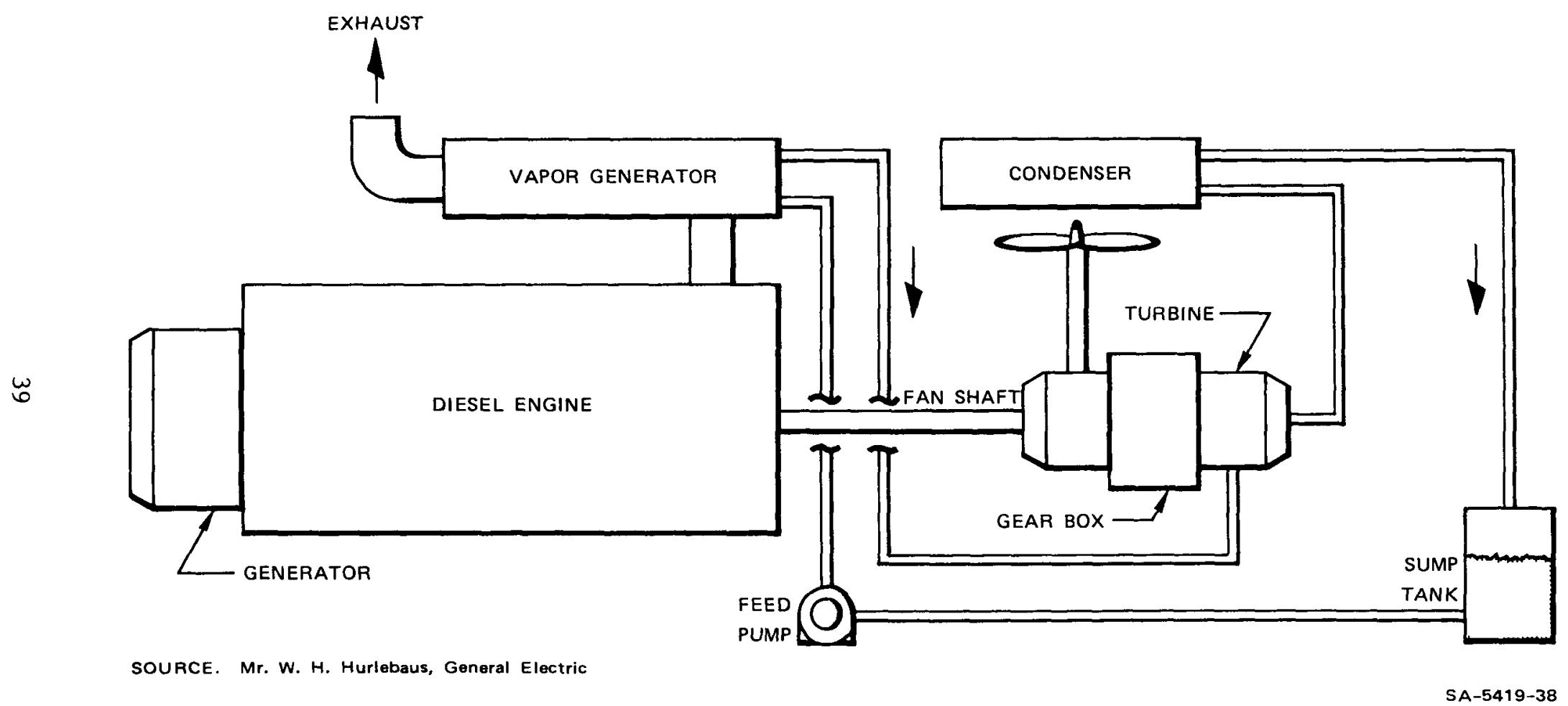

FIGURE 3 RANKINE BOTTOMING CYCLE FOR RAILROAD LOCOMOTIVE DIESEL 
Changes to the model input are:

$$
\begin{array}{ll}
\text { Spfc } & 0.041 \mathrm{gal} / \mathrm{hp}-\mathrm{h} \\
\text { Maintenance costs (5\% increase) } & \$ 0.213 / \mathrm{gal} \\
\text { Locomotive costs }(4,000 \mathrm{hp}) & \$ 306,500
\end{array}
$$

Analysis of a system utilizing a waste heat recovery system as described shows that an energy saving of about $8 \%$ can be achieved over an average route, with a corresponding nominal cost savings of about $0.3 \%$.

The bottoming cycle can be made from available components, but special designs to fit into the limited space in a locomotive will be required as part of the development process. The durability of diesels with a bottoming cycle unit needs to be demonstrated and the maintenance costs verified to convince railroad operating companies that the technology is a good investment. As with other rolling stock, financing should be available due to portability of the collateral.

Because of the potential savings and apparent marketability of adding a bottoming cycle unit to a diesel unit, we have prepared a more detailed investment analysis, using data supplied by GE's Air and Space Division. We modified the original assumptions about specific fuel consumption and held the price of fuel constant. (GE's analysis assumed rising fuel costs.) The results show that the unit will produce a $10 \%$ return investment after taxes with a payback period of about five years if the duty cycle and maintenance costs are as specified by our source. The return on investment is best if the unit is applied to larger engines. A higher (or lower) return could be obtained by railroads that operate their locomotives at duty cycles that are different from the national average.

In our investment analysis, we estimated the payback period for three levels of fuel savings (see Figure 4). The upper curve represents the payback function for a $12 \%$ fuel savings estimated for a 4,000 hp diesel operated on an AAR-approved duty cycle. The same $12 \%$ fue 1 savings applied to a smaller locomotive operating on a national average duty cycle was used to calculate the second curve. The bottom curve was plotted using the model results, which account for the effects of grade and curvature, mismatch of consists, etc. The effect of the amount of fuel saved on payback period (at $10 \%$ interest rate) is shown in Figure 5. The curve shows that waste heat recovery systems should be considered primarily for large units with potential fuel savings of more than 50,000 gal annually.

The economics of the bottoming cycle unit appear to be favorable for original installation on a locomotive, but the cost to retrofit an existing locomotive is much higher. With such a constraint, the introduction of bottoming cycle units will be slowed because many locomotives have been installed in the last five years, and quite a few are now on order, as the last of the units put into service after World War II 


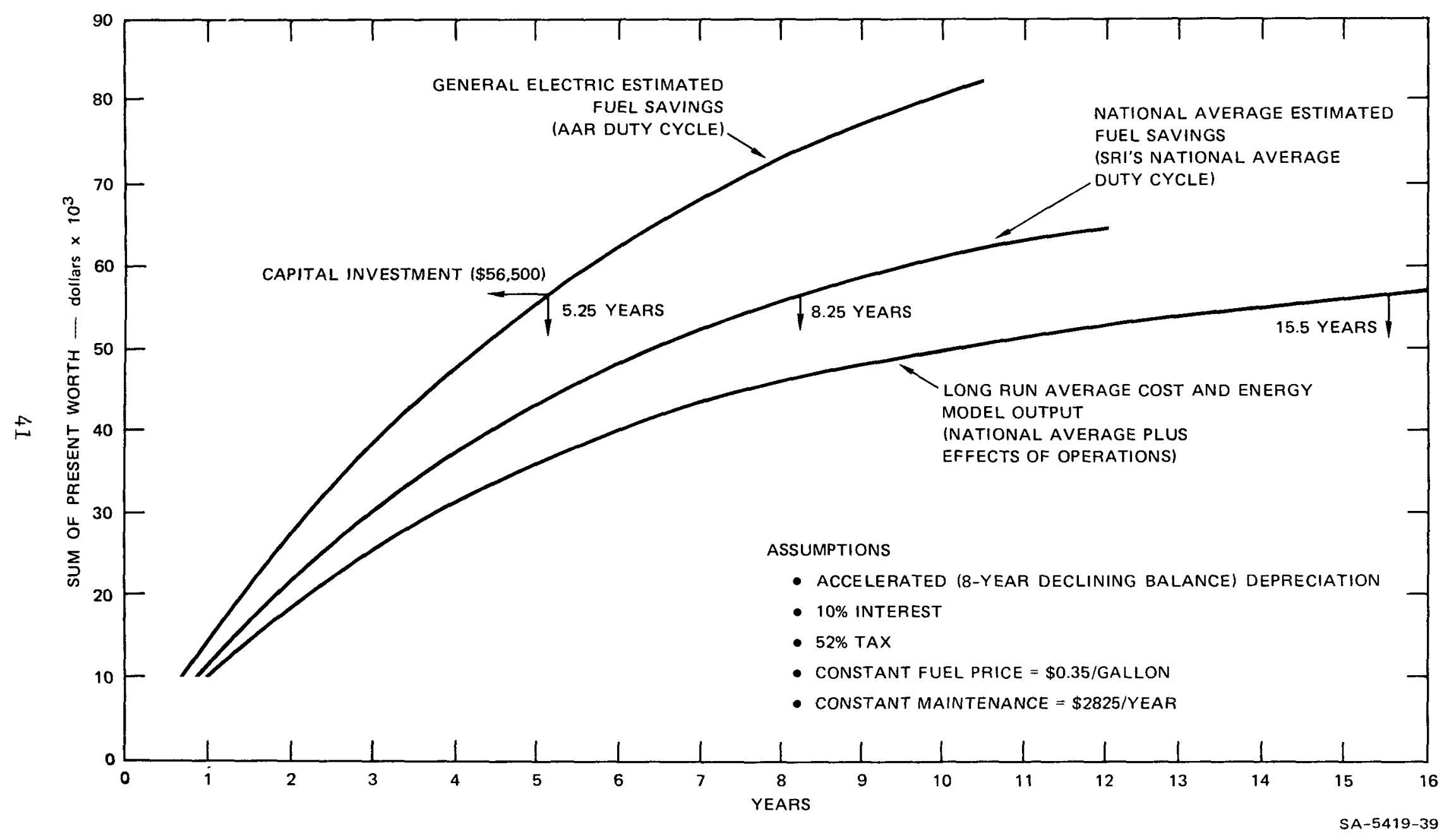

FIGURE 4 SUM OF PRESENT WORTH VERSUS YEARS FOR DIESEL WASTE HEAT RECOVERY SYSTEM 


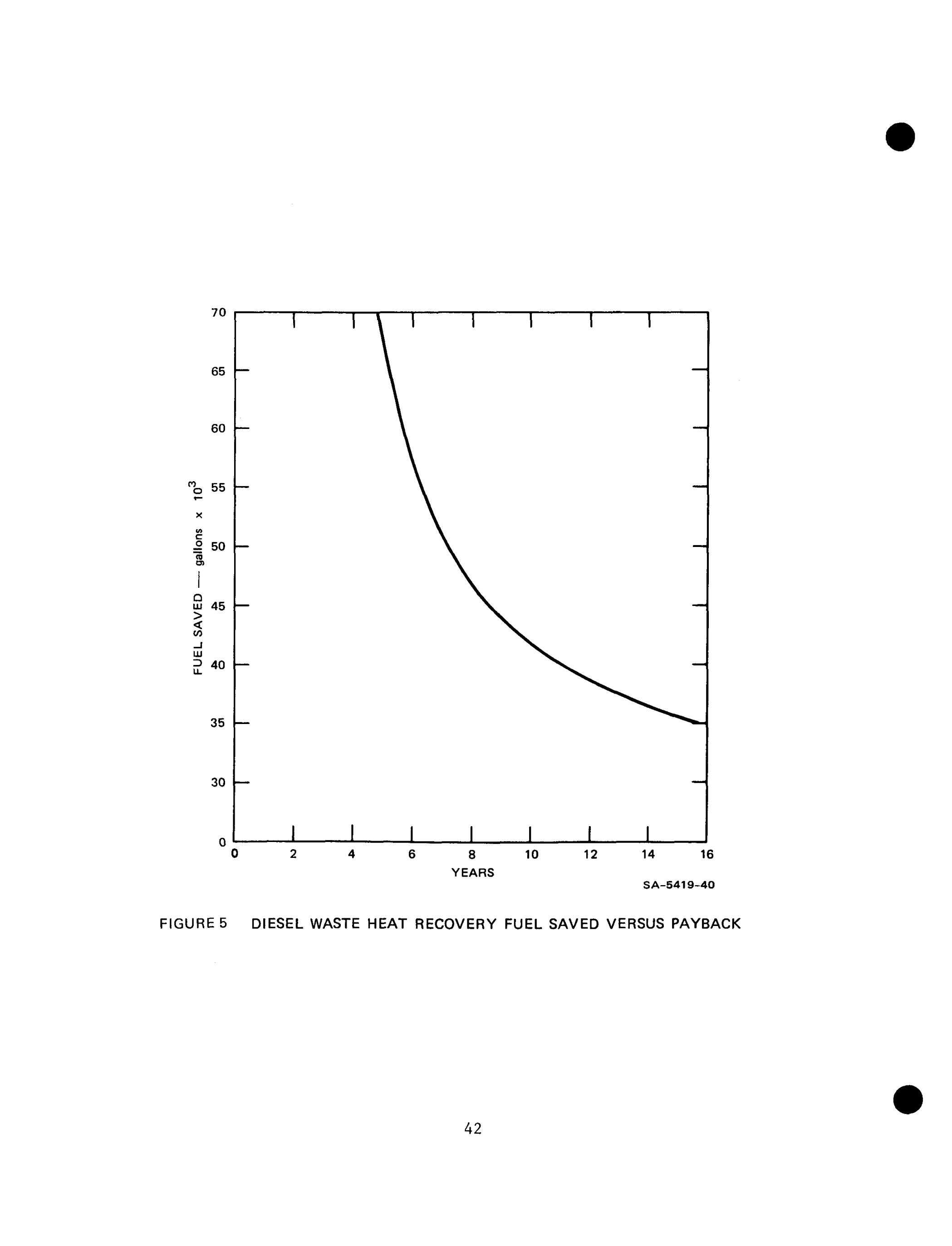


are replaced. A locomotive has a life of about 20 to 25 years, so it will be some time before another big locomotive replacement opportunity exists. This lead time for the market to develop may inhibit manufacturers from initiating development work in a timely fashion.

The details of the bottoming cycle design, development, and costs were provided by a locomotive manufacturer. Although bottoming cycles are being developed for other applications, we are not aware of any active development of the bottoming cycle principally for railroad application.

\section{Adiabatic Diese1}

In an effort to improve the specific fuel consumption of the conventional diesel engine, engineers are experimenting with an adiabatic diesel cycle, in which heat rejection from the engine to a coolant is minimized. The engine draws its name because compression in the engine occurs without loss of heat to the cylinder walls, in contrast to the conventional diesel engine whose cyclinder walls are cooled. Eliminating the cooling system improves the potential efficiency of the engine through two effects:

- Power needed to operate the cooling system--fans and pumps--is no longer needed.

- Since all of the heat of the cycle is rejected through the exhaust, exhaust temperatures are higher, and recovery of heat energy through turbocompounding and use of a bottoming cycle is more efficient.

Because the engine is not cooled, internal temperatures are much higher than those encountered for conventional internal combustion engines. The higher temperatures require new materials for the cylinder and piston, as well as new concepts in lubrication. Potential improvements of specific fuel consumption to 0.29 are possible after an extensive development program that will be required to develop materials, designs, and installation. Application of the adiabatic diesel to railroad use could be implemented within 15 to 25 years.

\section{Improved Maintenance Practices}

Locomotive maintenance practices vary from railroad to railroad. Although locomotive manufacturers recommend locomotive maintenance cycles, most railroads feel that the cycle should be tailored to their operating and road conditions. In addition, the railroads are hesitant to publish maintenance practices and the results of their maintenance programs. It is thus difficult to estimate the cost benefits of maintenance practices. We can, however, provide some information on areas where fuel savings might be achieved. 
A great deal about the condition of a diesel can be deduced from viewing the smoke. When the exhaust smoke is not clear, combustion is incomplete. White smoke indicates excess, unburned fuel, and black smoke indicates an imbalance in air and fuel mixtures. Both situations cause the diesel to burn more fuel at a given output. Through educational programs for engineers, these and other symptoms that indicate the need for maintenance could more effectively be brought to the attention of maintenance personnel.

The gages and readings on locomotives are adequate for controlling and protecting the diesel. Some of these gages and readings could be used to initiate maintenance actions. Two readings in particular, turbo air pressure and fuel oil pressure, could be useful if kept on a continuing basis. Other instrumentation could be installed to track deterioration in critical components. Watt-hour meters are available which measure generator output and provide cumulative readings over the locomotive life as well as readings on a per-trip basis. Other instrunents could be used to record fuel flow and cylinder exhaust temperature to provide additional information about the need for maintenance of specific components.

The instrumentation mentioned above is available or could be developed easily if there were a market. However, guidelines for the use of the information recorded by such instruments have not been established. This would require some research and development. Once general guidelines are available, the improvement should be evaluated on the basis of the maintenance practices of individual railroads. The costs of the installations and associated maintenance would have to be balanced against the estimated savings in fuel consumption.

\section{Consist Load Matching}

A device known as the Fuel Saver is being tested. This device provides the engineer with the capability of putting one or more units into throttle notch 1 while operating the remaining units at higher throttle notches. Under present multiple-unit controls, all locomotives operate at the same throttle setting as that commanded by the unit operated by the train operator. When power demands are less than the capability of the combined units, all locomotives are operated at low power outputs. Since the spfc is lower for higher throttle settings, better efficiency could be achieved by operating one or two units at throttle notch 7 or 8 , and others at notch 1 or in idle. The Fuel Saver allows the engineer to utilize the locomotive consist more efficiently.

Individual control of locomotives in a multiunit consist is being tested by a manufacturer, a railroad operating company, and the FRA, as described in Appendix A, under the Locomotive and Equipment heading. The results of their research should provide additional information with which to estimate the benefits of both the hardware and the procedures. The cost of the hardware is sma11. Constraints to the use of consist 
load matching are that additional activities are required of the operator and his attention to detail will largely govern the effectiveness of the procedure. Automation of consist load matching may be possible after the effectiveness of the procedure is demonstrated. Although automation would increase costs, it would overcome labor problems. Retrofitting for either manual or automated consist load matching seems possible.

\section{Diese1-Hydraulic Locomotives}

In the diese1-hydraulic 1ocomotive, the diesel engine is coupled to the driving wheels by a hydraulic transmission similar in concept to automatic transmissions in automobiles. These hydraulic transmissions use combinations of fluid torque converters and gearboxes to allow wide variation in the tractive effort and speed produced by a locomotive. Some of the more well-known hydraulic transmissions are Mekhydro, Voith, SRM, and Rolls Royce.

Advantages of the diesel-hydraulic locomotive include:

- Continuous low-speed operation at full load without overheating.

- Production of the high starting tractive effort required in many locomotive applications via the high-torque conversion ratio available with the hydraulic transmission.

- Ease of maintenance and repair, and a reduction in repair costs.

- Ability to exert full tractive effort at standstill without damage or overheating.

- Shut-off and quick-start capabilities that avoid long idling periods, thereby reducing fuel consumption, noise intrusion, and air pollution.

- Lower unsprung weight on axles than the electric drive.

- Hydraulic braking to reduce wear and other problems connected with the normal locomotive braking system.

Many European railroads use diesel-hydraulic units for both switching and road haul work. Because such units are more advantageous than diesel-electric locomotives only up to about $1,500 \mathrm{hp}$, their application in the United States has been limited to yard switching and industrial work. (At present, about one-third of the U.S. diese1electric fleet is at or below 1,500 hp.)

Three U.S. railroads (ATSF, Southern, and ICG) have recently been testing a $1,250 \mathrm{hp}$ diese1-hydraulic unit manufactured in Romania. ATSF found that fuel consumption during yard service was $9.8 \mathrm{gal} / \mathrm{h}$; Southern, $4.8 \mathrm{gal} / \mathrm{h}$; and ICG, $6.9 \mathrm{gal} / \mathrm{h}$. ICG personnel indicate that this 
switcher, known as the "Quarterhorse," probably saves about 1.5 to $2.0 \mathrm{gal} / \mathrm{h}$ when compared with $1,300-\mathrm{hp}$ diesel-electric switch engines doing the same type of work. This represents about a $25 \%$ decrease in fuel consumption. Diesel-hydraulic units can be turned on and off quickly. However, this estimate does not include the savings that can be gained from reduced idle time.

These field tests in switchyards also indicate that the diese1hydraulic unit is quieter than equivalently powered diesel-electric units and has very good adhesion and acceleration. However, concern has been voiced about the mechanical reliability and maintainability of these units as well as their compatibility with the rest of the locomotive fleet. (The "Quarterhorse" cannot be operated as a multiple unit with diesel electrics.)

Evaluation of the diese1-hydraulic engine in either road haul or switcher service by means of the Long-Run Average Cost and Energy Model is not now possible because of the lack of performance information. It might be useful, however, to investigate these engines further when the results of the "Quarterhorse" evaluation are final.

\section{Wheel Bearing and Sea1 Resistance}

Railroads use plain and roller bearings on freight cars. A plain bearing depends on hydrodynamic forces of the lubricant in the sliding journal for support. The roller bearing, which has rollers between the wheel and axle, is superior to the plain bearing, though more expensive. It displays less starting resistance, higher reliability, and about $10 \%$ lower resistance over normal operating speeds. ${ }^{16}$ Today all new freight cars are equipped with roller bearings, and conversion of older cars is 50 to $60 \%$ complete. Since this conversion is in progress and requires no R\&D effort, it will not be considered further.

Roller bearings must be lubricated and kept free from contamination in an operating environment with seals that fit around the axle as it rotates. These seals are constructed of rubber rings supported by a metal grease seal case. In a roller bearing seal, the rubber ring has a dual lip. The outer lip, called a dust lip, keeps contaminants out of the bearing. The inside lip, called a fluid lip, is designed to keep lubricants in the bearing. The fluid lip is typically held in place with a spring. The two lips (especially the fluid lip) cause considerable resistance to rotation.

Recently, Brenco Incorporated, of Petersburg, Virginia, introduced a new seal that exhibits considerably lower resistive torque. The design carefully controls lip shapes and spring tension. Brenco's limited laboratory tests of this seal show a $32 \%$ reduction in resistive torque over the worst competitive seal. To estimate the effects of this seal on fuel consumption most accurately, the resistance equation coefficients for journal resistance must be changed. Brenco claims 
that the most widely used competitive seal requires 86 in.-1b of torque and that its seal requires on 1 y 59 in.-1b. Assuming the average rail car has 4 axles, 16 new seals, and 36-in.-diameter wheels, we get the following resistance equation:

$$
\text { [(86-59) in. }-1 \mathrm{~b} / 18 \mathrm{in.}] \times 16 \text { seals }=24 \mathrm{lb} \text { resistance/car }
$$

We assume that the resistance is not related to velocity or weight of the car. Thus, the $24-1 b$ reduction is a constant term, and we can "adjust" the resistance equation in our model by subtracting a constant $24 \mathrm{lb} / \mathrm{car}$. (We will assume that no changes to locomotive sea1s are made.) This is probably the maximum expected improvement from these seals; in field conditions, we expect that dynamics and contamination will degrade performance.

Brenco claims that its seals provide increased protection from contamination and leakage. It appears that this is a true claim under test conditions. However, other manufacturers point out that they have rejected low-torque designs because they cannot perform over the 1ong period of service required. ${ }^{17}$ Although, based on present information, we could not estimate the maintenance implications of the seal, this appears to be the critical point in acceptance of this seal by the railroad industry.

The cost of the new seal is not significantly different from present bearing seals. The overa11 cost of seals is estimated to average $\$ 4 /$ seal industrywide.

To account for the use of this seal, the resistance equation in the Long-Run Average Cost and Energy Mode1 must be adjusted by subtracting $24 \mathrm{lb}$ or resistance per car.

If it can be shown that the 1ife cycles of both old and new bearings and seals are the same, an energy savings of about $6 \%$ can be achieved at almost no cost. We understand that tests are now underway to demonstrate the durability and effectiveness of low-resistance seals.

Benefits from the new seals will not accrue for a long time if the seals are installed on only new and rebuilt cars. Although older cars are continually being replaced or rebuilt, the life of a freight car may be 20 to 25 years, and a substantial portion of the fleet has been installed in the last 10 years. Retrofitting of cars in service, especially those that accumulate high annual mileages, may be economical, but research is needed to show the extent of retrofitting that could be economically justified.

Once the durability and life of the new seals is established, their marketability should not be a problem: the new seals would replace existing seals at a similar cost and offer better performance to the user. 
$\underline{\text { Regeneration }}$

Improvements in the reduction of grade and curvature involve large capital expenditures. It is beyond the scope of this project to estimate the amount of energy consumed to reduce a grade, which is highly dependent on soil conditions, local fill restrictions, environmental considerations, and the construction season. However, the magnitude of the amount is probably well beyond the energy savings in several years of operations. Because of a lack of clear, large-magnitude energy savings and the variabilities in the reduction of grade and curvature, we make no attempt to estimate the impacts of such reduction on railroad costs. Instead, we focus on the viability of energy regeneration.

Regeneration involves the capture and reuse of energy now dissipated in braking. The most practical means for capturing the energy is to use onboard generators (or traction motors as generators) to generate electricity and brake the train. The electric energy generated would have to be used immediately or stored (either onboard or at wayside). In an electrified railroad, the regenerated energy can be fed to the catenary and used by other trains. The receptor trains must be scheduled so that they will need the available energy at the time it is regenerated.

Scheduling trains to use regenerated energy when it is available is the least difficult problem to solve in theory. In practice, however, there are situations where a storage capability might be desirable. In a nonelectrified application, onboard storage is the most practical means for using regenerated electricity. Both wayside and onboard energy storage are discussed below.

\section{Wayside Energy Storage}

Most of the work in assessing the potential technologies available for energy storage on a large scale has been conducted by the electric power companies. The purpose of this work has been to allow power companies to meet peak power needs more effectively. In a report for the Electric Power Research Institute (EPRI), the Public Service Electric and Gas Company of Newark, New Jersey, surveyed seven energy storage technologies to identify systems for use by electric utilities. ${ }^{8}$ The systems are similar to those envisioned for wayside storage devices. The data contained in the EPRI report provide a good starting point for assessing the viability of wayside storage for railroads. Table 6 shows the technical and cost characteristics of the seven potential storage systems.

For applications to railroads, we assume that the wayside storage device will be capable of storing the energy generated by two trains descending a grade that requires brake application through $200 \mathrm{ft}$ of vertical drop. A typical train made up of three engines and 100 cars, half of which are loaded, would weigh 6,000 tons. If each train negotiated the grade in $20 \mathrm{~min}$, about $1,000 \mathrm{kWh}$ of energy and 3,000 kW 
Tab1e 6

EXPECTED TECHNICAL AND COST CHARACTERISTICS OF SELECTED ENERGY STORAGE SYSTEMS FOR USE BY ELECTRIC UTILITIES

\begin{tabular}{|c|c|c|c|c|c|c|c|c|c|}
\hline \multirow{3}{*}{ Characteristics } & \multicolumn{5}{|c|}{ Near Term } & \multicolumn{3}{|c|}{ Intermediate Term } & \multirow{3}{*}{$\begin{array}{l}\text { Long Term } \\
\text { Supercon- } \\
\text { ducting } \\
\text { Magnetic }\end{array}$} \\
\hline & \multirow{2}{*}{$\begin{array}{l}\text { Hydro- } \\
\text { Pumped } \\
\text { Storage }\end{array}$} & \multirow{2}{*}{$\begin{array}{l}\text { Compressed } \\
\text { A1r }\end{array}$} & \multicolumn{2}{|c|}{ Therma1 } & \multirow{2}{*}{$\begin{array}{l}\text { Lead Acid } \\
\text { Batteries }\end{array}$} & \multirow{2}{*}{$\begin{array}{l}\text { Advanced } \\
\text { Batteries }\end{array}$} & \multirow{2}{*}{ Flywheel } & \multirow{2}{*}{$\begin{array}{r}\text { Hydrogen } \\
\text { Storage }\end{array}$} & \\
\hline & & & Steam & 011 & & & & & \\
\hline $\begin{array}{l}\text { Commercial } \\
\text { availability }\end{array}$ & Present & Present & $\begin{array}{l}\text { Before } \\
1985\end{array}$ & $\begin{array}{l}\text { Before } \\
1985\end{array}$ & $\begin{array}{l}\text { Before } \\
1985\end{array}$ & $1985-2000$ & $1985-2000$ & $1985-2000$ & Post -2000 \\
\hline $\begin{array}{l}\text { Economic plant } \\
\text { size (MWh or } \\
M W)\end{array}$ & $\begin{array}{c}200-2000 \\
\mathrm{MW}\end{array}$ & $\begin{array}{c}200-2000 \\
\mathrm{MW}\end{array}$ & $\begin{array}{c}50-200 \\
\text { MW }\end{array}$ & $\begin{array}{c}50-200 \\
\mathrm{MW}\end{array}$ & $\begin{array}{r}20-50 \\
\text { MWh }\end{array}$ & $\begin{array}{l}\text { 20-50 } \\
\text { MWh }\end{array}$ & $\begin{array}{l}10-50 \\
\text { MWh }\end{array}$ & $\begin{array}{l}20-50 \\
\text { MW }\end{array}$ & $\begin{array}{l}\text { Greater than } \\
10,000 \mathrm{MWh}\end{array}$ \\
\hline $\begin{array}{l}\text { Power-related } \\
\operatorname{costs}(\$ / \mathrm{kWh})\end{array}$ & $90-160$ & $100-210$ & $150-250$ & $150-250$ & $70-80$ & $60-70$ & $65-75$ & $500-860$ & $50-60$ \\
\hline $\begin{array}{l}\text { Storage-related } \\
\text { costs }(\$ / \mathrm{kWh})^{*}\end{array}$ & $2-12$ & $4-30$ & $30-70$ & $10-15$ & $65-110$ & $20-60$ & $100-300$ & $6-15$ & $30-140^{\dagger}$ \\
\hline $\begin{array}{l}\text { Expected } 11 \mathrm{fe} \\
\text { (years) }\end{array}$ & 50 & $20-25$ & $25-30$ & $25-30$ & $5-10$ & $10-20$ & $20-25$ & $10-25$ & $20-30$ \\
\hline Efficiency $(\%)^{\ddagger}$ & $70-75$ & 5 & $65-75$ & $65-75$ & $60-75$ & $70-80$ & $70-85$ & $40-50$ & $70-85$ \\
\hline $\begin{array}{l}\text { Construction lead } \\
\text { time (years) }\end{array}$ & $8-12$ & $3-12$ & $5-12^{\star \star}$ & $5-12^{* \star}$ & $2-3$ & $2-3$ & $2-3$ & $2-3$ & $8-12$ \\
\hline
\end{tabular}

Source: Ref. 12 .

* Constant 1975 dollars; does not include cost of money during construction.

+ These numbers are very preliminary

Flectric energy out to electric energy in, in percent.

5 Heat rate of $4200-5500 \mathrm{Btu} / \mathrm{kWh}$ and compressed air pumping requirements from $0.58-0.80 \mathrm{kWh}$ (out).

** Long lead time includes construction of main power plant 
of power per train would be generated. Thus, under our assumptions, a wayside storage system would require an energy capacity of 1 to 2 MWh and a power capacity of 3 to $6 \mathrm{MW}$.

of the candidate storage systems presented in Table 6, only batteries and flywheels offer potential economic advantage in these energy and power ranges. Every other candidate requires a considerably larger plant size to be economically viable. Advanced batteries offer the potential for lowest cost at reasonable efficiencies. However, in the smaller size ranges, flywheel costs could be reduced more easily. Estimates of costs for a system that would store 1 to 2 MWh are shown in Table 7. These estimates are not exact because both advanced batteries and flywheels are only in the developmental stage. The costs used in calculating these figures are in the middle of the range of costs projected by the EPRI report and at the high end of the land requirements. The land is projected high to account for access roads, protection fencing, etc.

Table 7

COSTS OF PROPOSED ENERGY STORAGE SYSTEMS

\begin{tabular}{|l|c|c|c|}
\hline \multicolumn{1}{|c|}{ System } & $\begin{array}{c}\text { Land } \\
\text { Requirements }\end{array}$ & $\begin{array}{c}\text { Equipment } \\
\text { Costs }\end{array}$ & \multicolumn{1}{c|}{$\begin{array}{c}\text { Life } \\
\text { Span }\end{array}$} \\
\hline Lead acid battery & $1,936 \mathrm{ft}^{2}$ & $\$ 240,000$ & $5-10$ years \\
Advanced battery & $575 \mathrm{ft}^{2}$ & 126,000 & $10-20$ years \\
F1ywheel & $425 \mathrm{ft}^{2}$ & 324,000 & $20-25$ years \\
\hline
\end{tabular}

It appears from Table 7 that an advanced battery system would be the most economical energy storage system for railroad wayside applications. It is the logical system from both a cost standpoint and a total system view. The battery system could be incorporated as part of the standby power systems for the railroad.

Current research in railroad energy regeneration is presented in Appendix A. Much of the background information contained in the EPRI report is of interest. Summaries of that information for each of the seven systems are provided below.

\section{Hydropumped Storage}

In a hydropumped storage system, energy is stored by pumping water from a lower to a higher elevation. The energy is recovered for 
later use by passing the water from the higher to the lower elevation through a hydroturbine driving an electric generator. The technology for this system is established, and hydropumped storage plants are in operation. The application of this system to railroads is doubtful. The capital costs of the power-related equipment make such a system uneconomical for systems that are required to store less than $200 \mathrm{MW}$ (see Table 6).

Furthermore, to allow for large storage areas for water, hydropumped storage systems must be installed on sites that have natural reservoirs, such as a lake. These systems are therefore clearly inappropriate for railroad use.

\section{Compressed Air Storage}

In compressed air storage systems, unused energy drives a compressor that compresses the air in a large storage facility. When the energy is needed, it is recovered by releasing the pressure to drive a hot gas generator. Because of the high costs of power-related equipment (hot gas generator and compressor), this system is economical only for systems required to store large amounts of energy. Compressed air storage requires a topology that will allow excavation and construction of large storage areas for air. Because the sites selected for installation of these systems usually have natural reservoirs, such as mined caverns, compressed air storage systems are clearly inappropriate for railroad use.

\section{Thermal Energy Storage}

Thermal energy storage systems are under development and should be available by 1985 . Excess energy is used to heat a material (the storage medium) such as water, oil, or salt. When the energy is needed, it is released as thermal energy to drive a heat engine or generator which would produce the needed electrical energy. Again, the power-related equipment costs limit the use of thermal energy storage to fairly large systems ( 50 to $200 \mathrm{MW}$ ). In addition, the storage tanks required for the storage medium would add to the costs.

\section{Battery Storage}

Battery storage is a fairly well known form of chemical energy storage that electrochemically converts dc electrical energy to chemical energy during the charging of the store and chemical energy to dc electrical energy upon discharge. Many characteristics of battery storage systems make them attractive in railroad applications. Batteries provide a rapid electrical response with a short period in turnaround from charge to discharge, which is necessary for railway systems unless the scheduling becomes more complex or delays from turnaround in the 
energy storage operation can be tolerated. Two types of batteries have been investigated:

- Static batteries, which do not require auxiliary equipment other than cooling equipment.

- Circulating reactant systems, which resemble complex chemical plants.

For battery systems, the basic units are cells of a few kilowatt hours. These can be linked together into a system of any size, which is definitely an advantage for rail applications.

A number of different batteries could be used in battery storage systems. The lead-acid battery is currently in use throughout the United States. Other batteries using different chemicals are currently under development. Lead-acid batteries are now used as standby power systems for electric railroads, which makes them very attractive as the candidate storage system. One disadvantage is their short life of 5 to 10 years. Advanced battery systems are predicted to extend this life to 10 to 20 years. Another disadvantage is that batteries cannot tolerate a high, rate of charge, although converter systems can be designed to handle any rate.

\section{Hydrogen Storage}

In hydrogen storage systems, excess electricity and water would be used to produce hydrogen by electrolysis. Hydrogen would be stored as compressed gas in pressure vessels. The conversion of the hydrogen to electric energy can be done in fuel cells and combustion devices (boilers or gas turbines). One drawback of these systems is the low efficiency of the hydrogen to electricity conversion (40 to $50 \%$ ).

The cost of electrolyzers and fuel cells usually makes hydrogen storage attractive for systems that are required to store 20 to $50 \mathrm{MWh}$. The one major disadvantage of the hydrogen storage system for the railroads is that a fairly large facility is required to house equipment and storage tanks.

\section{F1ywheel Energy Storage}

Kinetic energy of the rotating mass in a combination motorgenerator can be used to store and later retrieve energy that would otherwise be lost from braking on downgrades or station stops. Wayside and onboard systems have been proposed. Onboard systems of low energy density (a few $\mathrm{kWh}$ ) have been constructed and used on automobiles and transit vehicles. Advanced, higher capacity systems are being proposed and some components are being built and tested. A complete, reliable system with high capacity has yet to be developed. 
A wayside system does not have the size and weight restrictions of an onboard one, and therefore has a more immediate potential for application to railroad operations. The main disadvantage is that much research must be done before a highly reliable system can be produced for railroad energy storage. The Long-Run Average Cost and Energy Model indicates energy savings of from 2 to $8 \%$ depending on whether the line is electrified, at costs from 1 to $4 \%$ higher.

\section{Superconducting Magnetic Energy Storage}

Superconducting magnetic energy storage systems are in the very early stages of development. The system stores electrical energy in the magnetic field produced by a circulating current in the winding of a magnet. Preliminary results project that these systems will be economical only for very large systems, so we do not consider them further.

\section{Onboard Energy Systems}

For onboard energy storage, several problems must be overcome. First, the storage device must have a minimum weight, and the volume must be small enough to fit aboard railroad equipment. Second, the device must be capable of accepting high power rates. The charge cycle for such a system applied to road-haul engines would be perhaps 20 minutes to one hour. Finally, for the system to be economical, repeated charge cycles are required. A cycle life on the order of 10,000 cycles is probably a minimum, depending on the costs and individual railroad preference for replacement.

Table 8 lists and compares possible onboard energy storage devices.

In keeping with the previous assumptions, a single train in linehaul service would have to have provisions for onboard storage of $1,000 \mathrm{kWh}$ of energy and power capabilities of about $3,000 \mathrm{~kW}$. A stee 1 flywheel capable of this storage would weigh 33 tons (see Table 8). Gas compression would require 125 tons of equipment. This is near the limit of weight desirable in a single rail car, but not outside the realm of possibilities. Almost all the systems possess power densities that could support the rail application. However, it makes sense to choose only the lightest piece of equipment for storage. We saw previously that there are cost disadvantages to compressed air storage on a "small" scale; the same disadvantage applies to the hydraulic accumulator. The cycle life (in small sizes) of natural rubber deformation and batteries precludes their further consideration for onboard storage. We thus conclude that the flywheel shows the most potential for onboard energy storage.

Several applications of flywheel storage to railroad-size equipment are in progress (see Appendix A). Garrett AiResearch is testing two New York City subway cars equipped with a pair of energy storage 
Table 8

ENERGY STORAGE COMPARISON

\begin{tabular}{|l|c|c|c|}
\hline Storage Phenomenon & $\begin{array}{c}\text { Energy } \\
\text { Density } \\
\text { (Wh/1b) }\end{array}$ & $\begin{array}{c}\text { Power } \\
\text { Density } \\
\text { (W/1b) }\end{array}$ & $\begin{array}{c}\text { Deep (75\%) } \\
\text { Discharge Cycle } \\
\text { Life (Cycles) }\end{array}$ \\
\hline $\begin{array}{l}\text { Compression of gases } \\
\text { Hydraulic accumulator }\end{array}$ & 3.5 & $10^{4}$ & $10^{7}$ \\
Elastic deformation & 3.5 & $10^{4}$ & $10^{7}$ \\
Steel spring & 0.04 & $10^{4}$ & $10^{7}$ \\
Natural rubber band & 4.0 & $36 *$ & $1000-5000$ \\
$\begin{array}{l}\text { Electrochemical reaction } \\
\text { Lead-acid battery }\end{array}$ & 8.1 & $36 *$ & $300-500$ \\
Nickel-cadmium battery & 13.9 & $36 *$ & $1000-3000$ \\
Kinetic energy & 25.2 & $10^{4}$ & $10^{5}$ \\
Maraging steel flywheel & 15.1 & $10^{4}$ & $10^{5}$ \\
4340 steel flywheel & &
\end{tabular}

Source: L.J. Lawson, "Kinetic Energy Propulsion for Mass Transportation," paper presented at the Ground Transportation Symposium, University of Santa Clara, Santa Clara, California, June 1973.

* Set to this value to facilitate comparison.

flywheels. The capacity of each flywheel is $3.2 \mathrm{kWh}$ at $100 \%$ speed. The flywheels are spun up during deceleration by an electric regeneration scheme. The stored energy is then used during acceleration instead of drawing third-rail current. Although the energy levels demonstrated in this test are low compared with those required for locomotive service, the success of the program demonstrates the usefulness of energy storage flywheels.

This regenerative braking application of a flywheel energy-storage device would seem most appropriate for regeneration during flatyard switching operations, which are characterized by a repetitive duty cycle of high acceleration and deceleration of the switch engine. The FRA, in cooperation with both a manufacturer of a flywheel energy-storage device and several railroads, is considering investigating the practicality of such units. 
Based on the results of the Garrett AiResearch's tests on New York City subways, we estimate that flywheels could reduce fuel consumption by 20 to $25 \%$ in switchyard applications. We will use the higher figure for modeling purposes.

For line-haul applications, a flywheel could be used to regenerate energy during braking. In practical designs, the locomotive engine would most likely be coupled to the flywheel for spin-up during the long idle periods, which would allow the diesel to run at more constant speed. Diesel engines (or turbine engines, for that matter) do not operate efficient1y under low-load or no-load conditions; in fact, a significant fraction of the fuel consumption occurs during engine idle. Energy stored during low-load or no-load conditions would be used to provide additional power under full-load (acceleration) conditions.

Because such an operation is dependent on the use of the locomotive, we will not estimate its overall impact. We estimate that about $1 \%$ of energy used could be recovered over a typical main-line section of track and yard operations by a flywheel energy-storage device. The cost of such a system would be about the same as for the system presently used. Selection of application would result in higher energy and cost savings.

\section{Alternative Fuels}

A1ternative fuels are not considered for their energy conservation potential but rather as a necessary step toward reduced dependence on petroleum products. Some alternative fuels may in fact provide some savings; however, the savings alone would not justify their consideration in most cases. In this section, we discuss alternative fuels for diesel-electric locomotives and railroad electrification.

Several alternative fuels have been proposed and/or tested in diesel engines. Some of the research is described in Appendix A. We discuss below four alternatives of promise: degraded petroleum-derived fuels, derived synfuels, ammonia, and hydrogen. We emphasize the effects of these alternative fuels on diesel-electric locomotive performance. Alternative fuels that require conversion of diesel engines to Otto cycle (spark ignition) engines are not considered here.

\section{Petroleum-Derived Fuels}

Diesel fuel is a distillate of crude petroleum. Crude oils generally contain a mixture of gasolines, distillates, and lube oil stocks. During the refining process, the yield of any one of these products effects the amount of the other products available. An additional byproduct of refining is a heavy black residue that must be heated to flow. This residual fuel can also be burned and has a high heating value. 
During the mid-1950s, experiments using this residual as a secondary fuel in locomotives were carried out. 19 The heavy fuel was burned in throttle notches 5-8, and the regular diesel fuel was burned at lower speeds. In the long run, however, the problems offset the benefits. The dual system worked best on roads where long periods of heavy loads and high speed reduced the number of throttle changes. Frequent changes (as a result of speed adjustments) from one fuel to the other were difficult to perform effectively. Residuals were discontinued for several additional reasons. They are often less consistent in quality than diesel fuel, cause injectors to clog more easily, and require higher maintenance because of their high sulfur content. More recent research has indicated that the wear rate of the top compression ring approximately doubles as sulfur content of fuels exceeds $1.0 \% .20$ We assume that the cost of removing the additional sulfur found in these residuals would be prohibitive, and thus we estimate that some increase in maintenance, perhaps 30 to $70 \%$, would be required. Maintenance costs would increase by a like amount, and engine downtime (presently estimated at $10 \%$ of total available time) would increase by 13 to $17 \%$. Based on an estimated $6 \%$ increase in thermal energy per gallon, the specific fuel consumption of such an operation should go down. We previously estimated a value of $0.059 \mathrm{gal} / \mathrm{hp}-\mathrm{h}$ as the specific fuel consumption (adjusted for duty cycle) of a diese1-oil-powered locomotive. The new estimate is $0.057 \mathrm{gal} / \mathrm{hp}-\mathrm{h} ; 83.2 \%$ of the fuel burned is the residual, and the remainder is diesel oil. The cost and performance estimate changes for dual fuel operation are:

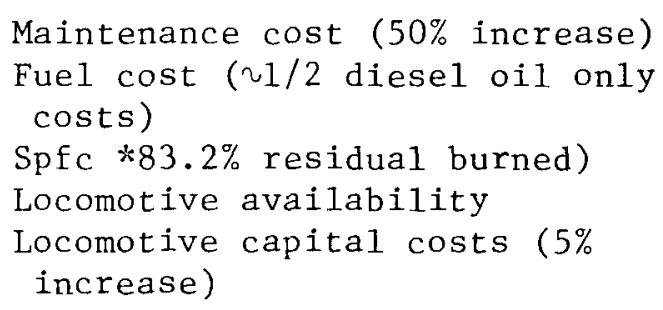

$$
\begin{aligned}
& \$ 0.30 / \mathrm{gal} \\
& \$ 0.18 / \mathrm{gal} \\
& 0.057 \mathrm{gal} / \mathrm{hp}-\mathrm{h} \\
& 7446.0 \mathrm{~h} / \text { year } \\
& \$ 262,500 / \text { unit }
\end{aligned}
$$

These characteristics result in a modest $1 \%$ decrease in cost, at the expense of an increase in total energy consumption of approximately $1 \%$. The real tradeoff is the alternative use for the middle distillate diesel fuel saved at the expense of using more heavy fractions.

\section{Derived Synfuels}

Petroleum-1ike products (synfuels) can be extracted from coal and oil shale or sand by several methods. Synfuels differ very little from petroleum-derived products in terms of heating values, sulfur content, and appearance. They have been burned in diesel locomotives, notably in South Africa, where coal is the prime source, and in Canada, where CP tested tar-sand-derived synfuels in 1971.21 CP is still using this fuel in more than 100 locomotives. Although the use of synfuels instead of diesel oil would cause little change in the operation of locomotives, there would be an increase in the cost of the product. It is estimated 
that low-sulfur distillate oil would cost $\$ 3.50$ to $\$ 5.00 / \mathrm{million}$ Btu in 1975 dollars. This converts to a cost of $\$ 0.48$ to $\$ 0.69 /$ gal at $137,300 \mathrm{Btu} / \mathrm{ga} 1$.

\section{Ammonia}

Several proposals for using ammonia in diese1 engines have been investigated and tested. The value of ammonia is that it can be synthesized from air and water in nuclear- and coal-generating plants. Primary interest in this concept has been related to the use of ammonia for battlefield vehicle propulsion. 22

Luthra et al. summarize experiments that have been carried out using ammonia in a small bifuel diesel engine. 22 Such an engine is operated like a conventional diesel except that ammonia is mixed with the intake air charge, and only a small "seed" amount of diesel oil is injected to initiate combustion. Autoignition of ammonia requires compression ratios of 35 and upwards. Therefore, the use of pure ammonia is impractical without major engine redesign and modification. The lower ignition characteristics and the slower burning of ammonia relative to diesel oil make its use in low-speed diesels especially attractive. As rpm increases, the tendency for incomplete combustion to occur also increases.

From the experiements with ammonia in bifuel diesels, it was found that the diesel oil flow rate must be from 27 to $40 \%$ of the ammonia flow rate for combustion to occur. The exact percentage depends on the engine speed. The spfc of diesel oil appears to be from one-half to one-third of the consumption figure for a pure diesel oil operation. Diesel spfc drops from 0.23 to $0.07 \mathrm{~kg} / \mathrm{hp}-\mathrm{h}$ at $1,800 \mathrm{rpm}$ and $4 \mathrm{hp}$ with the ammonia flow rate at $110 \%$ of the diese1 flow rate. Thermal efficiency increases from 10 to 35\%. Spfc for ammonia added at $70 \%$ by weight of diesel oil for an engine run at $1,500 \mathrm{rpm}$ (and full 1oad) was $0.55 \mathrm{lb} / \mathrm{hp}-\mathrm{h}$; the spfc for diesel oil was $0.13 \mathrm{lb} / \mathrm{hp}-\mathrm{h}$. ${ }^{*}$ This compares with an spfc of $0.69 \mathrm{lb} / \mathrm{hp}-\mathrm{h}$ for straight diesel oil operation. We thus estimate that the overall spfc for large diesels at full load might be $90 \%$ by weight of the straight diesel figure for this type of operation.

It seems reasonable to assume that capital costs and maintenance costs will increase by $5 \%$. Note, however, that information on the impact of ammonia on maintenance is not available. The changes to model inputs are:

\footnotetext{
* The ratio by weight of ammonia to diesel is assumed to be $70 \%$ for
} model purposes. 


$\begin{array}{ll}\text { Maintenance cost ( } 5 \% \text { increase) } & \$ 0.241 / 1 \mathrm{~b} \text { fuel } \\ \text { Fuel costs (same as diese1 } & \$ 0.053 / 1 \mathrm{~b} \\ \text { only costs) } & \\ \text { Spfc (10\% improvement 70\% } & 0.3531 \mathrm{~b} / \mathrm{hp}-\mathrm{h} \\ \quad \text { ammonia) } & \\ \begin{array}{l}\text { Locomotive capital costs ( } 5 \% \\ \text { increase) }\end{array} & \$ 262,500.00\end{array}$

The cost and energy implications of the assumed ammonia engine performance are to increase total cost by $25 \%$, while total energy consumption increases by $153 \%$. These cost and performance estimates, coupled with the relatively untried operational concept of an ammonia engine, suggest that considerably more basic developmental work is required on this technology before a railroad application can be undertaken.

\section{Hydrogen}

The burning of hydrogen is being considered as a substitute or adjunct to large-scale electrification. Foster and Escher consider the feasibility of burning hydrogen in a diesel locomotive. 21 Based upon considerable internal combustion experimentation with hydrogen fuels and talks with industry representatives, Foster and Escher suggest that hydrogen-converted diesel prime movers can be readily achieved.

The effects on efficiency of burning pure hydrogen fuel in diesels are expected to be minimal. Estimates range from a loss of 1 to $2 \%$ to a gain of $5 \%$, depending upon the configuration. However, the expansion energy of the injected hydrogen should increase the power output by 15 to $20 \%$. A total of 32 to $44 \%$ increase in output is possible in turbocharged engines where aftercooling of the air charge with the cryogenic hydrogen is possible. To estimate the spfc of hydrogen relative to diesel fuel, let

$$
\left(w_{\text {net }}\right)_{K}=\left(n_{B}\right)_{K} Q_{K} /\left(n_{M}\right)_{K}
$$

and

$$
\left(\mathrm{w}_{\text {net }}\right)_{\mathrm{H}_{2}}=\left(\mathrm{n}_{\mathrm{B}}\right)_{\mathrm{H}_{2}} \mathrm{Q}_{\mathrm{H}_{2}} /\left(\mathrm{n}_{\mathrm{M}}\right)_{\mathrm{H}_{2}}
$$


or

$$
\left(n_{B}\right)_{H_{2}}=\left(n_{M}\right)_{H_{2}}\left(W_{n e t}\right) H_{2} / Q_{H_{2}},
$$

where

$$
\begin{aligned}
W_{\text {net }} & =\text { net work of the engine } \\
n_{B} & =\frac{h p-h / 1 b}{\text { brake spfc }} \text { (brake thermal efficiency) } \\
n_{M} & =\text { mechanical efficiency } \\
Q & =\text { heat release/1b air } \\
H_{2} & =\text { hydrogen } \\
K & =\text { kerosine (equivalent to diesel). }
\end{aligned}
$$

Then,

$$
\left(\mathrm{W}_{\text {net }}\right)_{\mathrm{H}_{2}} \cong 1.21\left(\mathrm{~W}_{\text {net }}\right)_{\mathrm{K}}
$$

Therefore,

$$
\left(n_{B}\right)_{H_{2}}=\frac{\left(n_{M}\right)_{H_{2}} \frac{1.21\left(n_{B}\right)_{k} Q_{K}}{\left(n_{M}\right)_{K}}}{Q_{H_{2}}}
$$

If we assume that $\left(n_{M}\right)_{H_{2}}=\left(n_{M}\right)_{K}$ and we substitute values for the vari-
ables, then

$$
\begin{aligned}
\left(n_{B}\right)_{H_{2}} & =\frac{1.21 \frac{0.138}{0.34} 1,240 \mathrm{Btu} / 1 \mathrm{~b} \text { air }}{1,510 \mathrm{Btu} / 1 \mathrm{~b} \text { air }} \\
& =0.40
\end{aligned}
$$


Finally,

$$
\left(n_{B}\right)_{2}=\frac{0.049}{\text { brake } \operatorname{spfc} H_{2}}
$$

Therefore, the brake spfc of hydrogen is $0.121 \mathrm{lb} / \mathrm{hp}-\mathrm{h} . \mathrm{.}^{2} \mathrm{l}$ This spfc is not adjusted to account for duty cycle. The computation indicates, however, that the spfc of hydrogen would be about $35 \%$ of diesel.

The cost of liquid hydrogen at the rail fueling point is estimated to be $\$ 3.00$ to $\$ 4.50$ per million Btu or $\$ 0.155$ to $\$ 0.232$ per $1 \mathrm{~b}$ at $51,600 \mathrm{Btu} / 1 \mathrm{~b}$. Because of the extremely volatile nature of hydrogen, locomotive costs will increase by $10 \%$. An estimated additional $\$ 35,000$ will be required per locomotive to cover the cost of the hydrogen tender. The changes required to the model inputs are:

Locomotive costs ( $10 \%$ increase

+ tender

$\$ 310,000.00$

Fue1 cost $\$ 0.18 / 1 b$

Spfc (hydrogen)

$0.137 \mathrm{lb} / \mathrm{hp}-\mathrm{h}$

With this assumed performance, using hydrogen fuel results in a cost increase of $11 \%$ and an energy increase of $8 \%$. The energy required to produce the hydrogen is not included in this estimate. While the assumed performance of the hydrogen fuel makes it more attractive than ammonia, a significant amount of demonstration work is needed to show that a hydrogen engine will be reliable, durable, and economical. The marketability of the hydrogen locomotive will be hampered relative to some other synthetic fuels because of investments in additional facilities that will have to be installed for storage, handling, and transport.

\section{Railroad Electrification}

Electrification is the technology most often suggested for reducing the fuel consumption of railroads. However, a number of studies have indicated that railroad electrification would not increase the actual energy efficiency of rail transportation.

The electrification of railroad lines allows greater use of alternative energy sources for generation of the required power. These sources include coal, nuclear, hydroelectric, solar, and geothermal power generation. If the energy sources for electrified train operations are not petroleum based, a substantial amount of petroleum can be saved. The solid line in Figure 6 shows the relationship between petroleum savings and the number of route miles electrified. This relationship was developed by MITRE and is based on the following assumptions : 


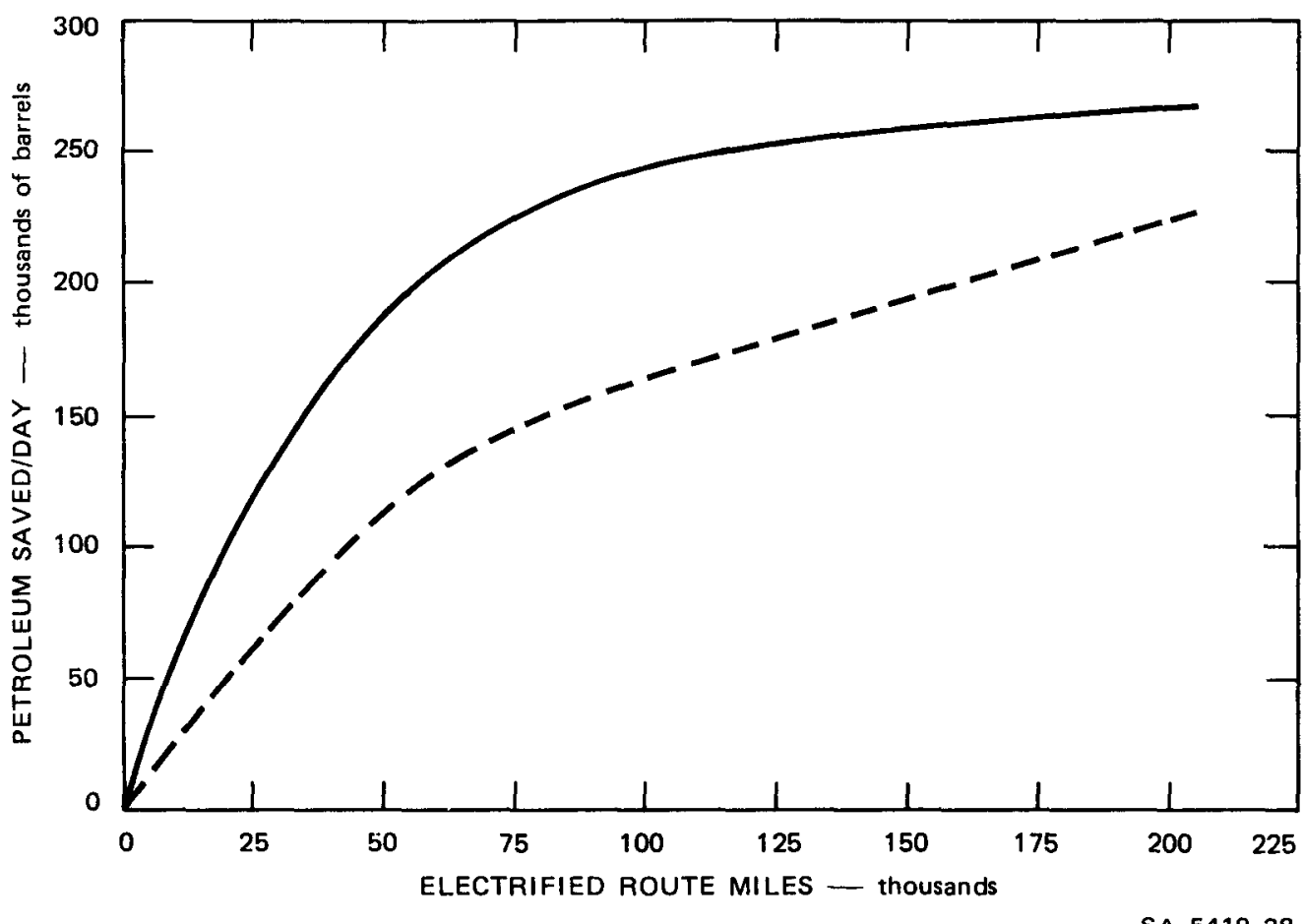

FIGURE 6 RELATIONSHIP BETWEEN ELECTRIFICATION EFFORTS AND PETROLEUM SAVINGS

(1) The routes with the highest density are electrified first,

(2) Electricity generation is not based on petroleum,

(3) Average fuel consumption does not vary because of route densities.

Because about $17 \%$ of all electrical power in the United States is generated using petroleum as the energy source, assumption 2 causes the relationship to overstate the potential fuel savings of electrification. In addition, the assumption that average fuel consumption does not vary because of route densities is suspect. The output of the Long-Run Average Cost and Energy Model indicates that branch-line operations, which typically occur on low-density lines, are approximately twice as fuel intensive as main-line operations. Thus, the relationship in Figure 6 overestimates the potential fuel savings on low-density lines. The broken line in Figure 6 probably is more representative of the potential petroleum savings from railroad electrification.

Electrification technology has advanced significantly within the last decade. However, new technological developments, which have reduced the costs associated with electrification and have increased operating efficiency, have not yet been implemented on a large scale. 


\section{Thyristor Controls}

The use of thyristor-controlled locomotives is the latest in a series of technological improvements to rectifier motive power. Rectifier motive power was first developed in the late 1940s. It allows the use of ac power at the commercial frequencies available from utility companies and thus eliminates the need for expensive power conversion equipment and special transmission lines. Rectification was originally performed with a water-cooled ignitron system and later with a mercury arc rectifier system. These systems were supplanted by a silicon diode rectifier system developed in 1963. The silicon diode rectifier was in turn supplanted by a silicon controlled rectifier (SCR), or thyristor.

Thyristor controls have many positive features. They allow extremely smooth, notchless control of separately excited traction motors, which improves a locomotive's adhesion properties and thus enables a given locomotive to haul heavier trains. With improved wheel slip control, thyristor controlled locomotives can operate at about $25 \%$ adhesion. Diesel-electric units operate at about $18 \%$ adhesion. An energy savings of 4 to $5 \%$ is possible due to the increased adhesion associated with thyristor-controlled locomotives. The application of thyristor controls has significantly reduced the maintenance costs of electric locomotives. When used in conjunction with vacuum circuit breakers, thyristor controls allow the use of higher and more efficient voltages.

\section{Power Distribution Systems}

Thyristor-controlled electric locomotives, vacuum circuit breakers, and other relatively new technologies have enabled the railroads to use $50-\mathrm{kV}$ power distribution systems instead of $12.5-$ or $25-\mathrm{kV}$ systems. A $50-\mathrm{kV}$ system has two principal advantages over lower voltage systems. First, a $50-\mathrm{kV}$ system can substantially reduce the number of substations required for an electrification project. For the 78 miles of the Black Mesa to Lake Powell Railroad, a $50-\mathrm{kV}$ system required only one substation, whereas a $25-\mathrm{kV}$ system would have required three substations. In genera1, the substation costs for a $50-k V$ power distribution system wil1 be about 35\% less than the substation costs for an equivalent $25-\mathrm{kV}$ system. A second advantage of a $50-\mathrm{kV}$ system over a $25-\mathrm{kV}$ system is that it allows the use of a lighter catenary.

The costs associated with power distribution systems have been reduced through the use of different materials and different catenary and power collection designs. The material most often used for the overhead contact system is hard drawn copper or bronze contact wire. However, contact systems made of aluminum or stee1-reinforced aluminum have been used for selected applications in Canada and France. When and if these aluminum components are perfected, they may allow significant savings in weight and cost. 
Numerous materials have been used for the construction of catenary masts. These include galvanized steel, wood poles, and reinforced concrete. The selection of the best material depends on the specific application and is related to availability and initial cost, construction cost, the material's lifespan, and replacement costs. The warping, excessive flexibility, and guyline requirements of wood poles may prohibit their universal use.

The basic catenary design used in the United States consists of a messenger, an auxiliary contact wire, and a contact wire. The auxiliary contact wire is unnecessary for train speeds up to $75 \mathrm{mph}$. For lower speeds, such as in yards, a "simple stitched" catenary consisting of a contact wire supported at each suspension arm by a stitch wire can be as much as 30\% less expensive than the standard catenary design.

Noncontact power collection techniques and technologies have also been investigated for their usefulness in electric train operations. These include electric arc, magnetic induction, electrostatic (capacitive) coupling, and electromagnetic waveguide coupling. None of these technologies is suitable for the normal operation of electrified freight trains.

Analysis of electrification along the average route of the Long-Run Average Cost and Energy Model results in a $3 \%$ increase in cost and a $6 \%$ reduction in energy. The cost increase suggests that considerable selectivity will be required in choosing lines where the density of traffic can justify the cost of electrification. Marketability of electrification is in question because of the large investment necessary to achieve a viable portion of a railroad system. 
- 


\section{INTERMODAL SYSTEMS}

An intermodal system of highway and railroad vehicles, where unit loads can be easily transferred from one vehicle to another, has potential economies and energy-saving characteristics. The intermodal capability offered by TOFC and COFC services does not achieve these economies or energy savings because of mismatches between the load characteristics of highway and railroad vehicles. With a properly engineered and matched system of components, the intermodal system will offer improved services to shippers. Additional traffic will be attracted to a system that offers transportation at energy intensities that are lower than either railroad or highway systems. As more is attracted to intermodal systems and new technology becomes available, advanced intermodal systems will be developed that offer even better matches between the system components. Some of the current research to improve intermodal systems or design new ones is described in Appendix A.

\section{Rationale for an Intermodal System}

The railroad system in the United States offers a relatively lowcost way of moving goods at low energy intensities. However, service is slow and unreliable due to switching in intermediate terminals and congestion at major gateways in many urban terminal areas. Also, some parts of the railroad operation are more costly and fuel intensive than others. For example, the line-haul portion of railroad operations allows high productivity from locomotives and crews, because of high speeds and long trains, and good fuel economy. However, local delivery of freight cars to customer sidings is performed by short trains at slow speeds and is often subject to delays, especially in congested urban terminals. Energy intensity is also high in the local delivery operation because of the high ratio of equipment weight to the weight of the goods delivered. Finally, the local railroad network is limited; potential customers for carload traffic are somewhat limited in their opportunities for plant location and seldom have competing railroad carriers available.

The needs for improved environmental quality are in direct conflict with continued (and sometimes inefficient) industrial operation. Railroad tracks are an impediment to automobile and pedestrian traffic in. dense urban areas, and operations over these lines present safety hazards. Urban railroad switchyards and shops occupy space that frequently can be developed to provide high profits for the owner and increased tax revenue for the community. Efficient and profitable industries frequently move away from central urban areas to suburban locations. However, the abandonment of railroad service in central urban areas would cause increased problems for the remaining, less profitable, industries. The loss of jobs that would result is a major 
reason for retention of these lines. Thus, although many communities (and railroads) would like to remove expensive and inefficient facilities from the interior of urban areas, they have been pressured to refrain from doing so by requirements to maintain service to existing industries.

The over-the-road trucking system in the United States offers faster and more reliable service than the railroads at costs and energy intensities that are about three times higher than those of railroad operations. The relative efficiencies of the highway system are opposite to those of the rail system, however. In trucking, productivity in the line haul is limited by the size and weight of the vehicles. These limits are determined by considerations of the safety of operating vehicles of mixed size in traffic and the design and wear and tear on the highway itself. The line-haul cost of the truck operation is therefore high. In local delivery operations, speed and size are less important, and trucks can perform local delivery with smaller amounts of manpower per unit of freight delivered than railroads. Also, the weight and cost of truck equipment, relative to the load size, is more favorable than that of the railroad in this kind of service, leading to operating economies and fuel savings. Finally, the pervasiveness and ubiquity of the local highway system provide great flexibility of access to the trucking system. This translates into both flexibility for the trucking system user in his plant location and access to plants by competing trucking companies.

For some shipments, then, a combination of truck and railroad services is attractive. The combined service can provide the low cost, increased reliability, and greater accessibility of local delivery by highway vehicles and the low cost line-haul characteristics of railroads. It is based on a mechanism by which the load can be efficiently transferred between the highway vehicle and the rail vehicle. One of the keys to the efficient transfer of a load is the unit load; that is, a single, large container or other unit that enables a significantly sized shipment to be transferred at one time and does not require the handling of individual cartons or portions of the load at the transfer point. The unit load also protects the shipment against damage and loss by pilferage or separation of portions of the load.

\section{Present Intermodal Systems}

TOFC and COFC services provide an intermodal capability and are examples of the unit-load concept. These services have not been widely accepted by either the railroads or shippers because of high operating costs, unsatisfactory service, and lack of a truly integrated national system. Institutional problems severely compromise the cost and quality of the services offered, and the technology used is an unsophisticated, minimum-investment piecemeal adaptation of available technologies. The broad problem areas of TOFC and COFC can be classified as follows:

- Lack of agreement on the goals or objectives to be achieved by offering intermodal service. 
- Technical problems with the hardware, systems, operations, and marketing.

- General problems with the introduction of technological change into the railroad industry.

The differing goals and objectives can best be illustrated by the identification of several different benefits from the use of intermodal service. For example, eliminating way trains, branch lines, or urban yards and spurs; offering a service to compete with over-the-road truckers; and providing inland or overland service for marine containers represent different goals. The services and equipment to best meet each goal may be quite different. Providing a high level of service speed and reliability (with their associated higher costs) to compete with trucks is not necessarily compatible with the possibility of providing a substitute to existing low-cost railroad carload transportation for those shippers located on abandoned branch lines. There may also be a conflict between these two provistons and the provision of rail service for marine containers. The stacking requirement and structural rigidity of the shipboard container may present tare weight penalties that adversely affect the other two provisions.

The specific problems associated with intermodal services center around the adequacy of the technology, systems, and marketing used. Some of these problems may result from conflicting goals held by different interested parties. We present below some examples of the technological and service problems of railroad intermodal systems.

- Truck-rail intermodal systems are built around trailers, containers, and a combination of the two. Although some carriers found it necessary because of clearance problems to use containers, most have continued to operate with trailers despite such obvious disadvantages as high center of gravity, high aerodynamic drag, poor payload-to-gross-weight ratio, and higher total system investment.

- Questions of trailer and container size, weight, and standardization have plagued TOFC, COFC, and marine container development. A current problem is to figure out how to carry two 45-ft trailers on an 89-ft flatcar. The causes of this problem are the limitations and influences of state and federal (and to some extent forelgn) maximum allowable trailer sizes, weights, and combinations (doubles, triples) for highway vehicles. As various changes have taken place over the years (and more are in prospect) it has been difficult to standardize on intermodal system hardware components that will not become obsolete.* The response to their

* The relatively short life, large resale market, and absence of onerous "system conformity" requirements allow truckers to convert rather quickly to new and larger equipment when size and weight limits are changed. Hence, benefits are quickly captured and the penalties suffered are minimal. 
uncertainties has been to build "general-purpose" or "allpurpose" rail cars and to transfer equipment which can accommodate wide variations in the physical dimensions and other characteristics of trailers and containers. This response can be selfdefeating, however, because it builds in excessive penalties of costs, tare weight, aerodynamic drag, and complexity.

- For obvious and traditional reasons, new TOFC and COFC rafl car designs have been required to maintain a high degree of compatibility with the rest of the rail system. This requirement carries the implied assumption that the need for and value of being able to operate, for example, in "mixed" trains exceeds the penalties imposed on car cost, tare welght, drag, car length (which affects, for example, terminal configuration), car dynamics in trains, and the like. Little attention has been given to quantifying the penalties thus imposed, or to examining the possible benefits of breaking with traditional compatibility requirements. As examples, semipermanently coupled cars, multiunit articulated cars, cars with lower draw bar strength, and equipment dedicated to operate (and only able to operate) in "solid" intermodal unit trains need examination.

- Present TOFC and COFC systems generally use the cross-sectional capability of the rail system poorly. The cross section of the payload in loaded trailers or containers currently moving on the system often occupies one-third or less of the cross-sectional area of the clearance for cars moving in unrestricted interchange (see Figure 7). As a consequence, it takes many cars or very long cars and trains to accommodate significant volumes of revenue-producing freight. For train operation and in car design, this produces many undesirable side effects--high tare weight of equipment, high drag, excessive energy requirements, long sidings, and many others. In classification yards, the long overhang of $89-\mathrm{ft}$ flatcars used for TOFC and COFC sometimes makes it difficult to uncouple on the hump and results in fallure to couple on curves. It has been suggested the arbitrary costing methodology of the ICC is primarily responsible for the development of very long, "inefficient," TOFC and COFC cars. 23 Hangups on curves are also a problem. TOFC and COFC terminal design is also affected--terminal configuration must be long, or trains must be broken apart. This in turn creates switching costs, causes delays, and tends to produce more complicated and less land-efficient multitrack terminal configurations. Two-high stacking of containers on rail cars appears to be one feasible solution to this general problem. However, although the idea has been around for many years, little progress has been made on squeezing more paying freight into each foot of train length.

- Loading methods and equipment vary widely and include the traditional end-loading "circus" method; 1ift-on and 11ft-off with overhead gantries (both rubber-tired and ra1l-mounted) or front-end loaders ("piggypackers"); and side-loading methods 


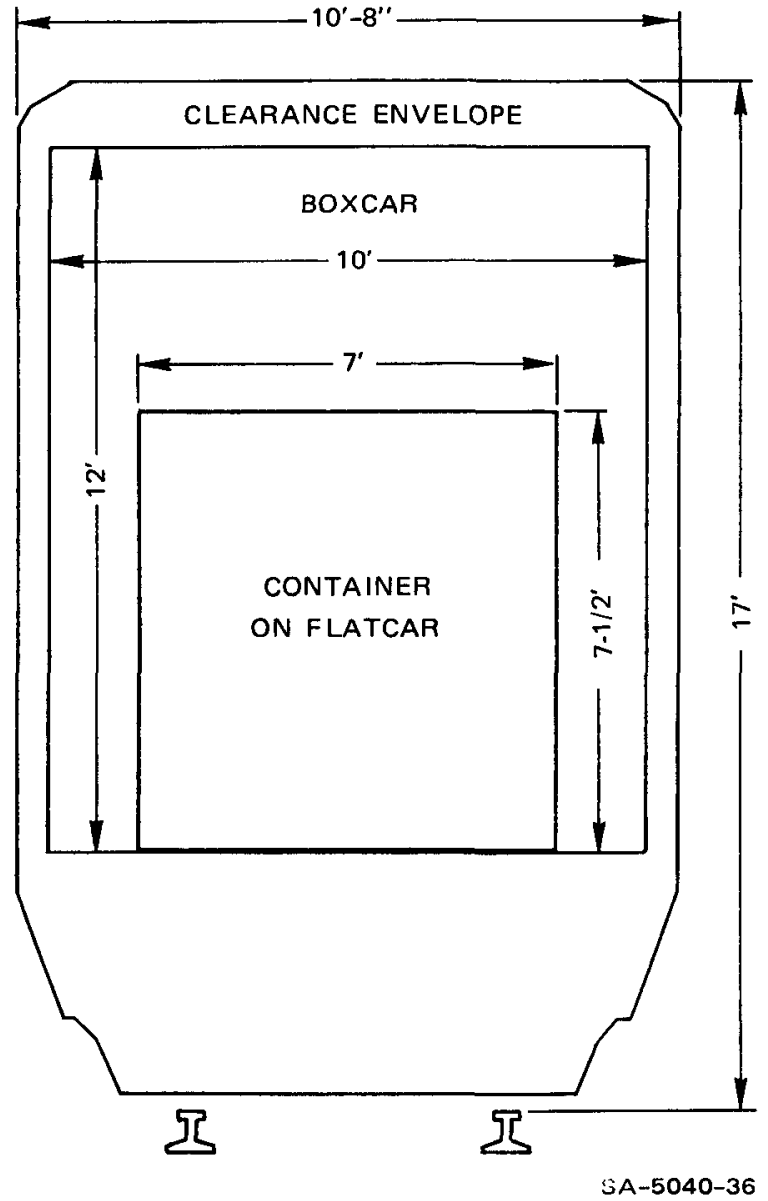

FIGURE 7 TOPICAL CLEARANCE ENVELOPE AND FREIGHT CROSS SECTIONS

such as the Steadman system or the Flexi-Van system (now abandoned). Both top- and bottom-1ift methods are in use.

- The industry has never fully worked out a sound technological and operating relationship with the marine container operators. Direct ship-to-rail transfer possibilities have generally been discarded in favor of separate terminals, marine containers are often transported on chassis, the stackability of the marine containers is not used to advantage in TOFC and COFC terminals or in rail car design, and rational commercial arrangements for using marine containers for domestic land movements (e.g., for backhauls and system balancing) are lacking. Major technical, 
operating, marketing, and institutional issues remain unresolved on the general question of a "domestic" or land-only truck-rail system versus an "international" or truck-rail-ship intermodal freight system.

- Little attention has been given to the concept of a "family of intermodal unit loads." For example, British Freightliner, Sealand, and Matson have developed families of compatible "containers"--dry, high cube, insulated, tank, half high, open top, refrigerated, skid, auto rack, and the like. Opportunities to move unitizable "neobulk" commodities in intermodal service may also have been overlooked.

- Questions of fuel consumption for TOFC and COFC trains and measures to reduce fuel consumption in intermodal services have received very little study until recent years. The effect of aerodynamic drag and its relationship to speed and cross winds, various types and locations of loads, and the role of tare weight reduction in improving fuel economy are areas where attention is needed and present practice is deficient.

The rate of development and introduction of technological change in the railroad industry is generally low in comparison with other industries, including the railroad industry's direct competitors. Numerous studies have sought to identify the nature and causes of this situation and to suggest remedial action. In Section III are described some of the factors that have impeded the introduction or adoption of new railroad technology, or that have affected in other ways the nature of the technology adopted.

\section{Development of an Intermodal System}

The delineation of the problems with the present railroad intermodal system suggests that the following components result in an economical and energy efficient intermodal system:

- Provision of a variety of services, among them:

-A substitute service for carload freight now provided for customers on branch lines and lightly used lines in urban areas.

-Premium merchandise service comparable to that provided by trucks at lower cost and energy consumption.

-Services for large users such as the postal service, freight forwarders, and perhaps some large shippers.

-Marine container service.

- Unit loads that are matched both structurally and in weight to the requirements of railroad and truck hauls.

- A network that balances the length of the truck haul against the cost of the truck haul and uses large, automated terminals and direct railroad service between the terminals. 
- Materials handling system that transfers unit loads between railroad and highway vehicles quickly and at low cost, with minimal penalty to the weight or size of the unit loads.

The FRA recently published the results of a study to develop a nationwide intermodal system. The study concentrated on a system designed around existing trailer technology and $0-D$ pairs that would provide adequate traffic for frequent, direct services and opportunities for balanced service (providing reduced backhaul). By concentrating on this market, the study found that the system would be profitable to the carriers and would provide savings to users. The next step is to develop new equipment and a system for using them. Work is under way on new hardware development.

\section{Advanced Intermodal Systems}

One of the problems with existing intermodal systems is that the requirements for weight, clearance, and other unit load factors are not compatible between rallroad and highway modes. Although profits can be maximized and costs reduced in the face of these constraints, at some point the constraints themselves should be scrutinized. Advanced systems may result from relaxing one or more of the constraints regarding truck size or rail cross-sectional clearance and gage. The discussion that follows illustrates how unit load dimensions and vehicle design can evolve from present technology into systems with progressively relaxed constraints. Our discussion illustrates a process; it does not predict the outcome of a complex systems engineering job.

A number of container rail car designs have been proposed to increase the utilization of the cross section. Generally in these designs one conventional $8 \mathrm{ft} \times 8 \mathrm{ft}$ container is stacked on top of another. To achieve this stacking capability, complicated car designs (either drop frame or "bottomless" side frame cars) are required. Even then, only one container will fit over the trucks. The maximum height of each container in the stacked position is about $8 \mathrm{ft} 6 \mathrm{in}$.

Other approaches to increasing the utilization of the cross section include placing containers on the rall car crosswise (container length would be limited to about $10 \mathrm{ft}$ ) or enlarging the cross section of longitudinally loaded containers to approximate the rail clearance. In the latter approach highway size limits--the predominant constraint in the sizing of intermodal containers--will be exceeded. However, "oversized" containers could be used if warehouses and consolidation facilities were accessible by private road from the intermodal terminals. Travel on public highways could be avolded and present limits would not apply (analogous to the Stac Pac assembled automobile equipment system). Oversized containers could also be used if special oversized highway permits were authorized for restricted or controlled movement of units of excess width or height within a limited distance of intermodal terminals. 
Instead of optimizing the size of the container of the present system, the present system itself can be enlarged. Greater height (rather than width) would probably be of great benefit to intermodal system design because two-high stacking would be achieved without complicated car designs. However, raising the center of gravity of loaded cars exposes them to a greater force from side winds. A high center of gravity is particularly disadvantageous on poor track because the rocking action produces high wear on car components and therefore heavy maintenance costs. Widening the clearance might open up additional possibilities for oversized or crosswise loaded containers, but the latitudinal stability of railroad equipment on the present 4-ft 8-1/2-in. gage track would probably severely limit the potential gain.

Since the mid-1950s railroads have done a great deal of work to increase their clearances to accommodate TOFC traffic, particularly in the northeastern states where many limitations still apply to moving high trailers. It may well be that vertical clearance will be increased for the installation of overhead catenary systems when (and if) the railroads are electrified.

It is possible to remove all of the constraints of the present intermodal system and to explore the nature of an optimized cross section for an advanced intermodal system. Under these conditions, cross section, gage, and many other constraints of the present system become variables in systems engineering studies. Below we hypothesize a wide gage, large clearance, intermodal system that would exploit the full potential of technology to meet the need for long distance movement of unitizable freight.

To increase the number of containers (i.e., the amount of freight) per rall car and the efficiency of cross-section utilization, a number of new car configurations and gage and clearance envelopes should be considered. Two possible wide gage versions would be an 8-ft gage to accommodate $17-\mathrm{ft}-$ wide loads, or a $3-\mathrm{m}$ gage (about $10 \mathrm{ft}$ ) to accommodate 20-ft-wide loads. These compare with the present 4-ft $8-1 / 2-i n$. gage that accommodates up to $10-\mathrm{ft} 8-\mathrm{in}$. loads. Both wide gage versions would accommodate containers or other unit loads up to $20 \mathrm{ft}$ high.

The 17-ft-wide system would accommodate two 8-1/2-ft containers side by side, allowing $1 / 2 \mathrm{ft}$ of growth potential for the present $8 \mathrm{-ft}$ highway containers; the $20-\mathrm{ft}$-wide system would allow 20-ft-long containers loaded athwart the rail car. The increased envelope height of both systems would accommodate two 10 -ft-high containers stacked, allowing $1 / 2$ ft of growth potential over the 9-1/2-ft-high "high cube" marine containers now in use. The 45-ft capability for length in the 8 -ft gage system would accommodate a new length of container compatible with many existing state laws and the maximum length of a single trailer recommended by a recent interagency task force. 24

Figure 8 shows these alternatives. The 8-ft gage, 90-ft-1ong rail car accommodates elght 45-ft contalners, and the 3-m gage, 90-ft-long 


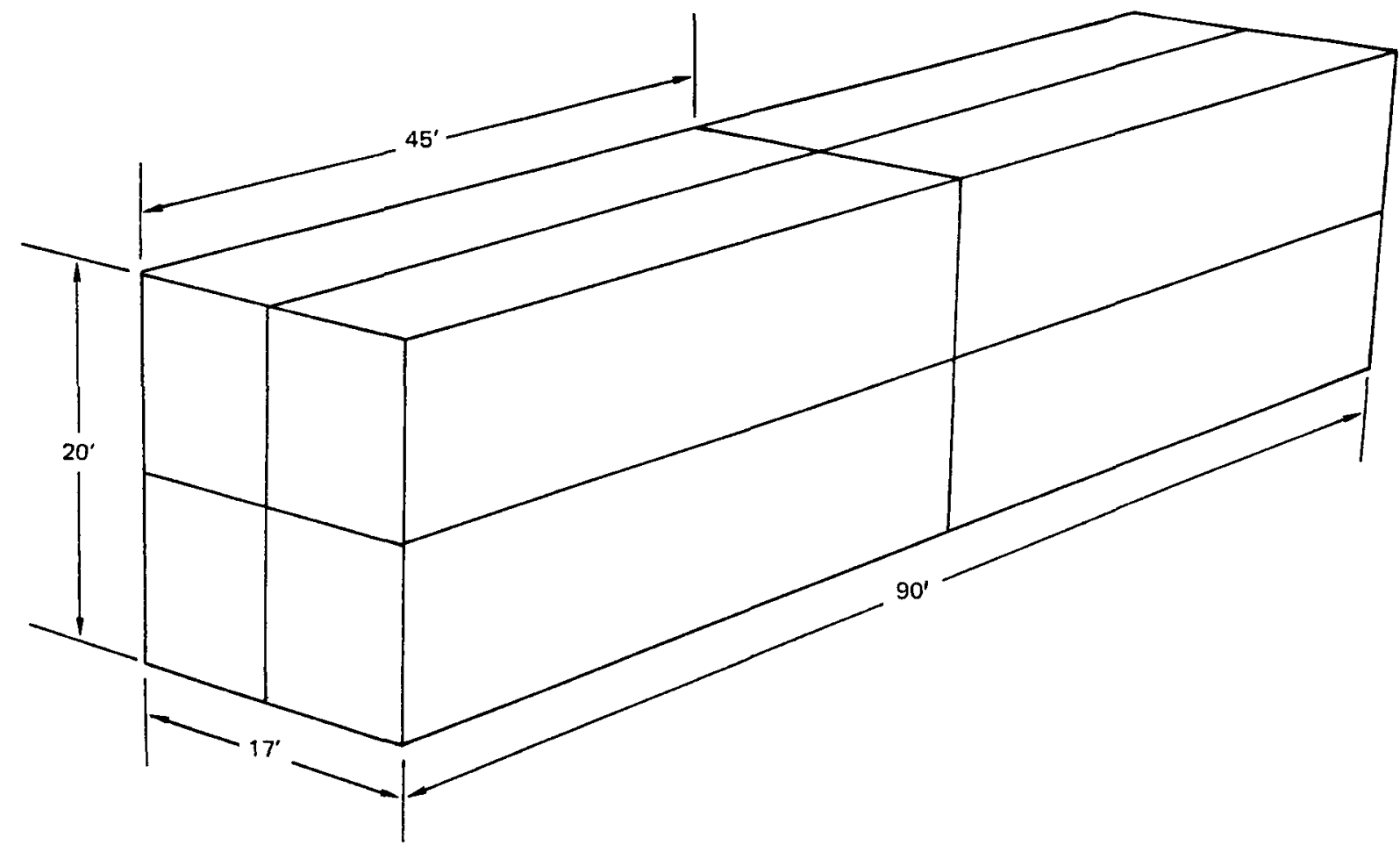

(a) FOR 8-ft GAGE

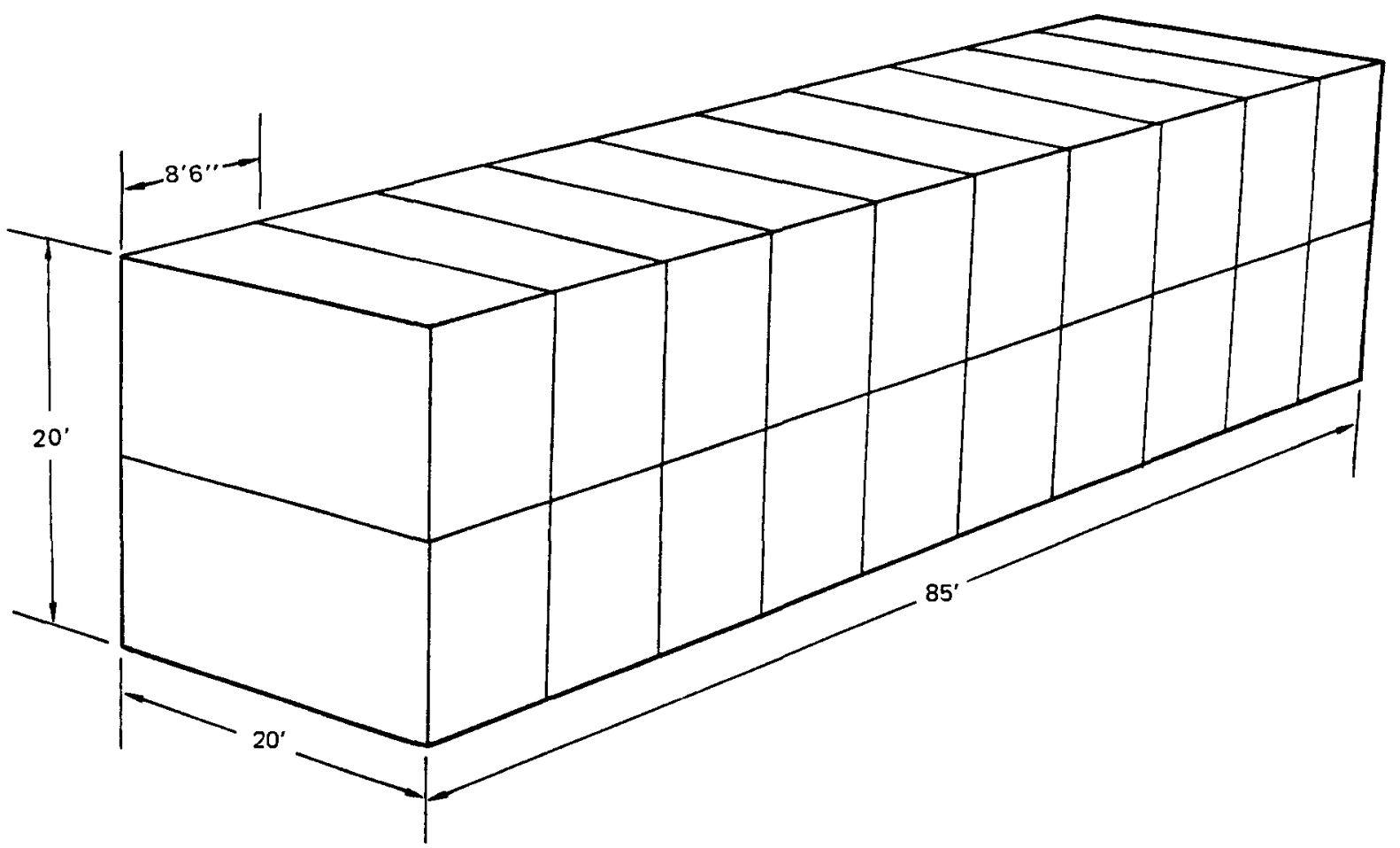

(b) FOR 10-ft GAGE

$S A-5040-37$

FIGURE 8 TWO WIDE-GAGE CONTAINER SIZE LIMITS AND STACKING ALTERNATIVES 
car handles twenty 20-ft containers. Both new cars are about the same length as present flatcars that accommodate only two 40-ft or four 20 -ft containers. Linear space utilization thus improves about four times in the first case and about five times in the second. Denser container packing has the following advantages:

- Shorter trains could be used, thereby decreasing (1) wind resistance (assuming the increase in frontal area does not offset the shorter train length); (2) the ratio of tare to total weight; (3) terminal length; (4) railcar inventory requirements; and (5) energy consumption.

- Larger and fewer raflcars would reduce the cost of electrification if the railcars themselves were to be powered (i.e., separate locomotives could be eliminated to further reduce cost and total train tare weight).

Selection between the two wide-gage versions would depend on the tradeoffs between container size and the convenience of loading the containers on rail cars. Loading athwart may be easier but could require more dock space. The $20-\mathrm{ft}$ container lengths are easier to handle and will be easier to route intact to final destinations. Highway vehicles could carry either one unit load on a single chassis, two unit loads on a 40-ft trafler, or three or more unit loads on multiple trailers. On the other hand, the lengthwise design would be more flexible in accommodating containers of various lengths. Widely used marine containers include lengths of $20,24,27,35$, and $40 \mathrm{ft}$. A 28-ft national standard has been recommended for double trailers. 24 With lengthwise loading, containers of varying lengths can fit onto the rail car. The 20-ft-wide cars could also accommodate long containers lengthwise, but cross-section utilization would be poor. 
VI MODAL SHIFT

Railroads can capture additional freight in two ways: (1) through modifications in present equipment and service, which would not significantly alter the basic concept of the railroad providing dock-to-dock boxcar service; and (2) through expansion and modification of intermodal operations, which would enable the railroads to provide truck or railroad service, depending on which service is most economical in a given situation. Some research projects to analyze and find ways of influencing the shipper's choice of mode are described in Appendix A.

Modal Competition Between Truck and Railroad

In 1975 , railroads carried about $37 \%$ and trucks about $21 \%$ of the two billion ton-miles of intercity freight traffic in the United States. ${ }^{25}$ Trucks have a significant share of the intercity freight market, despite costs that are two to three times greater and average energy consumptions that are three times greater than those of the railroads. A shift of freight traffic from trucks to railroads would save both energy and costs.

Shippers must look at the total cost of producing, transporting, distributing, and using their products. For some commodities, the cost of transportation is small relative to the total value of the product, and the cost of maintaining adequate stocks may outweight the consideration of transportation costs for producers or users of these commodities.

\section{Modal Analysis}

In this section we examine the economics of transportation and distribution, compare the performance of truck and railroad modes, give statistics on the use of truck and rail modes by shippers of various commodities, and present our conclusions for energy conservation policy and research.

Economics of Transportation Cost and Performance in the Production and Distribution Process

The speed and reliability of transportation services in part determine the total cost of producing and distributing goods because they govern the amount of inventory that must be carried to ensure good service or uninterrupted production. To minimize his total cost, the user of transportation services must continually balance the cost of carrying inventory against the cost of more reliable transportation. 
To understand the role of transportation speed and reliability in the production and distribution process, consider the series of steps in the manufacture and distribution of goods illustrated in Figure 9.

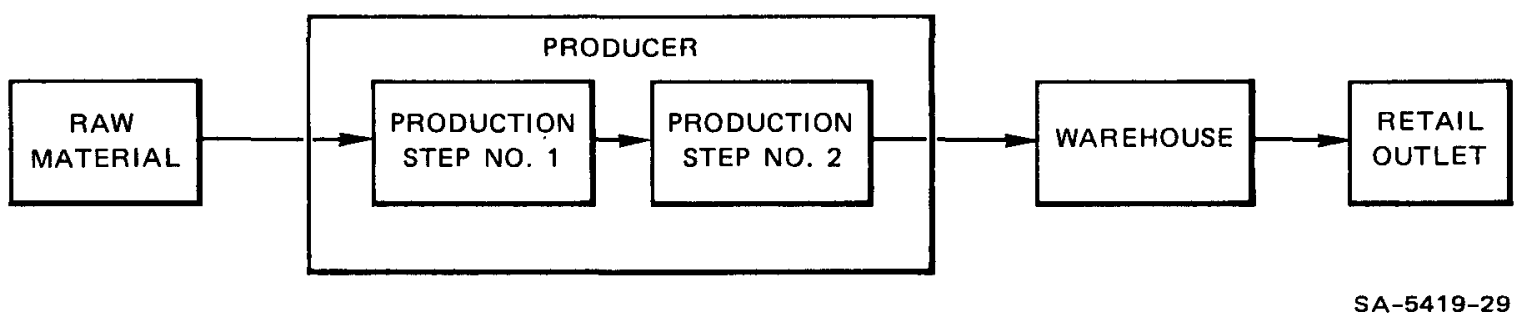

FIGURE 9 MANUFACTURE AND DISTRIBUTION OF GOODS

A customer arrives at the retail outlet to buy the product. If the product is in stock, the customer purchases and satisfies his need for the product. The retailer makes a profit from his markup, and the producer makes a profit from the production and sale of the product. If the product is not in stock, the consumer might go to another store or purchase another product to satisfy his needs. If the consumer goes to another store, the retailer who did not have the product in stock will not realize the profit from the sale. The consumer will have satisfied his need, but the retailer will have lost the profit forever. The profit lost might be considered a cost of not having the product in stock. Although carrying more stock would guard against the possibility of being out of stock, there are costs involved in having more stock. The holder of the stock must pay for it, and the money tied up in the stock is unavailable to him for other purposes. Thus, the cost of the money is represented in the stock. In addition, there are limitations of space in which to store, move, and display all products, so the retailer has to balance his stock against his need for space for other products. The retailer can assign a cost to each of these factors, (e.g., cost per square foot of floor space or cost per unit of display space).

The volume discounts given by the transportation system and the wholesaler are another cost factor. In general, the larger the quantity order is, the lower the unit cost. For example, the unit cost of 1tems in case lots will be less than items in unit lots, the unit cost per truckload will be less than that for case lots, and similarly for carload and trainload lcts. The retailer must balance volume discounts against the costs of storing and owning more stock.

Finally, the retailer must do his cost minimization in a dynamic and uncertain demand environment. Customers may want 10 units one day; 100, another day; and 50, another day. Retailer cost components, with a given average demand and an uncertainty of demand about that average, 


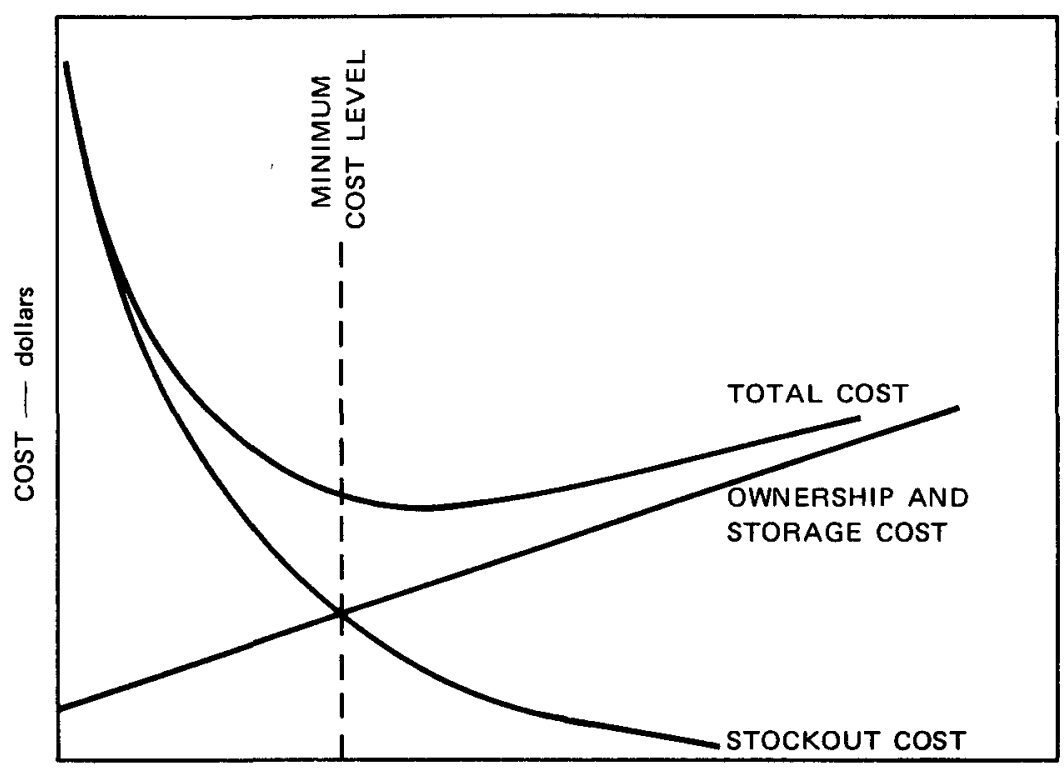

INVENTORY LEVEL - units

SA-5419-30

FIGURE 10 INVENTORY COST COMPONENTS

are illustrated in Figure 10, where the cost of owning and storing the inventory rises with the size of the inventory while the cost of stockout falls with the size of the inventory because the chances of being unable to meet the demand fall as the size of the stock grows.

A situation similar to that of the retail outlet occurs at other steps in the manufacture and distribution process shown in Figure 9. For example, the warehouse must carry stocks to meet the orders from retailers, and the producer must maintain inventories of goods in process at various production steps in order to balance uneven production rates. Further, production processes and shipments occur in discrete lots rather than continuously.

The average time and the uncertainty in the time to process and fill orders from one step of the process to another add to the requirements for inventory. Thus, if the retailer were assured that his order would be filled instantly, he would keep his stock at the minimum cost level illustrated in Figure 10. If there is a delay in filling his order, he will have to keep an additional, higher level of stock so that his expected level of inventory will be equal to the minimum specified above just before the new order arrives. Figure 11 illustrates the additional level of stock required under uncertain demand. Transit time and the uncertainty in transit time add to the time and the uncertainty in filling orders. 


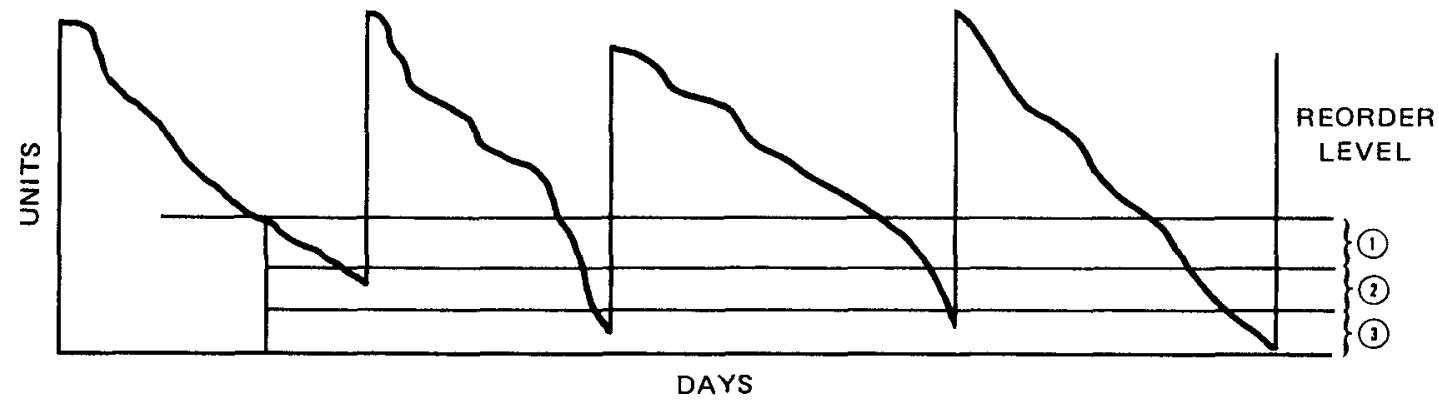

(1) AVERAGE USAGE $\times$
AVERAGE DELIVERY TIME

SA-5419-31

FIGURE 11 INVENTORY LEVEL WITH UNCERTAIN DEMAND AND ORDER FILLING TIME

In general, the amount of additional inventory needed is the average demand times the average time to fill the order, plus an additional amount to overcome the effects of uncertainty in filling the orders. Martland illustrates how average time and uncertainty in filling orders affect inventory levels. ${ }^{26}$ Figure 12 shows the effect of changing average transit times. Uncertainty can be measured as the standard deviation of the difference between the actual arrival time and the average, or mean, arrival time. Figure 13 illustrates the effect of the standard deviation of arrival time on the inventory level. The standard deviation in arrival time has a relatively great effect on the required inventory level, especially when a low stockout probability is desired (see Figure 13). If the transit time is predictable, the inventory in transit can almost be considered a part of the total inventory; if the arrival time is uncertain, sufficient stock must be kept against the possibility of a late shipment.

\section{Relative Performance of Truck and Rallroad Transportation}

Truck service for truckload shipments is generally faster than rail shipment, and the reliability of truck transit time is usually higher. Thus, trucks offer a higher level of transportation service for their high cost.

Figure 14 illustrates the relative average transit times for railroads, TOFC, and truck. These transit times are typical, somewhere between the best and the worst that might be obtained. ${ }^{27}$ Transit time for railroads varies, depending on the location of the origin and destination of the shipment, and on the routing used between the origin and destination. The variation in transit time for the same mileages is caused by en route classification, passage through major gateway areas, interchange between connecting rallroads, and local service at 


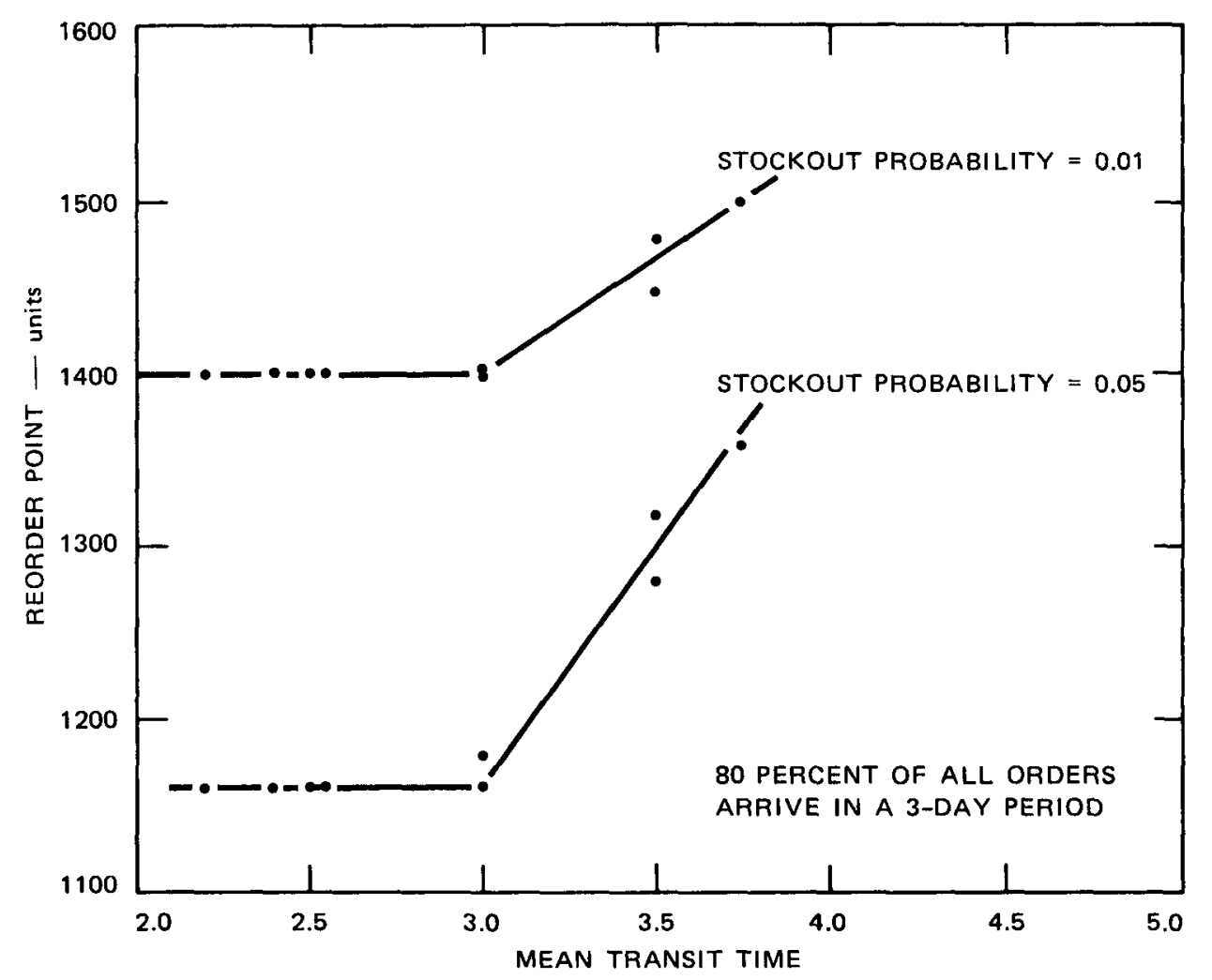

SOURCE: Reference 26

SA-5419-32

FIGURE 12 EFFECT OF TRANSIT TIME ON STOCK LEVEL

the origin and destination. Thus, for origin-destination ( $O-D)$ points that are served by through-train service and have relative large volumes flowing between them, little en route switching would be required, and a fast trip would result. Chicago, St. Louis, Kansas City, Cincinati, and other cities where there are many local train movements between points in the area present congestion problems and extensive delays. Infrequent pickup and delivery at the origin or destination resulting from less than daily service will also lengthen transit time. Truck hauls are subject to fewer of these delays; urban congestion is the worst delaying factor.

Uncertainty of delivery time on the rallroad is appreciable and varies with the total time required for the move. Figure 15 shows the relationship between transit time and uncertainty of delivery time. The uncertainty results from en route switching, terminal delay and congestion, infrequent pickup and delivery; and occasionally from bad weather or other natural forces. 


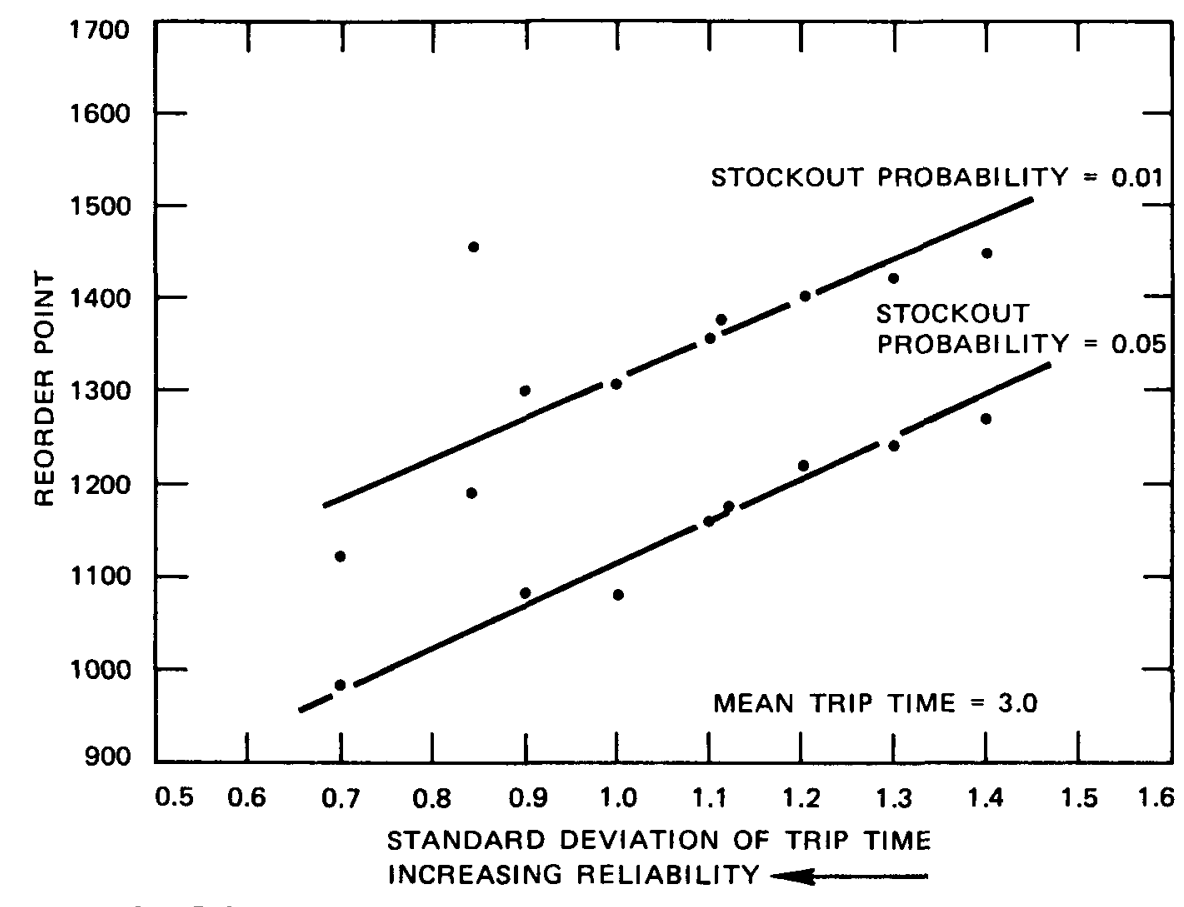

$S A-5419-33$

FIGURE 13 EFFECT OF CHANGING VARIANCE OF TRIP TIME ON INVENTORY LEVEL

Data on truck transit time uncertainty are not avallable. However, because there are fewer factors delaying a truck en route than a train, there is less opportunity for uncertainty. Natural forces or congestion are the primary causes of truck uncertainty.

With the advantages in mean transit time and trip time reliability of trucks, there will be some products whose unit value, distribution patterns, and patterns of demand justify the higher cost of truck transportation.

Freight damage also contributes to unreliable service. Products are damaged more easily in railroad shipment than in truck shipment for several reasons. The impacts received by a freight car during switching and as the car moves in a train cause shifts in the loading of a car. If a car is not loaded properly, cartons and packages can be damaged. A truck is not subject to the impact from train action or switching, and the suspension of a truck frequently provides better vertical cushioning of the load. 


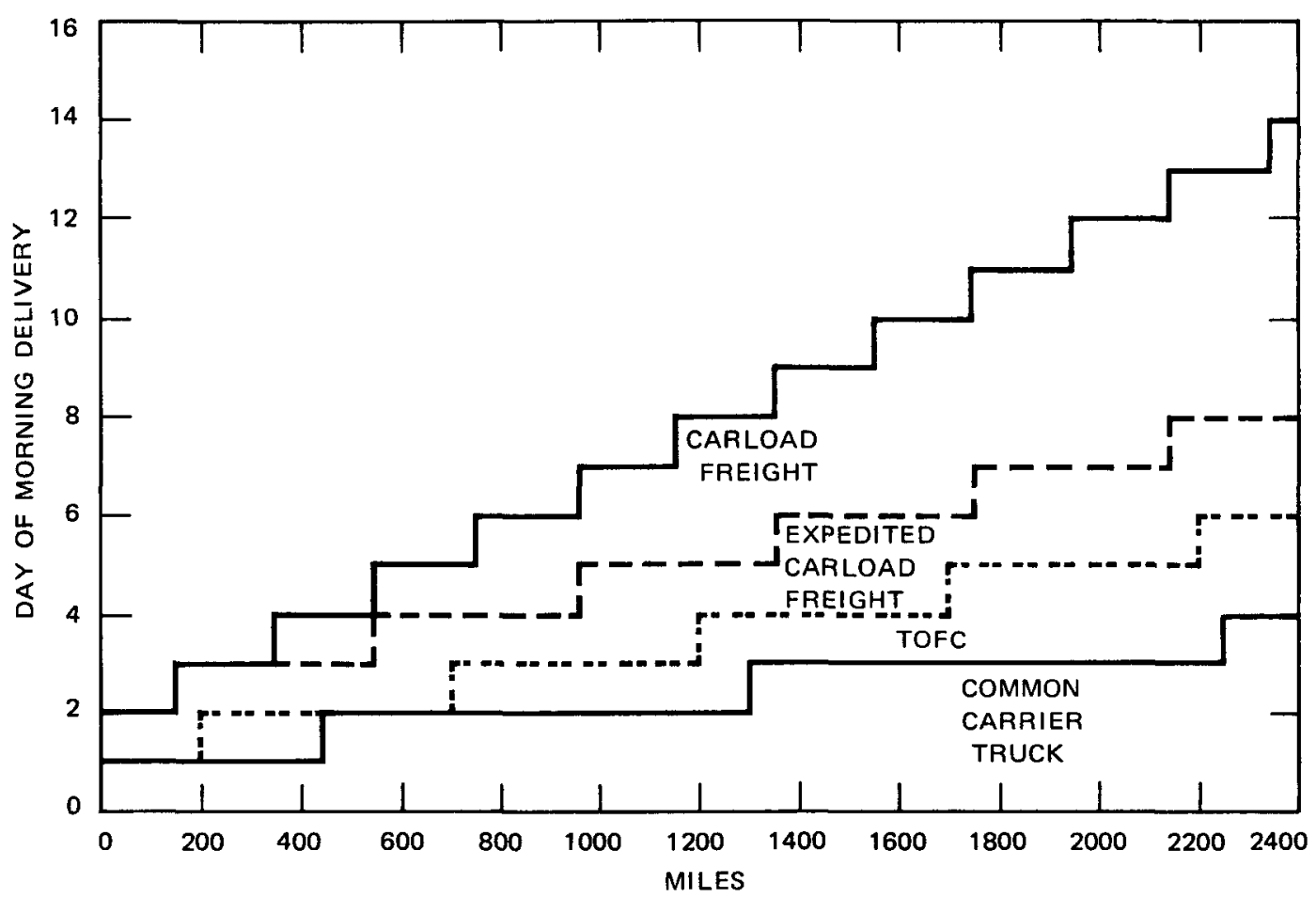

SOURCE: Reference 27

$S A-5419-34$

FIGURE 14 COMPARATIVE RAIL, TOFC, AND TRUCK TRANSIT TIMES

\section{Modal Shares of Various Commodities}

Figure 16 shows the fraction of transportation for various aggregate commodity groups carried by trucks and rallroads, and the cents per dollar of producers' prices that result from transportation. This statistic shows the relative importance of transportation costs in the total cost of a product and indicates the relative cost of transportation compared with production and distribution of the product. Commodities whose transportation cost is a larger fraction of their value tend to be moved by the less expensive rail mode, whereas those whose transportation cost is a smaller fraction of this value are frequently shipped by truck.

Other characteristics that influence the choice of shipment are the length of haul and the size of the shipment. ${ }^{28}$ Figure 17 shows the sizedistance characteristics of three kinds of shipments: those where truck transportation predominates, those that are competitive between railroad and trucks, and those where rall transportation predominates. Although Figure 17 shows the average for all commodities, individual commodity groups have been analyzed as well.27 About one quarter of the tons of freight shipped are in the competitive range. 


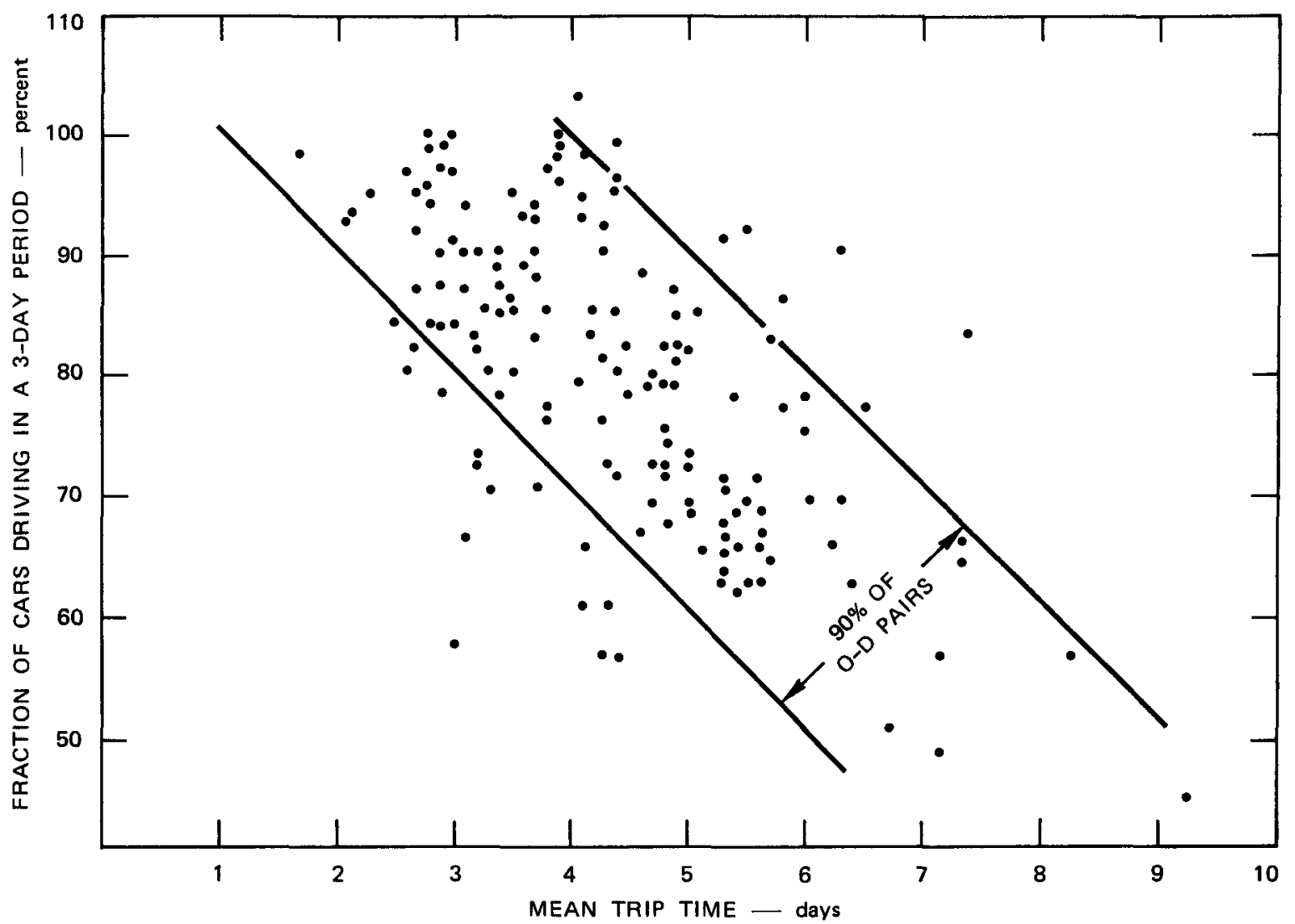

NOTE: Each dot represents one $O-D$ Pair

SOURCE: Reference 26

FIGURE 15 RELATIONSHIP BETWEEN RELIABILITY AND MEAN TRIP TIME

Energy Conservation through Less Energy-Intensive Modes

About $25 \%$ of loaded freight traffic tonnage is competitive between railroads and trucks; trucks predominate in shipping over short distances and for smaller shipments. 27 The railroads can capture a greater share of the traffic in the competitive area by improving railroad trip time and service reliability for some commodities in some markets. Improvements in the railroads' share of traffic predominantly shipped by truck will be difficult to make, but increased freight forwarder activity, coupled with improved transit time and reliability, may produce marginal changes. To produce more pronounced changes, direct measures against truck shipping will have to be taken.

To ensure that the rallroad energy conservation objective is met, traffic that is more effectively moved by railroads must be promoted. Movements with large empty backhauls or where a significant part of the movement is by a local train or switch engine will not produce the desired energy savings. 


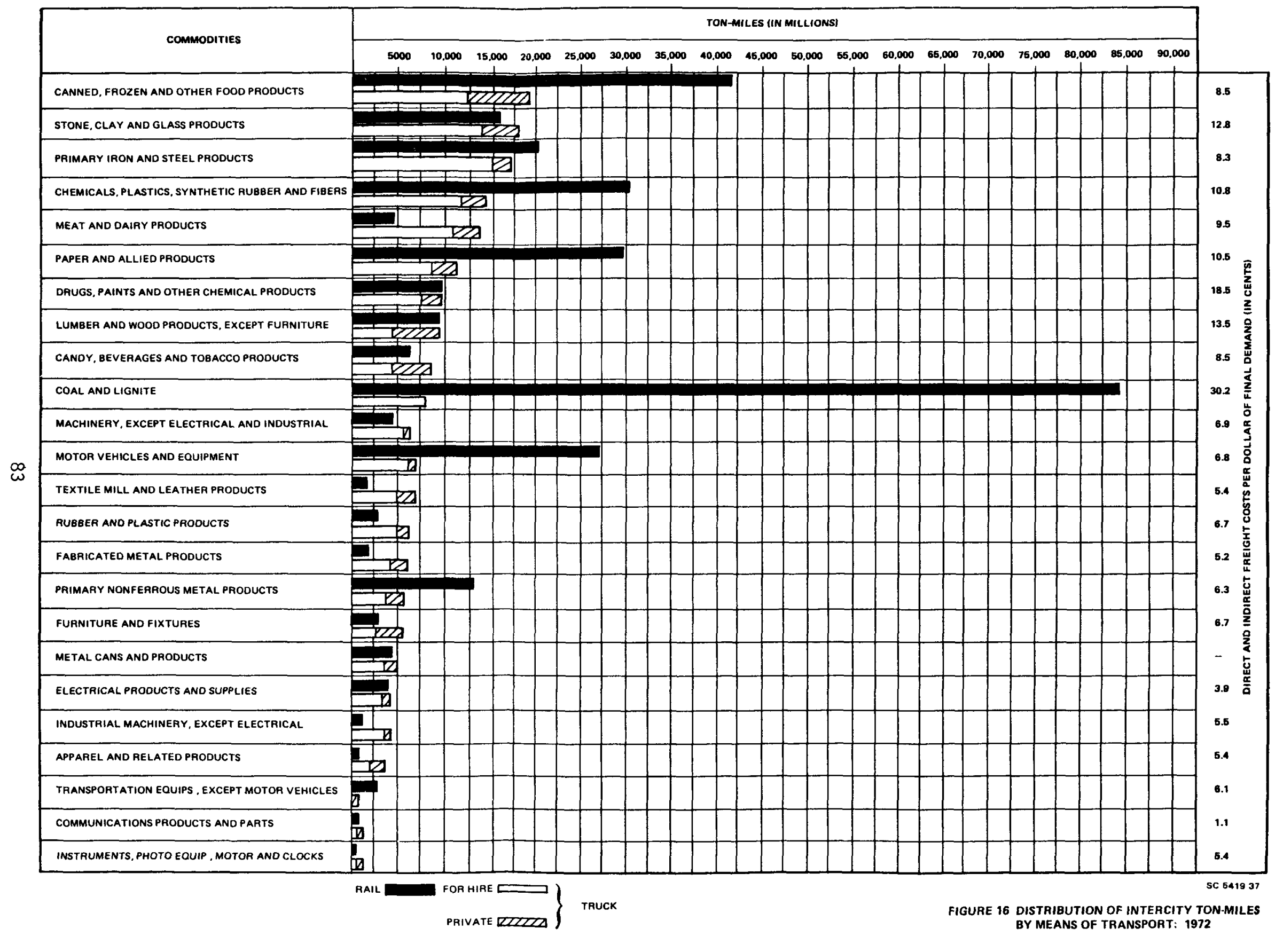


-

• 


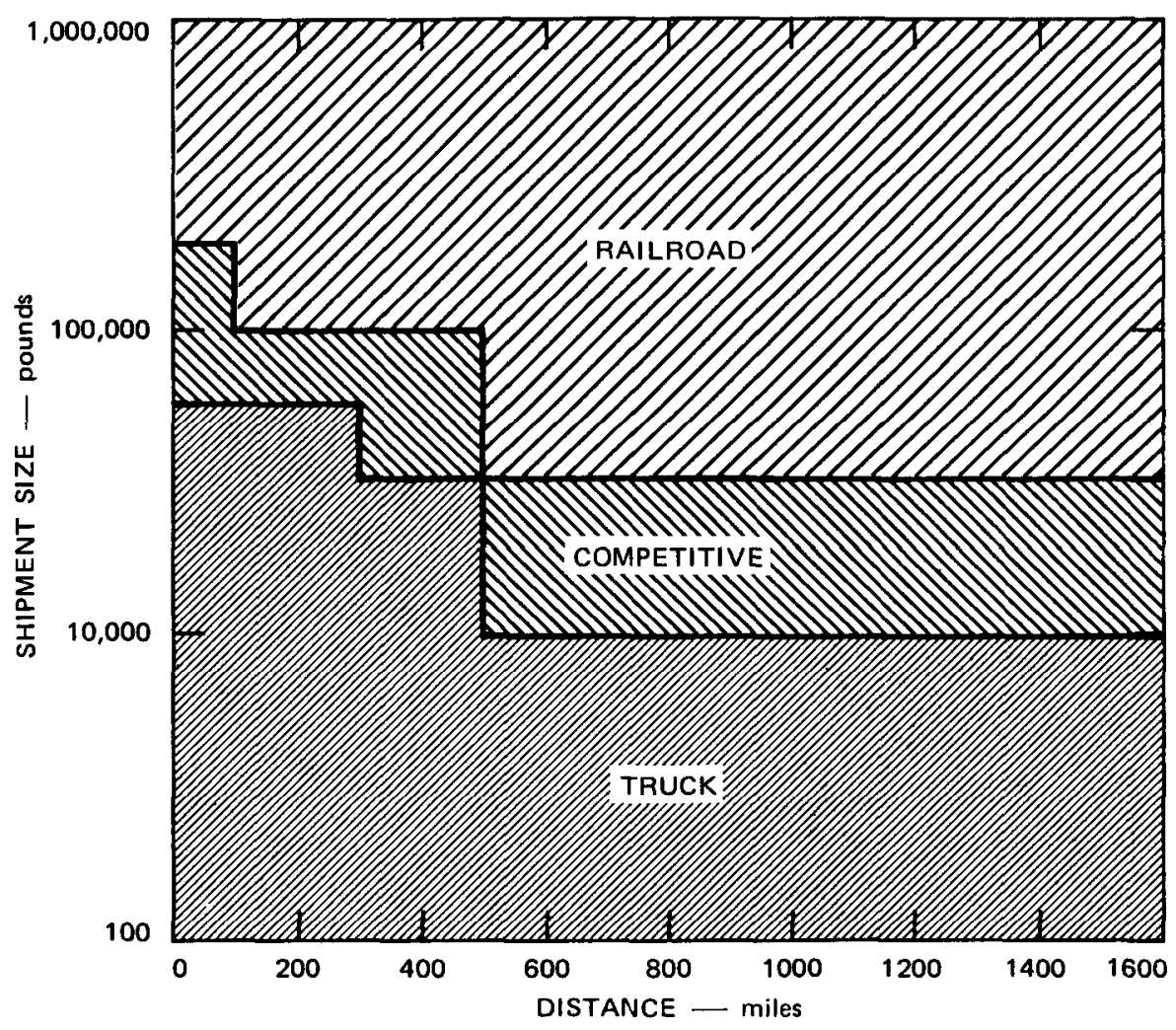

SOURCE: Reference 28

SA-5419-36

FIGURE 17 MODE PREDOMINANCE AS A FUNCTION OF SHIPMENT SIZE AND DISTANCE SHIPPED

\section{Improving Railroad Service}

\section{Many of the factors that cause unreliable or extended trip} times are associated with the classification of the car en route and the transfer of cars from one train to another. Minimizing the need to reclassify cars or to move them from one train to another will result in faster overall trip times, less uncertainty, and less damage to the shipment. It seems clear that such a strategy is much more likely to result in improvements in service than using faster maximum speeds on the system. Because present transit times include so little time in line-haul movement, an increase in speed will not be very effective and will result in higher fuel consumption and more unreliability because of the increased probability of breakdown from added stresses put on equipment and facilities.

Improvements in the following areas will result in faster and more reliable trip times:

- Planning for system operations

- Car tracking and scheduling 


\section{- Marketing development}

- Intermodal system development.

Planning for System Operations--One of the best ways to improve reliability and transit time is to avoid classification at yards. This can be done by scheduling blocks of cars to bypass as many yards as possible before being reclassified, and by scheduling trains to carry these blocks as far as possible before transferring them to other trains. Some railroads now offer coast-to-coast service for cars carried on a train that stops only for crew changes along the way. Although the train travels over the property of at least two railroads, engines and cabooses are "run through" to the end of the train line, and only the employer of the crews changes at the interchange points. Better blocking and train scheduling techniques are now possible because of recently developed analytical tools. In the plan to restructure six bankrupt railroads in the northeastern United States, the number of car handlings in yards was reduced by about 8 percent through the use of these techniques. 29

Car Tracking and Scheduling--The railroads can improve car connections through better planning and scheduling. The Southern Railroad has systematically analyzed car movements to determine ways of handling traffic that will result in better car utilization for the railroad as well as improved service for the shipper.30,31

A handicap to the analysis of current rallroad operations is the lack of data on particular car movements. Railroads are much more interested and experienced in moving trains than cars; ${ }^{30}$ comments that "all trains run on time, but all cars are late" are frequently heard. Improved data collection and analysis are needed to show where there are consistent car delays. A few railroads have systems with this capability, but the industry is several years away from an across-theboard ability to perform an analysis of car movements.

Marketing Development--Marketing can be used to improve reliability, which will in turn lead to improved market share. If marketing concentrates on developing movements between selected city pairs, sufficient traffic may be obtained to justify the use of through trains that move between the city pairs without the need for intermediate sorting. The through trains will provide improved service which will in turn result in more traffic. Railroad marketers will have to study potential traffic by commodity for selected city pairs to identify potential opportunities.

Intermodal System Development--Advanced intermodal systems can significantly improve service and market share by eliminating both the need for local terminal operations and a great deal of the en route 
classification that is not required. Intermodal systems use fewer and larger terminals where traffic origins and destinations are concentrated, which allows more opportunities for direct terminal-to-terminal service. Distribution from these terminals is by truck. We discuss the development of intermodal systems in Section $V$.

Some research is under way to evaluate both the effectiveness and cost of improving railroad services. Additional research needs to be carried out to quantify the energy saved from improved services and to identify alternative methods and techniques that will improve services from an energy conservation standpoint.

\section{Freight Forwarder Development}

Figure 15 shows that smaller shipments move by truck over the entire span of distances shown. Part of the reason for this movement is that the railroads will not accept shipments of less than freight carload lots. However, freight forwarders--independent agents--now accept smaller shipments and consolidate them into carload-sized shipments. The Western Pacific Railroad has established a freight forwarding subsidiary that has been very successful in soliciting traffic on the west coast for shipment to Utah and east. The success of this subsidiary shows how aggressive marketing can capture freight traffic for the railroads.

\section{Truck Disincentives}

It appears that major shifts of traffic from truck to railroad-say on the order of $50 \%$ of the current tonnage--can be accomplished only by major disincentives to the use of trucks. The relative value of transportation in the value of some commodities (see Figure 16) indicates that great increases in the cost of transportation (e.g., by increasing the cost of fuel for truck use) would not have a significant effect on the economics of the shipper. Therefore, specific regulations and prohibitions might have to be combined with price manipulation to achieve conservation of fuel for transportation by a specific mode. Our discussion of inventory cost provides the framework for identifying the economic costs of such regulations and prohibitions. 
- 


\section{RECOMMENDATIONS FOR RAILROAD ENERGY CONSERVATION RESEARCH AND DEVELOPMENT}

In the railroad energy study, we have analyzed the energy consumption patterns, structure, and regulations and rates of the railroad industry and identified proposals for improving the energy efficiency of railroad freight operations. We conclude that a railroad energy conservation $R \& D$ program must address the following areas:

- New hardware technology

- Improved railroad operations

- Regulatory policies

- Modal shifts to railroads.

New Hardware Technology

The evaluation of alternatives for railroad energy conservation shows that the following efficiency improvements should be developed or research should be done to explore ways of using them for energy conservation:

- Locomotive diesel waste heat recovery (bottoming cycle)

- Wheel bearing seal resistance

- Lightweight freight cars

- Positive traction control

- Energy storage

- Improved track structure

- Intermodal systems analysis.

Research is being conducted on all of the above improvements except the bottoming cycle for the diesel locomotive. We discuss each improvement below.

\section{Diesel Locomotive Waste Heat Recovery}

R\&D is needed for the design and development of bottoming cycle components applied to diesel locomotives. The principle of a locomotive bottoming cycle is well understood, having been applied to other kinds of heat engines, and components have been built that will perform the functions that are needed to implement the system. However, integrating 
the components into the physical space available in a locomotive, and matching the component characteristics to the diesel engine to provide both low pressure drop for the exhaust heat exchanger and power coupling of the bottoming cycle motor to couple to the diesel engine are problems that must be addressed. The performance of the system and its durability in service must then be developed and demonstrated.

The following three-phase development and demonstration project is suggested:

\section{Phase 1: Demonstration of the Principle}

A demonstration of the principle of a locomotive bottoming cycle might be effected by assembling existing components and installing them on an instrumented diesel locomotive. This breadboard unit should have components located outboard of the enclosure of the locomotive for the test program to speed the demonstration. The fuel consumption of a locomotive equipped with a bottoming cycle in a test situation would provide design information and show potential fuel savings.

This demonstration would have to be conducted at a test facility because the maintainability of the units does not lend them to service in road operations. The DOT test track in Pueblo, Colorado, the AAR laboratories in Chicago, Illinois, or the manufacturer's facility would be possible sites for this prototype demonstration.

\section{Phase 2: Prototype Design and Test}

In this phase, locomotive layouts would be designed, and the components to be used on the production locomotive units would be designed and fabricated. A prototype locomotive unit would be assembled from a modified locomotive unit and the components of the bottoming cycle system. After appropriate shakedown testing, we recommend that the locomotive be installed at the FAST testing facility at the DOT test center. Although the FAST facility concentrates on tests of the design and durability of track and components, it offers a good opportunity to test a locomotive under controlled conditions and to accumulate hours, miles, and load on the unit in a short period of time.

After the prototype design and test is completed, recommendations should be made for changes in components, fuel savings and performance should be demonstrated, and firm estimates should be made of maintenance and manufacturing costs. Necessary additional analysis or testing should be identified at this point.

\section{Phase 3: Feasibility of Retrofit on Existing Locomotives}

The research in this phase would consider the economics, operational implications, and durability of the equipment used in 
adding heat recovery hardware to existing locomotives. The feasibility of retrofit depends on making components that can be fit within the dimensional structure of existing locomotives. Furthermore, the costs of the components should be low enough to maintain the economics of the unit, and they should be durable enough to withstand the operating and service environment. Once the feasibility of building a new diesel equipped with a bottoming cycle is established, a decision can be made to proceed with similar research for a retrofit version of the bottoming cycle.

Federal sponsorship of phases 1 and 2 of the program will assure that the principle is thoroughly explored in a timely fashion and will enable suppliers to risk a test and demonstration that may not be successful or a market that may not be economical. The manufacture of bottoming cycle units should be undertaken by individual manufacturers at their own risk after they have evaluated the market.

\section{Development Time and Cost}

We estimate that phase 1 of the research and development program will cost between $\$ 250,000$ and $\$ 500,000$, depending on the availability of suitable components, the location of the test, and the complexity of instrumentation used. The estimated time for the demonstration is from nine months to one year.

Phase 2 of the program will cost between $\$ 1$ and $\$ 2$ million for each of the original equipment and retrofit programs, depending on the complexity of the test program that is needed. Calendar time for the project is estimated at 18 months.

A locomotive manufacturer is the most suitable contractor for the research, as he is most likely to have test and fabrication facilities available. Some railroad operating companies have the necessary facilities and might be potential contractors. Economic and market studies to support the program and to demonstrate the market for the locomotives should be done by an independent contractor.

\section{Wheel Bearing Sea1 Resistance}

Development is underway or planned by suppliers and the AAR to demonstrate the effectiveness and durability of the new wheelbearing seal designs. The costs of retrofitting existing cars should first be determined and then examined to see whether they are justified by the energy saved. The study could be conducted by a contractor (including the ARR), a railroad operating company, or an independent organization. Such a study is estimated to cost from $\$ 75,000$ to $\$ 125,000$. The estimated time for the study is six months to one year. 


\section{Lightweight Freight Cars}

Suppliers of 1ightweight cars have devised cost-estimating procedures to aid in their marketing efforts. The cars are most marketable to users in high-density service. A relatively small project, which might be carried out at an academic institution, is to determine the life cycle energy content of a car and the potential for reclaiming the aluminum in a car once its useful life is ended.

\section{Positive Traction Control}

The Canadian National Railroad developed the positive traction control device and is promoting it. Several railroads are evaluating its usefulness. The methodology for analyzing individual train operations to make the best use of the device is available to most large railroads, so no new research and development is needed.

\section{Energy Storage}

Both wayside and onboard flywheel storage for switch engines are now under study. The work on wayside flywheels should include an analysis of the traffic density and other factors that will determine whether helper crew districts, wayside flywheels, or complete electrification is appropriate for a line. Research continues on advanced batteries and other energy storage technology. This research needs to be monitored to identify when to undertake specific railroad application studies as new technologies are developed.

\section{Track Structure}

A very extensive program is underway to analyze both the interactions between the track structure and the freight cars passing over it and the effectiveness of various kinds of track structure. Research should be initiated to determine the effects of these interactions on energy consumption. The research should initially include the collection of data on the relationship between train resistance and the occurrence of hunting or rock and roll. Later, models of energy consumption should be developed along with models of car and track behavior. Research relating the track condition to the coefficients of train resistance should also be undertaken so that the energy effects of track maintenance can be identified.

\section{Intermoda1 Systems Analysis}

Present intermodal system studies concentrate on economic and service effects. An R\&D program should be initiated to identify an intermodal system that would provide maximum energy benefits in terms 
of both railroad energy reduction and attraction of shipments from truck to rail.

\section{Alternative Fuels}

There are several studies of alternative fuels underway to estimate the effects of their use on society and the economy in general (including transportation systems). Further emphasis on energy conservation in these programs is not necessary.

\section{Railroad Operations}

Operational improvements leading to energy conservation can be promoted by demonstrating the benefits of such improvements to the railroad personnel who will be modifying their operations. Improved railroad operations that will save energy include:

- Improved timing and standards of maintenance

- Speed reduction and more nearly optimal train operations.

\section{Improved Timing and Standards of Maintenance}

Research performed on diesel engines as part of exhaust emission studies indicates that maintenance can have an effect on fuel consumption. In addition, maintenance costs might be reduced if maintenance were performed on the basis of measured parameters rather than by calendar time. A research program that identifies quantities of engine performance, fuel consumption, and output and relates fuel consumption and maintenance to these measurements should be performed. The research should be performed in two phases.

The first phase would monitor diesel engine or alternator output, fuel consumed, and other pressures and temperatures to identify critical factors associated with degraded performance.

In the second phase of the work, a locomotive would be instrumented to monitor the critical factors identified in the first phase and a maintenance policy based on those factors would be established. The maintenance frequency and cost and the fuel consumption of the instrumented unit should be compared with control units to determine the benefit of the improved maintenance.

The research should be undertaken by a railroad operating company, under Federal sponsorship. The estimated cost for the project would be between $\$ 250,000$ and $\$ 500,000$ over a two- to three-year period. 
Speed Reduction and More Nearly Optimal Train Operations

Research on speed reduction would show the benefits of matching speed to grade and roadbed conditions for minimum energy use, consistent with service requirements. Selection of the proper locomotive consist and the Fuel Saver should also be considered in the program. After fuel and cost savings have been demonstrated and techniques refined, computer programs and employee training should be developed to implement the policies.

\section{Regulatory Policies}

Regulatory policies developed in the past, when energy was plentiful, may need to be reevaluated to ensure that they give proper weight to energy conservation. It has been shown that regulation has both direct and indirect effects on energy conservation and on the diffusion of new technology in the railroad industry. For these reasons, a capability should be developed for analyzing proposals to create new regulations and to modify existing ones so that the impact of energy conservation can be shown.

The following areas would be subject to such analysis:

- Circuity reduction

- Improved freight car utilization

- Revision of long-haul rates

- Branch-1ine abandonment cases and policies.

\section{Circuity Reduction}

Research and analysis of reduction in circuity of freight car routing would initially focus on the cost and energy penalties that are incurred by retaining multiple-authorized routings between external gateway points on the property of a single railroad. Data should be collected on carloads of traffic moved over each alternate route within a few major carriers and on the costs and energy required to move these additional miles of train operation.

\section{Improved Freight Car Utilization}

The extent of poor freight car utilization and its causes are being studied by the railroad industry and the federal government. One of the proposals to improve freight car utilization is to modify the rules requiring direct return of cars to their owners when they are unloaded by a customer on another railroad. If, as expected, the data show that these rules increase empty car miles, the energy interest should be strongly represented as a reason for modifying the rules. 


\section{Revision of Long-Haul Rates}

The effect of the rate structure on energy consumption must be considered in the regulatory process. This will require a commodityby-commodity and market-by-market study to compare the energy impact of existing and proposed rates with alternative rates.

\section{Branch-line Abandonment}

Energy savings on branch lines should be considered on a case-bycase basis. Methods for evaluating individual energy impacts must be developed and policies for considering energy impacts must be established.

\section{Modal Shifts to Railroads}

The economics of transportation and distribution favors trucking over railroad transportation for many commodities because the railroad costs of owning and storing additional goods exceeds the cost increments of trucks. For longer trips, an advanced intermodal system, such as that described in a recent report for the DOT, ${ }^{32}$ will be competitive in service and lower in cost than trucking and is therefore expected to cause some shippers to shift to railroads.

Earlier in the railroad energy study, we pointed out that measures to substantially discourage truck shipment would probably have to be applied to effect a major shift to railroads. Given a sufficiently grave concern for energy, drastic measures may be in order. A study of modal choice and energy conservation should be instituted to identify ways in which modal shifts could be effected and the costs of alternative strategies of effecting the shifts. Some of these alternative strategies include intermodal service; short, high-speed trains operated on premium schedules and moving without intermediate yard classification; higher fuel costs; higher road-user taxes; and direct taxes on highway transportation. The energy and economic impacts of each strategy should be evaluated. 
Appendix A

RAILROAD ENERGY RESEARCH AND DEVELOPMENT 
Appendix A

RAILROAD ENERGY RESEARCH AND DEVELOPMENT

The principal agencies engaged in research and development ( $R \& D$ ) for railroad energy conservation in the United States are the Department of Transportation (DOT) and the Energy Research and Development Administration (ERDA).* The railroad industry and invidual railroads have performed some $R \& D$ on operations to reduce fuel consumption and attendant costs and pollution. The $R \& D$ of the railroad supply industry is limited by the uncertainty of a payoff in the marketplace for new technology. State and local government activity in the energy area is related to the retention of railroad services in opposition to abandonment proceedings.

To avoid overlap and to assure that effective energy conservation is carried out, the Secretary of Transportation and the administrator of ERDA executed a memorandum of understanding, dated April 26, 1976, that defines the policy of working together to support energy-related transportation research. In general, the policy states that DOT is recognized as the source of transportation system requirements and implementation needs and is $r$ esponsible for research, development, testing, assessment, and evaluation of al1 modes of transportation as necessary to support regulatory, operational, intermodal balance, and policy responsibilities. ERDA is responsible for ensuring the advancement and consideration of new conservation technologies, particularly advanced system components and propulsion systems. The memorandum also provides policies and procedures for joint planning, comments on programs, and information transfer.

$R \& D$ project titles and abstracts are given below. These have been compared with programs exchanged between ERDA and DOT. Programs that were not underway at the time the memorandum was written have been added to the list of $R \& D$ projects.

\footnotetext{
* The functions of ERDA have been transferred to the U.S. Department of Energy.
} 
OPERATIONS

Study To Develop a Transportation Network and Operations Based Methodology To Examine the Energy Cost, Shipper Impact and Transportation Investment Tradeoffs Implied by Various Conservation Options for Freight Movements

A multimode intercity network employing various mode operations for freight flows and energy-use and transportation requirement simulators will be used to generate the basic information for the evaluation. Conservation options may be portrayed as variations in mode operations or technology, changes in freight flow patterns, or mode diversions. The model will compute changes in energy use, implied mode investments, and shipment characteristics.

Sponsoring agency: Department of Transportation, Transportation Systems Center, Kenda11 Square, Cambridge, Massachusetts 02142 Study released March 8, 1976

RFP 210-0120-ES

\section{A Study of Impacts of Energy-Use Constraints on U.S. Freight Operations}

Performing agency: CACI Inc., Federal, 1815 N. Fort Myer Drive, Arlington, Virginia 22209

Sponsoring agency: Department of Transportation, Transportation Systems

Center, Kendall Square, Cambridge, Massachusetts 02142

Study awarded September 9, 1976

Contract DOT-TSC-1252

Demand Information and Forecasting Research Project

The objective of this project was to develop functional specifications for an advanced demand information and forecasting system to support intrarailroad car distribution. The system will be sufficiently generalized that it could be adopted by most Class I railroads on a voluntary basis. Phase I of the project, now completed, identified the requirements of the data system and the most promising forecasting technique. Sample data from several railroads were collected and analyzed to provide information about the current environment and associated problems. In Phase II, the recommendations of Phase I will be implemented on a Class I railroad. This demonstration is expected to provide the framework for evaluating the technical feasibility, operational suitability, and economic desirability of the system for other carriers.

Performing agency: Association of American Railroads

Investigat or: Minger, WK (Tel 202-293-6256)

Sponsoring agency: Federal Railroad Administration

Responsible individual: Braddock, $\mathrm{CH}$ (Tel 202-426-2920)

Contract DOT-FR-30058 
Start date: 1974

Completion date: 1976

Freight Car Management Program

This program presently involves four phases: (1) Systems operations including service reliability studies, data interface standards, and car cycle sampling; (2) Operating practices as involved with car service rules, per diem rates, and car distribution procedures; (3) information technology developing a car assignment model and a demand forecast model; and (4) Operating systems with the line operations phase involving Grand Trunk Western and Missouri Pacific and the yard operations phase involving the Kansas City Southern at Shreveport, Lousiana, and the Chicago Railroad Terminal Information System.

Performing agency: Federal Railroad Administration, Office of Rail System Analysis and Program Development

Sponsoring agency: Federal Railroad Administration

Responsible individual: Braddock, $\mathrm{CH}$ (Te1 202-426-2920)

Status: Active

Notice date: Feb. 1976

Acknowledgment : FRA

Freight Car Utilization Research Program--Phase I

Since an increase in car utilization would effectively increase the car supply, a research and action program directed at improving utilization has been undertaken. A significant improvement probably can be achieved without revolutionary changes on the part of shippers, railroads, and government agencies. A quantitative assessment of the potential for improvement can be made when an adequate data base on car cycles is available. Analysis of these car cycles from load to load would reveal the fraction of time a car spends being loaded, moved by railroads, and unloaded. Car utilization is expressed in terms of a wide variety of indices. None is wholly satisfactory for evaluation of all aspects of utilization and none in common use permits analysis of the economic effectiveness of use of the car fleet. A $\$ 12$ million program, extending through 1980, is projected. The first phase, a two-year-program, includes the following studies: (1) analysis of current practices and problems; (2) development of car utilization measurement standards; (3) collection of data for a more complete car cycle analysis; (4) recommendation of projects for FRA consideration; (5) analysis of the impact of AAR and ICC rules, directives, and orders on car utilization; and (6) study of freight car time reliability. Each study is expected to identify specific opportunities for improvement in car utilization.

Performing agency: Association of American Railroads

Sponsoring agency: Association of American Railroads; Railway Progress Institute; Federal Railroad Administration; Interstate Commerce Commission; Railroad Labor Organizations; Transportation Association of America 
Responsible individual: Leilich, GM (Tel 202-293-5018)

Completion date: January 1977

Freight Car Utilization Research Program. Phase I. Task 6--Reliability Studies

The objective of Task 6 is to design and conduct a series of experiments, coordinated with Task 3, that will permit statistically sound evaluations of alternatives to improve rail service reliability and the effects these alternatives have or equipment utilization.

For further information on related studies see also RRIS 099398, Section 26A, 099399 17A, 099400 17A, 099401 17A, 099402 24A.

Performing agency: Association of American Railroads Investigator: Yarbrough, $\mathrm{HF}$ ( $\mathrm{Tel}$ 404-688-0800) Sponsoring agency: Association of American Railroads Responsible individual: Leilich, GM (Te1 202-293-5018)

Study of Shipper Demand Concerning Empty Railroad Freight Cars Needed for Material and Commodity Loading

Create a functional design of the elements and processes (system architecture) necessary for a technically advanced system to collect and predict shipper requests (orders for freight cars to load). Such a system must be operationally suitable and economically justifiable for use by individual Class I railroads as part of their systemwide empty freight car distribution activity. These are related to current FRA project reports on Car Management Studies.

Performing agency: Association of American Railroads Sponsoring agency: Federal Railroad Administration Responsible individual: Shamberger, RC (Te1 202-426-2608) Contract DOT-FR-30058(CR)

Active: February 1976

Start date: June 1973

St. Louis Termina1 Project

The railroad industry's Labor/Management Committee, which is comprised of the chief executives of railroads and labor organizations, established a number of labor/management programs to work on specific problem areas. The St. Louis Terminal Project is one such activity. A Task Force on Terminals was established by the Labor/Management Committee with the objective of increasing the reliability, speed, and efficiency of car movements through a major existing railroad terminal so that the quality and saleability of rail transportation will be improved, thereby attracting additional traffic and improving employment opportunities. The improvements are to be made without capital expenditures. This objective is being achieved through a series of experiments involving changes in operating practices, labor agreements, rates, and regulations. Missouri Pacific's St. Louis Terminal division was selected as the laboratory for this experimentation. A project team was formed to head up the project. 
The project director and associate director were recruited from the ranks of management and labor. The St. Louis Terminal Project consists of the following activities: (1) identification of potential changes, (2) implementation of experiments, and (3) development of a method to measure the quantitative impacts of experiments. A computerized car movement evaluation system was developed. This system and the underlying approach can be used by any railroad. This project is unusual in that labor and management are working together to implement significant changes in railroad terminal operations that will lead to improved service and more and better jobs. The lessons learned from this project should have wide application throughout the industry.

Performing agency: Task Force on Rail Transportation of the Labor/Management Commission

Investigator: Dyer, VG (Te1 314-622-2750) Zamarioni, FJ

Sponsoring agency: Railroad Labor Organizations; Association of American Railroads; Federal Railroad Administration; Missouri Pacific Railroad

Responsible individual: Collins, DW (Te1 216-228-9400, X 32)

Contract EB-400-0-ARR-849

Development of a Train Handling Control Model for Freight Train Locomotive Engineer Performance

The objective of this project is to reduce data taken in locomotive cabs on revenue freight runs to the form of a mathematical model of the train handling performance of a locomotive engineer. As a minimum, the following phases of freight train handling will be modeled: starting the train from rest, controlling the train through changes in grade, and stopping the train. The data records include settings of locomotive controls, speed, accelerations, motor load, brake system pressures, wheel slip, drawbar force, slack condition, drawbar angle, and main generator voltage. Also available are supervisor ratings of each engineer's performance on each recorded test run. The development of this model is expected to contribute to the understanding and improvement of selection, training, and evaluation of engineers and to support the development of improved locomotive operating controls and displays.

Funds for this project are administered by DOT/Transportation Systems Center, Cambridge, Massachusetts.

Performing agency: Turpin Systems Company Investigator: Birdsal1, JB (Te1 213-998-1404) Sponsoring agency: Federal Railroad Administration Responsible individual: Ofsevit, D (Te1 213-893-6321) 
LOCOMOTIVE AND EQUIPMENT

Fuel Saver System for Train Locomotive with Relay Sets for GP-40

Locomotive

Performing agency: Touch Stone Mfg. Co., Jackson, Tennessee 39301

Sponsoring agency: U.S. Department of Transportation, Transportation Systems Center, Kenda11 Square, Cambridge, Massachusetts 02142. Attn: Procurement Office, Code 8323-1

Study awarded October 15, 1976

PR 611-7323-FB/s

Develop and Test Self-Synchronous Motor Traction System

Performing agency: General Motors Corporation, Delco Electronics Division, Goleta, California 93017

Sponsoring agency: Department of Transportation, Transportation Systems Center, Kendal1 Square, Cambridge, Massachusetts

02142. Attn: Procurement Office, Code 8322

Study awarded February 23, 1977

Contract DOT-TSC-1303 (TSC/612-0377-GF)

Fabrication and Packaging of Two Engineering Prototype Nondestructive Railroad Roller Bearing Diagnostic Systems

Performing agency: SKF Industries Inc., 1100 First Ave., King of Prussia, Pennsylvania 19406

Sponsoring agency: Department of Transportation, Transportation Systems Center, Kendall Square, Cambridge, Massachusetts 02142. Code TSC -852

Study awarded March 18, 1977

RFP TSC/611-0364-GMF

Investigation of the Aerodynamic Drag of Containers and Trailers on Flatcars

Wind tunnel tests have been conducted on one-fortieth scale models of trailers on flatcars (TOFC) and containers on flatcars (COFC). Various configuration changes to reduce aerodynamic drag were explored. Experiments on very simplified models were also conducted to obtain a fundamental understanding of the phenomena involved.

Performing agency: Hammitt (Andrew G) Associates

Investigator: Hammitt, AG ( $\mathrm{Te} 1$ 213-541-1328)

Sponsoring agency: Transportation Systems Center, 612-0278-AT

Responsible individual: Barrows, $\mathrm{T}$ (Te1 617-494-2451)

Completion date: March 1976 
Advanced Concept Train: Vehicle Demonstration and Evaluation

This project involved the fabrication of a new lightweight train featuring an advanced flywheel energy storage system with twice the capability of current flywheel designs. Savings of 30 to 40 percent in total power requirement were anticipated.

Sponsoring agency: Department of Transportation

Freight Car and Locomotive Costing

The object of this project is to develop a set of methodologies and procedures for use in estimating the nature of cost and its variability in purchasing, maintaining, and operating freight cars and locomotives.

Performing agency: Peat, Marwick, Mitche11 and Company

Sponsoring agency: Federal Railroad Administration

Responsible individual: Pomponio, J. (Te1 202-426-0771)

Contract DOT-FR-55055

Completion date: January 1978 
REGENERATION AND STORAGE

University of Wisconsin Flywheel Energy Management Powerplant System Evaluation

Performing agency: University of Wisconsin, Madison, Wisconsin

Sponsoring agency: U.S. Department of Transportation/UMTA, UAD-72,

2100 Second St., S.W., Room 6418, Washington D.C. 20590

Study awarded January 19, 1977

Contract DOT-UT-70037

Study of F1ywhee1 Energy Storage: Phase 1

Performing agency: General Electric Company and Garrett Airesearch Manufacturing Company of California

Sponsoring agency: Department of Transportation, Urban Mass Transportation Administration, Office of Procurement and ThirdParty Contract Review, Major Systems Division, UAD-71, 2100 Second St., S.W., Room 6416, Washington, D.C. 20590

Study awarded February 15, 1977

Contract DOT-UT-60096T and DOT-UT-60097T

Flywhee1 Energy Storage Unit for Yard Switch Engine-Feasibility Study

The objective of this research is to determine the technical and economic feasibility of employing flywheel energy storage technology to yard switch engines as a potential means of reducing fuel consumption, noise levels, exhaust emissions, and overall maintenance costs. This work will include the development of a "breadboard" installation for testing with a $1500 \mathrm{hp}$ locomotive. A trailing car will be used to house the flywheel unit, and the necessary control integration and traction motor modification will be made to a railroad-furnished switcher. Four different railroads will assist in conducting 90-day operational evaluations.

The contract to a performing organization has not yet been awarded.

Sponsoring agency: Federal Railroad Administration, Office of Research and Development

Responsible individual: Cracker, WF, Jr (Te1 202-426-0855)

Start date: February 1976

Completion date: January 1978 
INTERMODAL SYSTEMS

Systems Engineering for Rail-Highway Intermodal Freight System

The objective of the systems engineering effort in connection with intermodal systems is to define and analyze the great number of variables that affect the design, layout, and equipment for use in a rail-highway intermodal system. The areas to be investigated include the functions required of gateway and intermediate terminals (light density as well as heavy density service in each type of terminal); the equipment needed to operate an efficient system, such as rolling stock, handling equipment, and propulsion; and the control processes necessary to optimize utilization of plant. It is anticipated that test and evaluation of the design concepts selected will be conducted in cooperation with the railroad industry and local and state governments on a cost sharing basis. The project will involve two phases of work; the first will be a parallel, 180-day phase covering exploratory planning and the preparation of proposals for the second phase. It is anticipated that a 12-month type contract for the second phase will be awarded to one of the first phase contractors. The systems engineering work will be related to the development of improved rail-highway intermodal services and will involve the equipment, systems, and facilities utilized therein, such as transfer handing equipment, rail rolling stock and motive power, intermodal containers, intermodal trailers, terminals, and management information and control systems. The services to be performed will include exploratory planning, systems ana1ysis, concept formulation, evaluation of alternatives, developmental planning, and preliminary engineering.

Sponsoring agency: Department of Transportation, Federal Railroad Administration, 4007 th St., S.W., Rm. 5413A.

Attn: J. Kerner, Washington, D.C. 20590

Study released November 15, 1976

RFP DOT-FR-4249/JK

Determination of Unit Maintenance Costs for Intermodal Flatcars

The objective of this project is to determine accurately the maintenance cost per mile of intermodal flatcars operating in dedicated service between city pairs. The method used is to operate six specially identified cars between Chicago and New Orleans on the Illinois Central Gulf Railroad. All repairs will be tabulated through the AAR Data Exchange System, and the mileage for each car will be recorded on an axle-mounted odometer. Pretest and posttest measurements of critical components will be made in order to project their useful life.

Performing agency: Trailer Train Company Investigator: Greenfield, LP (Tel 321-786-1200)

Sponsoring agency: Trailer Train Company

Completion date: July 1976 
An Experiment in Freight Modal Choice: Delineating the Rail-Truck Interface

The specific objectives of this project are: (1) to identify the economic characteristics of freight traffic that is rail and truck competitive in more detail than has been practicable to date; (2) to identify the marketing strategies most likely to succeed in attracting freight traffic to the most socially desirable and efficient mode of rail or truck transportation in terms of governmental economic, energy, and environmental policies; (3) to estimate the true magnitude of any misallocation of traffic between the rail and truck modes of transportation and what might be done to alleviate that misallocation.

Performing agency; Pennsylvania State University, University Park Investigator: Stenger, AJ

Sponsoring agency: Office of Systems Development and Technology, Department of Transportation

Responsible individual: Meck, JP (Te1 202-426-4138)

Contract DOT-0S-50210 (CS)

Completion date: June 1976 


\title{
ALTERNATIVE FUELS
}

\author{
Canadian Railway Electrification Study: Phase I--Development of \\ Study Plan
}

The objectives of this study are to bring into sharper focus the time frame within which electrification of significant portions of Canadian railways is 1ikely to occur, and to develop and describe a program of investigation, research, and development designed to permit a smooth transition to effective electrified operation at that time. The study will identify the factors that will influence the decision of the Canadian railways to electrify operations. These factors will be explored in order to determine their effect on the timing and economics of conversion and to identify gaps in technological, operational, and managerial knowledge or skills necessary to achieve conversion satisfactorily. Programs of investigation, research, and development will be developed to overcome the identified gaps in technological, operational, and managerial knowledge or skills and to enable smooth transition to electrified operation under Canadian conditions. The cost items involved in electrification will be identified and an approach for the methodology for costing the electrification stages will be recommended. General economic criteria for evaluation of the electrification decision will be established and alternative approaches to, and methods of, financing electrification will be identified. A process for monitoring future trends of relevant characteristics of particular factors that will have a significant influence on the electrification decision will be developed. Appropriate areas will be considered for Canadian railway pilot electrification projects, both freight and passenger, that might be implemented as intermediate, experience-gaining steps towards major conversions, and the rationale and general planning for their implementation will be suggested.

Performing agency: Canadian Institute of Guided Ground Transport Investigator: Corneil, ER (Tel 613-547-5777)

Sponsoring agency: Transportation Development Agency

Responsible individual: Brenkmann, M ( Tel 514-283-7846)

Contract 14 ST. T8200-5-5507

Completion date: June 1976

\section{Railroad Electrification/Energy Program}

Project Independence seeks to reduce vulnerability to petroleum import disruptions. Electrification of a major segment of the nation's railroads will contribute toward achieving this goal. FRA is in the planning stages of an electrification program for identifying the benefits that accrue to both the nation and the railroad operators from electrification, determining the incentives the railroad industry needs to start electrification, and performing $R \& D$ where it is most cost effective in the field of electrification. Already established is the fact that 100,000 barrels 
of petroleum would be saved per day if 22,000 miles of track were electrified (and 22,000 seems economically justified). Additional savings would result if modal shifts from auto and intercity truck freight occurred. There are plans to electrify the 14-mile passenger track at the Transportation Test Center. The immediate use of the electrified track will be for testing of Northeast Corridor equipment prior to putting it into revenue service and for determining cost effective methods of installing the catenary system. In addition, the railroad industry will be surveyed to determine what use it may have for the facility.

Contract not yet awarded, planned for FY 1977.

Sponsoring agency: Federal Railroad Administration, Office of Passenger Systems Research and Development

Responsible individual: Novotny, $R$

Status: Proposed

Notice date: February 1976

Acknowledgment: FRA

Continuation and Expansion of Existing Program on Upgrading of Coal Liquids

Performing agency: UOP Inc., Des Plaines, Illinois 60016

Sponsoring agency: Energy Research and Development Administration, Washington, D.C. 20545

Study awarded February 24, 1977

Contract EF-C-01-2566

Laboratory Program to Support Operations of the H-Coal Project

Performing agency: Hydrocarbon Research Inc., McLean, Virginia 22101

Sponsoring agency: Energy Research and Developemnt Administration, Washingt on, D.C. 20545

Study awarded February 24, 1977

Contract EF-77-C-01-2547

Railroad Energy Cost Data Projections for Diesel/Electric and Electrified Operation

Performing agency: Arthur D. Little, Inc., Cambridge, Massachusetts 02140 Sponsoring agency: Department of Transportation, Transportation Systems

Center, Kenda11 Square, Cambridge, Massachusetts 02142 Contract DOT-TSC-1156, Modification 2, (TSC/612-0379-GF)

Fuel Study

The navy has recently completed a survey of the worldwide availability of nonmilitary specification aircraft and shipboard fuels that could conceivably be utilized by the navy during periods when shortages of specification fuels exist. The navy has also recently initiated a program to produce 100,000 barrels of oil shale crude which will be subsequently refined into military fuels. A need exists to (1) identify 
the consequences on system safety, operation, maintenance, and reliability resulting from the use of nonmilitary specification petroleum-base fuels in naval boilers, diesels, and gas turbines; and (2) develop a test and evaluation plan for the products resulting from the 100,000 barrel 0il Shale Experiment. Accordingly, the navy is seeking interested parties, and funds have been budgeted for the development of fuel qualification procedures, the qualification of nonspecification conventional fuels through laboratory analyses and combustion experiments, and the development of logistics and usage guidelines for conventional and synthetic fuels.

Sponsoring agency: Office of Naval Research (Code 611), 800 North Quincy St., Arlington, Virginia 22217

Study released February 11, 1977 
ROLES OF INSTITUTIONS

Regulation of Rail Transportation or (Economic Studies of Railroads)

This study investigates regulatory issues, such as carrier costs, rates, ratemaking, competition, and financial analysis.

Performing agency: Ernest and Ernst, 1025 Connecticut Avenue, Washingt on, D.C. 20036

Sponsoring agency: Department of Transportation, Office of the Secretary, Procurement Operations Division, TAD 43, 400 Seventh

St. S.W., Washington, D.C. 20390

Study awarded August 10, 1976

Contract DOT-0ST-019

Report of Analysis and Evaluation of Foreign Transportation Regulatory Experience

Performing individual: James R. Nelson, Amherst, Massachusetts 01002

Sponsoring agency: Federal Railroad Administration, Department of Transportation, 400 Seventh Street S.W., Room 5416A, Washingt on, D.C. 20590

Study awarded August 17, 1976

Contract DOT-FR-T5150

Study Entitled Policy Sensitive Freight Model Development

Performing agency: Massachusetts Institute of Technology, Cambridge, Massachusetts

Sponsoring agency: Department of Transportation, OS, TAD-43, 400 Seventh St. S.W., Washington, D.C. 20590

Study awarded January 17,1977

Contract DOT-OE-70006 (DOT-OST-039)

Design of a System for Dissemination, Communication, and Technology Transfer of Energy Related Programs to Local Governments

Performing agency: Public Technology, Incorporated, Washington, D.C. 20036 Investigator: S. Markovich

Sponsoring agency: Energy Research and Development Administration Operations, Division of Procurement, Washington, D.C. 20543 Study awarded February 22, 1977

Study of Rail Mergers and Consolidations

The Rail Services Planning Office of the Interstate Commerce Commissions has commenced a nationwide study of rail mergers and consolidations. The purpose of the study is to review the advantages and disadvantages of 
such arrangements, to identify the principal problems involved, and to propose solutions to the problems identified. The office anticipates the use of some outside contractors and consultants in studying specific issues. Individuals and firms interested in possible contracts should submit detailed information concerning their capabilities and prior experience not later than 15 April 1977.

Sponsoring agency: Rail Services Planning Office, Section of Transportation Policy Planning

Study released March 22, 1977.

Effects of Partial Deregulation in the Transportation Industry

This investigation focuses on movements of commodities, such as grain, that are exempt from regulation when moved by highway and waterway and includes an examination of the implications of extending the regulatory exemptions to railroads. The study will be correlated with a cost analysis to show the effects of deregulation on productivity, rates, and modal choice.

Performing agency: Transportation Center, Northwestern University, Evanston, I11inois

Investigator: Moses, LN

Sponsoring agency: National Science Foundation

Completion date: December 1977

Techniques for Evaluating Options in Statewide Transportation Planning/ Programming

The objective of this study is to provide transportation planning methodologies that will be policy sensitive, that is, allow the testing and evaluation of options in a fashion that will produce timely results for decision making. Unified transportation funds, multimodal financial programming, and federal interest in "low-capital intensive" options are among the reasons for identifying major transportation issues facing state decision makers. Policy issues include transit operating subsidies, public acquisition of railroad rights of way, study of rail service versus highway construction, and impact analyses of various options.

Performing agency: Voorhees, (Alan M) and Associates, Inc., PEI Division, $8-18$

Investigator: Bellomo, SJ (Tel 703-893-4310); Stowers, JR

Sponsoring agency: Transportation Research Board, National Cooperative Highway Research Program

Responsible individual: Spicher, RE (Te1 202-389-6741)

Completion date: February 1978

Freight Data Requirements for Statewide Transportation

Many state departments of transportation (and other state and regional agencies) are now concerned with preparing, or assisting in the preparation of, statewide "master plans" for highway, rail, air, pipeline, and water facilities to serve existing and future freight flows. The 
objective of this study is first to develop the type, amount, and relative importance of freight data required to develop statewide transportation system plans and then to design and develop techniques, methods, and procedures for assembling these data. A manual describing in detail appropriate techniques for data acquisition, processing, verification, and maintenance will be prepared.

Performing agency: Creighton, Hamburg Inc., 8-14

Investigator: Memmott, FW; Blackwell, RB

Sponsoring agency: Transportation Research Board, National Cooperative Highway Research Program

Responsible individual: Spicher, RE (Te1 202-389-6741)

Completion date: February 1977

Rail Line Abandonment-Curtailment and Rural Development

The purpose of this project is to assist state governments in establishment and determination of state rail transportation planning and decision making. The project report emphasizes the options and alternative strategies open to state governments when faced with rural rail abandonments or rail service curtailment. The impacts on rural communities and their future development are also investigated.

Performing agency: Council of State Governments Investigator: Runke, JF (Te1 606-252-2291); Black, WR Sponsoring agency: Department of Commerce Responsible individual: Rendah1, R (Te1 202-967-2816) Contract 99-6-9383

Completion Date: November 1976

Developing Local Strategies as Alternatives to Abandonment of Light Density Railroad Lines

By identifying, compiling, and stressing innovative procedures that loca1 interests may take either to preserve their rail service or to facilitate transition to a new form of transportation service, this research aims to assist in ameliorating potential deleterious impacts of rail abandonment. The objective is to develop a handbook to assist shippers, local and state governmental units, and planners when their rail service is scheduled for abandonment.

Performing agency: Tennessee University Investigator: Patton, EP; Langley, CJ

Sponsoring agency: Office of University Research, Department of Transportation

Responsible individual: Murphy, T. (Tel 202-426-4416)

Contract DOT-0S-50125

Completion date: September 1976

\section{Computer-based Railroad Network Mode1}

The objective of this project is to develop a computer-based railroad network model that will be capable of facilitating the analyses of, and 
providing insights into, the potential impacts of alternative public policies aimed at plant and/or corporate rationalization of the railroad industry. Outputs of primary interest will include rates of plant utilization, revenue generation, estimated costs, and probable viability, all analyzed on a segment-by-segment basis. Additional modifications will be completed by April 1976.

Performing agency: International Business Machines Corporation

Sponsoring agency: Federal Railroad Administration

Responsible individual: Bouve, T (Tel 202-426-2920)

Contract DOT-FR-40012

Completion date: June 1976

\section{Effective Utilization of Work Force}

The objective of this project is to conduct research in the economic factors critical to effective utilization of the railroad work force. Factors to be included are employee compensation, effect of working conditions on employee productivity, investment in training/experience, effects on employment of line abandonments, employee willingness to relocate, and the like.

Contract not yet awarded.

Sponsoring agency: Federal Railroad Administration, Office of Rail Economics and Policy Development

Responsible individual: Collins, DM (Tel 202-426-0771)

Status: Active

Notice date: February 1976

Railroad Labor Study: Line Haul

The purpose of the study is to expand experiments at the St. Louis terminal to other terminals and conduct line-haul experiments to improve car utilization, employee productivity, and capital utilization.

Performing agency: Association of American Railroads

Sponsoring agency: Federal Railroad Administration, Office of Rail

Economics and Policy Development

Responsible individual: Collins, DM (Te1 202-426-0771)

Contract DOT-FR-43003

Notice date: February 1976 
-

- 
Appendix B

MODEL NETWORK DESCRIPTION 
- 
Appendix B

MODEL NETWORK DESCRIPTION

A network was constructed to represent an average freight haul. It was assumed that the freight was hauled along a branch line to a terminal where cars were sorted. The cars then move along a main line, pass through several intermediate yards, and arrive at a destination terminal where they are sorted again for their ultimate destinations. A listing of main-line variables is given in Table B-1. The cars are then delivered to their destinations aboard way trains along branch lines.

The input values for the model were chosen to approximate the average freight haul (see Table B-2). It was assumed that the net tons per year hauled on the main-line portion of the network was 20 million tons. Half of the net tons (10 million tons) were assumed to be hauled on a branch line a distance of 53 miles, which represents the average branch haul in the United States. This 53-mile haul was split so that half the distance $(26.5$ miles) is at each end of the main line. The branch-line average haul was assumed to be $70 \%$ of the branch-1ine length, giving 38 miles of branch line at each terminal. The main-line segment was assumed to be 463 miles, which resulted in 516 total miles hauled, which was the U.S. average haul in 1973. Corresponding to the U.S. average haul, 13 switches ( 7 per empty backhaul) per load were assumed. It was also assumed that the total branch-1ine miles in the network were $70 \%$ of the total miles hauled or 361 miles, of which 72 miles were modeled in detail in branch portion. The capital costs associated with the remaining 289 miles were included in the model. 
Tab1e B-1

MAIN-LINE VARIABLES OF THE LONG-RIN AVERAGE COST AND ENERGY MODEL

Definition

Physical description

Net elevation change direction

Descent Class C direction 1

Descent Class $C$ direction 2

Ruling grade direction 1

Ruling grade direction 2

Mi of 10 curves

Mi of $2^{\circ}$ curves

Mi of $3^{\circ}$ curves

Mi of $4^{\circ}$ curves

$\mathrm{Mi}$ of $5^{\circ}$ curves

$\mathrm{Mi}$ of $6^{\circ}$ curves

$\mathrm{Mi}$ of $7^{\circ}$ curves

$\mathrm{Mi}$ of $8^{\circ}$ curves

$\mathrm{Mi}$ of $9^{\circ}$ curves

Mi of $10^{\circ}$ curves

Mi of $11^{\circ}$ curves

Mi of $12^{\circ}$ curves

$\mathrm{Mi}$ of $13^{\circ}$ curves

$\mathrm{Mi}$ of $14^{\circ}$ curves

Capital-related factors

Land cost

Grading and preparation

Structures and culverts

Roadway less rails and ties

Communications and control, manual

Communications and control, ABS

Communications and control, CTC

Incremental communications cost/ additional track

Grade crossing, unprotected

Grade crossing, protected

Locomotive costs

Locomotive life

Car capital costs
Nominal Units

or Values

$$
\begin{aligned}
& 6.700 \mathrm{ft} / \mathrm{mi} \\
& 0.000 \mathrm{ft} / \mathrm{mi} \\
& 5.000 \mathrm{ft} / \mathrm{mi} \\
& 0.5 \% \\
& 0.5 \% \\
& 0.033 \mathrm{mi} / \text { track-mi } \\
& 0.000 \mathrm{mi} / \text { track-mi } \\
& 0.033 \mathrm{mi} / \text { track-mi } \\
& 0.000 \mathrm{mi} / \text { track-mi } \\
& 0.000 \mathrm{mi} / \text { track-mi } \\
& 0.033 \mathrm{mi} / \text { track-mi } \\
& 0.000 \mathrm{mi} / \text { track-mi } \\
& 0.001 \mathrm{mi} / \text { track-mi } \\
& 0.000 \mathrm{mi} / \text { track-mi } \\
& 0.001 \mathrm{mi} / \text { track-mi } \\
& 0.000 \mathrm{mi} / \text { track-mi } \\
& 0.001 \mathrm{mi} / \text { track-mi } \\
& 0.000 \mathrm{mi} / \text { track-mi } \\
& 0.000 \mathrm{mi} / \text { track-mi }
\end{aligned}
$$


Table B-1 (Concluded)

\section{Definition}

\section{Maintenance}

Weed control, etc.

Communications and control maintenance, manual

Communications and control maintenance, $A B S$

Communications and control maintenance, CTC

Grade crossing maintenance, unprotected

Grade crossing maintenance, protected

Tie replacement cost

Rail replacement cost

Rail weight

Surfacing costs

Locomotive maintenance

Car maintenance

Operating and Miscellaneous

Fuel cost

Crew cost

Crew utilization

Dispatch cost, manual

Dispatch cost, ABS

Dispatch cost, CTC

Empties to loads

Percent net tons, direction 1

Locomotive availability

Average locomotive hp

Speed

Taxes
Nominal Units

or Values

$500.000 \$ / \mathrm{mi}-\mathrm{yr}$

$265.270 \$ / \mathrm{mi}-\mathrm{yr}$

$265.270 \$ / \mathrm{mi}-\mathrm{yr}$

$265.270 \$ / \mathrm{mi}-\mathrm{yr}$

$323.900 \$ / \mathrm{mi}-\mathrm{yr}$

$371.400 \$ / \mathrm{mi}-\mathrm{yr}$

$75,000.000$ \$/track-mi

$40,000.000 \$ /$ track-mi

$132.0001 \mathrm{~b}$

$3,200.000 \$ /$ track-mi

$0.200 \$ / g a l$

$0.031 \$ /$ car $-\mathrm{mi}$

\section{$0.350 \$ / g a l$}

$28.040 \$ / \mathrm{h}$

0.880 hours available/h

$1.150 \$ /$ train-mi

$0.000 \$ /$ train-mi

$0.020 \$ /$ train-mi

1.000 ratio

0.500 ratio

$7,889.000 \mathrm{~h} / \mathrm{yr}$

2,000.000 hp/locomotive

$30.000 \mathrm{mph}$

0.020 \$/dollars of capital/yr 
ASSUMED VALUES AND INPUTS TO THE

LONG-RUN AVERAGE COST AND ENERGY MODEL

$\begin{array}{ll}\text { Branch-1ine haul (total) } & 53 \text { miles } \\ \text { Branch-1ine haul (per line) } & 26.5 \text { miles } \\ \text { Branch-1ine length (per line) } & 38 \mathrm{miles} \\ \text { Average load per car } & 61.2 \mathrm{tons} \\ \text { Terminal yards } & 2 \\ \text { Tons dispatched at terminal yards per year } & 10 \mathrm{million} \\ \text { Cost of handling at terminal yard } & \$ 30 / \mathrm{car} \\ \text { Total switches (7 switches per empty backhaul) } & 13 / 1 \mathrm{oad} \\ \text { Gas per switch engine hour } & 7.4 \mathrm{gal} \\ \text { Switching at terminal yards } & 0.125 \mathrm{hours} / \mathrm{car} \\ \text { Switching at intermediate yards } & 0.102 \mathrm{hours} / \mathrm{car} \\ \text { Cost of handling at intermediate yards } & \$ 25 / \mathrm{car} \\ \text { Main-line miles } & 463 \\ \text { Main-line net tons per year } & 20 \mathrm{million}\end{array}$




\section{REFERENCES}

1. S. J. Petracek, "Energy Study of Railroad Freight Transportation, Volume 3: Regulation and Tariff," Report on Task 2, Contract E4-76-C-03-1176, SRI Project TCU 5419, Stanford Research Institute, Menlo Park, California 94025 (January 1977).

2. A. E. Moon et a1., "Railroad Energy Study: Description of Rail Transportation in the United States," Vol. 1, "Freight Railroading," Report on Task 1, Contract E4-76-C-03-1176, SRI Project TCU 5419, Stanford Research Institute, Menlo Park, California 94025 (January 1977).

3. V. Sloss, T. Humphrey, and F. Krutter, "An Analysis and Evaluation of Past Experience in Rationalizing Railroad Networks," Massachusetts Institute of Technology, Cambridge, Massachusetts (March 1975).

4. Task Force on Railroad Productivity, "Improving Railroad Productivity," Final Report, Washington, D.C. (November 1973).

5. W. Allman, "A Survey of Rail Network Rationalization Proposals," paper presented at the 56th Annual Meeting of the Transportation Research Board, Washington, D.C., January 1977.

6. A. L. Morton, "The Changing Market for Rail Freight Transportation," Transportation Research Board No. 511, Transportation Research Board, National Research Council, Washington, D.C. (1974).

7. D. Curry et a1., "Transportation A1ternatives for the United States in the Next Fifty Years," SRI Project 5040, Stanford Research Institute, Men1o Park, California (March 1977).

8. Aluminum Company of America, "Lightweight, Long-Lasting Aluminum Freight Cars for Coal Unit Train Service," p. 1. Aluminum Company of America, Pittsburgh, Pennsylvania.

9. R. S. Berry and M. F. Fels, "The Production and Consumption of Automobiles: An Energy Ana1ysis of the Manufacture, Discard and. Reuse of the Automobile and its Component Materials," report presented to the Illinois Institute for Environmental Quality (July 1972).

10. W. M. Scott and R. B. Skene, "Positive Traction Wheel Slip Control: Its Development and Performance," paper presented at the Railway Fuel and Operating Officers Association Convention, Chicago, I1linois, 28 September 1976. 
11. R. Ke1ler, "Gas Turbine Drive for New High Speed Trains," paper presented to the American Society of Mechanical Engineers, New York, New York, March 1975.

12. S. J. Petracek et a1., "Energy Study of Railroad Freight Transportation, Volume 3: Regulation and Tariff," Report on Task 2, Contract E4-76-C-03-1176, SRI Project TCU 5419, Stanford Research Institute, Men1o Park, California (February 1977).

13. T. R. Broom, "Fuel Conservation," paper presented at the Railway Fuel and Operating Officers Association Convention, September 1975.

14. Society of Automotive Engineers, "Power Plants for Industrial and Commercial Vehicles: A Look at Tomorrow" (Society of Automotive Engineers, New York, New York, April 1965).

15. R. U. Ayres and R. P. McKenna, Alternatives to the Internal Combustion Engine (Johns Hopkins University Press, Baltimore, Maryland, 1972).

16. D. W. Tope, "Rolling Resistance of Freight Cars," The Timken Company (11 June 1971).

17. T. C. Keller, The Timken Company, Letter to Mr. F. A. Danahy, the American Association of Railroads.

18. Public Service Electric and Gas Company, Research and Development Department, Newark, New Jersey, "An Assessment of Energy Storage Systems Suitable for Use by Electric Utilities," Vols. 1-3. Final Report, EPRI Project 225, ERDA E(11-1)-2501 (July 1976).

19. D. DuVa1, "What You Should Know About Diesel Diets," Trains (May 1973).

20. C. F. Perry, "Recent Experience with Sulfur in Distillate Type Fuels Burned in U. S. Naval Diesel Engines," American Society of Chemical Engineers, January 1974.

21. R. W. Foster and W. J. D. Escher, "Hydrogen Fueled Railroad Motive Power Systems: A Feasibility Study," Escher Technology Associates, St. Johns, Michigan (September 1976).

22. S. P. Luthra et al., "Bi-Fuel Approach to Burning Ammonia in Diesel Engines," Industrial Engineering (India) Journa1-Mechanical Engineering, Vo1. 53, pp. 64-68 (November 1972).

23. A. J. Gellman, "Surface Freight Transportation," in Technological Change in Regulated Industries, W. M. Capron, ed. (The Brookings Institute, Washington, D.C., 1971).

24. U.S. Government Interagency Task Force, "Commercial Vehicle Post1980 Goals Study," Draft Report (May 1976). 
25. AAR, Yearbook of Railroad Facts, 1976 edition (American Association of Railroads, Washington, D.C., 1976).

26. C. D. Martland, "Rail Trip Time Reliability: Evaluation of Performance Measures and Analysis of Trip Time Data," Massachusetts Institute of Technology, Cambridge, Massachusetts (June 1972).

27. R. S. Reebie et a1., "National Intermodal Network Feasibility Study," Part 1 Reebie Associates, Greenwich, Connecticut (May 1976).

28. R. D. Roth, "An Approach to Measurement of Modal Advantage," paper presented at the Transportation Research Board Annual Meeting, Washington, D.C., January 1977.

29. USRA, Final System Plan, Vol. 1 (United States Railway Association, Washington, D.C., July 1975).

30. C. D. Martland, "Improving Railroad Reliability: A Case Study of the Southern Railway," Report MIT R74-28, Massachusetts Institute of Technology, Cambridge, Massachusetts (March 1974).

31. L. S. Miller, "The Great Railroads: Southern," Railway Age, Vo1. 178, No. 4 (February 1977).

32. R. S. Reebie et a1., "Nationa1 Intermoda1 Network Feasibility Study," Part 1, Reebie Associates, Greenwich, Connecticut (May 1976). 
-

- 


\section{BIBLIOGRAPHY}

Ainsworth, D. P., Keale, M. J., Liba, C. J., Levinson, H. M., "An Improved Truck/Rail Operation: Evaluation of a Selected Corridor," Reebie Associates, prepared for U.S. Department of Transportation, Federal Highway Administration, Contract DOT-FH-8158 (December 1975).

Aluminum Company of America, "Lightweight, Long-Lasting Aluminum Freight Cars for Coal Unit Train Service," paper presented to Power Company, Boise, Idaho, 1975.

"Aluminum Gondola for Canadian Coal," Railway Locomotives and Cars, pp. 23-24 (January 1972).

American Society of Mechanical Engineers, "1974 Rail Transportation Proceedings," papers and discussions from Joint ASME/IEEE Railroad Conference, Pittsburgh, Pennsylvania and Winter Annual Meeting of the ASME, Detroit, Michigan, 11-15 November 1973 and 1974.

"AMTRAK Receives Swedish Guest," Modern Railroads (October 1976).

Anyos, T., Lizak, R., Wilhelm, J., Hirschberg, K., "Technology TransferTransportation," NASW-2731, Stanford Research Institute, Menlo Park, California 94025 (September 1974).

Armbruster, F. E., Candela, B. J., "Research Analysis of Factors Affecting Transportation of Coal by Rail and Slurry Pipeline," Vol. 1, Hudson Institute, Inc., prepared for Burlington Northern Inc. (April 1976).

, "Research Analysis of Factors Affecting Transportation of Coal by Rail and Slurry Pipeline," Appendix, Vo1. 2, Hudson Institute, Inc., prepared for Burlington Northern Inc. (Apri1 1976).

Association of American Railroads, "Indexes of Railroad Material Prices and Wage Rates: Railroads of Class I," Series Q-MPW-90, Economics and Finance Department, Washington, D.C. (28 January 1976).

Association of American Railroads, "More Miles to the Gallon . . . The Railroads," Office of Information and Public Affairs, Washington, D.C.

Association of American Raflroads, "Operating and Traffic Statistics: Freight Train, Passenger Train, and Yard Service Performance; Motive Power and Car Equipment; and Traffic Statistics--Class I Line-Haul Railroads in the United States--Year 1974," 0. S. Series No. 216, 
Annual Issue, Economics and Finance Department, Washington, D.C. (Apri1 1975).

Association of American Railroads, "Railroad Mileage by States:

December 31, 1974," Economics and Finance Department, Washington, D.C. (December 1975).

Association of American Railroads, "Railroads in the Energy Crisis," office of Information and Public Affairs, Washington, D.C. (1974).

Association of American Railroads, "Revenues, Expenses, and Freight Traffic: Class I Railroads in the United States--Calendar Year Ended December 31, 1974," Economics and Finance Department, Washington, D. C. (3 July 1975).

Association of American Railroads, "Statistics of Railroads of Class I in the United States: Years 1964 to 1974," Statistical Summary Number 59, Economics and Finance Department, Washington, D. C. (Ju1y 1975).

Association of American Railroads, "Yearbook of Railroad Facts: 1976 Edition," Economics and Finance Department, Washington, D.C. (1976).

Baker, P. H., Schulze, F. W., "Progress in Railway Mechanical Engineering (1969-1970 Report of Survey Committee): Locomotives," Genera1 Electric Company, American Society of Mechanical Engineers (August 1970).

, "Progress in Railway Mechanical Engineering: 1970-1971 Report of Survey Committee--Locomotives," paper presented at the General Electric Company, American Society of Mechanical Engineers, Winter Annual Meeting, 28 November-2 December 1971.

, "Progress in Railway Mechanical Engineering: 1971-1972 Report of Survey Committee Locomotives," paper presented at the General Electric Company, American Society of Mechanical Engineers, Winter Annual Meeting, New York, New York, 26-30 November 1972.

Banner, P. H. "The Energy Situation: A Rail Viewpoint," Transportation Journal, Vo1. 13, No. 3 (Spring 1974).

Beachley, N. H., Frank, A. A., "Increased Fuel Economy in Transportation Systems by Use of Energy Management," Prepared for U.S. Department of Transportation, Office of the Secretary, Office of University Research, Contract DOT-TST-76-57 (1976).

Bjerkehagen, 0., Kollberg, B., "Energy Economics Through Solid-State Power Conversion," Railway Gazette International, Vol. 129, No. 12 , pp. 459-461, December 1973. 
"BN Gets Electrification Study Results: GE Sees Beginning of New Rail Era," Modern Railroads, Vol. 29, No. 6, p. 21 (June 1974).

Boeing Company, "SOAC: State-of-the-Art Car Engineering Tests at Department of Transportation High Speed Ground Test Center. Final Test Report. Volume I. Program Description and Test Summary," U.S. Department of Transportation Systems Center, Contract UMTA-MA-060025-75-1 (January 1975).

Boeing Company, "SOAC: State-of-the-Art Car Engineering Tests at Department of Transportation High Speed Ground Test Center. Final Test Report. Volume II. Performance Tests," U.S. Department of Transportation, Urban Mass Transportation Administration, Transportation Systems Center, Contract UMTA-MA-06-0025-75-2 (January 1975).

Boone, J. W., "The Implications of Railroad Energy Conservation for Logistics Systems Planning in the United States," Transportation Research, Vo1. 8, No. 4-5, pp. 415-418 (October 1974).

Bowick, D. M., "The Benefits of Railroad Electrification," British Railways Board, Railway Management Review, Vo1. 74, No. 2, pp. A37-A45 (1974).

Breimeier, R., "Energy Requirements of Inland Waterway Transport and Freight Trains (Complete Trainloads) Carrying Heavy Bulk Goods [Der Energiebedarf von Binnenschiffen und Gueterzuegen (Ganzzuegen) beim Massenguttransport], " Internationales Verkehrswesen, Vo1. 26, No. 3, pp. 104-107 (1974).

Brettman, E., "Investigating the Optimal Economic Speed for Rail Vehicles [Optima1-Wirtschaftliche Geschwindigkeit Spurgebundener Fahrzeuge]," Eisenbahntechnische Rundschau, pp. 26-34 (January 1975).

Brinegar, C. S., "Rail Service in the Midwest and Northeast Region," Vo1. 1, "A Report by the Secretary of Transportation," (1 February 1974).

Broering, L. C., Holtman, L. W., "Effect of Diesel Fuel Properties on Emissions and Performance," Cummins Engine Company, paper presented at the Society of Automotive Engineers meeting, 9-12 September 1974.

Broom, T. R., "Fuel Conservation," Florida East Coast Railway, paper presented at the Annual Railway Fuel and Operating Officers Association Meeting, 15 September 1975.

Burgess, S., Colucci, R., Rossi, L., "Solving the Branch Line Problem: A Critique of the Light-Density Line Analyses of the Preliminary System Plan," State of New York, Department of Transportation, New York State Railroad Task Force (2 April 1975).

Burgess, S. et al., "The Off-Branch Cost Myth: The Effect of Branch-Line Railroad Abandonments on System Costs," State of New York, 
Department of Transportation, New York State Railroad Task Force (September 1975).

Campbe1l, K., "Electrification: A Time for Reappraisal?" Canadian Pacific Rail, Railway Management Review, Vo1. 74, No. 2, pp. A1-A5 (1974).

Casey, R. F., "Summary Data For Selected New Urban Transportation Systems," U.S. Department of Transportation, Transportation Systems Center, Contract DOT-TSC-OST-72-35 (November 1972).

Cetinich, J. N., "Fuel Efficiency Improvement in Rail Freight Transportation," The Emerson Consultants, Inc., U.S. Department of Transportation, Federal Railroad Administration, Office of Research and Development, December 1975, FRA-0R\&D-76-136.

Chaddock, J. B., Sud, I., "Energy Study of Underground Rapid Transit," Duke University, High Speed Ground Transportation Journal, Vol 6, No. 3, pp. 391-407 (September 1972).

Chesser, A. H., "Transportation and Energy," United Transportation Union, Stan1ey H. Ruttenberg \& Associates, Inc. (1975).

Clemow, C. J., "Planning for Railway Electrification," British Railways Board, Institution of Electrical Engineers, Proceedings, Vo1. 119, No. 4, pp. 431-440 (April 1972).

"Cleveland Tests AC Traction Motors," Railway Locomotives and Cars, Vo1. 146, No. 3 (March 1972).

Clover, T. L., "The Steam Hydraulic Locomotive," paper presented to the Winter Annual Meeting of the Rail Transportation Division of the American Society of Mechanical Engineers, November 1973.

CONSAD Research Corporation, "Criteria for Line Retention," prepared for United States Railway Association (February 1975).

Creswick, F. A., "Energy Requirements for the Movement of Intercity Freight," Battelle Columbus Laboratories, Association of American Railroads (15 December 1972).

Creswick, F. A. et al., "A Study of the Environmental Impact of Projected Increases in Intercity Freight Traffic," Battelle Columbus Laboratories, Association of American Railroads (15 June 1971).

Curry, J. P., "Case Studies of Transit Energy and Air Pollution Impacts," De Leuw, Cather and Company, Inc., prepared for the Environmental Protection Agency (May 1976).

Danzig, J. C. et al., "Procedures for Analyzing the Economic Costs of Railroad Roadway for Pricing Purposes: Volume I, Procedures," TOPS On-Line Services, Inc., prepared for U.S. Department of Transportation, Contract DOT-FR-30028, Federal Rallroad Administration (January 1976). 
Davis, L. C. et a1., "Technical Feasibility of Magnetic Levitation As a Suspension System for High-Speed Ground Transportation Vehicles," Ford Motor Company, Contract DOT-FR-10026, Scientific Research Staff (February 1972).

"Diesel Engine Design Trends," Automotive Engineering, Vol. 83, No. 1 (January 1975).

Dukowicz, J. K., "The Single-Sided Lim with Saturated Back Iron," Mitre Corporation, Contract DOT-FR-7-35248 (January 1972).

DuVal, D., "What You Should Know About Diesel Diets," Trains, pp. 36-40 (May 1973).

Dyer, T. K. et al., "Rail Transit System Cost Study," Thomas K. Dyer, Inc., U.S. Department of Transportation, Transportation Systems Center, Urban Mass Transportation Administration, Contract DOT-TSCUMTA-75-22 (January 1976).

Eck, H. C., "Fuel Conservation and Train Operation," Chessie System, Railway Fuel and Operating Officers Association, paper presented at the Thirty-Seventh Annual Meeting of the Railway Fuel and Operating Officers Association, 1973.

"Electrification Outlook Brightens," Railway Signaling and Communications, Vo1. 63, No. 3, pp. 13-17 (March 1970).

"Electrifying Could Save Money," Railway System Controls, Vol. 4, No. 5 (May 1973).

"Energy Conservation and Public Transit: An Interim Rebuttal by the American Public Transit Association." (undated)

"Energy--Today's and Tomorrow's Energy Constraints Further Emphasize the Need For True Intermodalism to Get and Keep Our Economy Growing," Handling and Shipping.

Escher, William J. D., "Prospects for Hydrogen as a Fuel for Transportation Systems and for Electrical Power Generation," Escher Technology Associates, Oak Ridge National Laboratory, September 1972, ORNL-TM-4305.

Federa1 Council for Science and Technology, "Energy Research and Deve1opment Opportunities for Heavy Duty Transportation," Committee on Energy Research and Development Goals, Washington, D.C. (July 1972).

Federal Council for Science and Technology, "Research and Development Opportunities for Improved Transportation Energy Usage (REDOTEUS)," Committee on Energy Research and Development Goals, Washington, D.C. (Ju1y 1972). 
Feulner, A., "Gas Turbine Propulsions of the German Federal Railway [Gasturbinenantriebe bei der Deutschen Bundesbahn], " MTZ Motortechnische Zeitschrift, Vo1. 36, No. 6, pp. 161-167 (June 1975).

Foley, E. P., Shaw E. B., "Making and Economic Evaluation of Railroad Electrification," Railway Management Review, Vol. 74, No. 2, pp. A46-A65 (1974).

Foley, G., "Long-Range Planning and the Energy Crisis," Railway Gazette International, Vo1. 129, No. 12 (December 1973).

Foster, R. W., Escher, W. J. D., "Hydrogen-Fueled Railroad Motive Power Systems, A Feasibility Study," ETA Report PR-70, Escher Technology Associates, U.S. Energy Research and Development Administration (September 1976).

Fraize, W. E., "U.S. Transportation: Some Energy and Environmental Considerations," Mitre Corporation (September 1972).

Franzen, S., "Optimal Power in Electric Locomotives," paper presented at the International Electric Vehicle Symposium and Exposition, 19-21 February 1974 .

Friedlander, G. D., "Railroad Electrification: Past, Present, and Future," IEEE Spectrum, Vo1. 5, No. 7, pp. 50-65 (July 1968).

Fuller, J. W., Hyman, W. A., "Energy and Environmental Effects of Railroad Abandonment," Wisconsin Department of Transportation, Transportation Research Board Meeting, Washington, D.C. (January 1976).

Gannett, H., "A Dictionary of Altitudes in the United States," Fourth Edition, Bulletin No. 274, Series F, Geography 47, United States Geological Survey, Department of the Interior, Washington, D.C. (1906).

Garde, M. R., "Gas Turbine Train Development in France," French National Railways, American Society of Mechanical Engineers, paper presented at the Gas Turbine Conference and Products Show, Houston, Texas, 2-6 March 1975.

Gay, W. F., "Energy Statistics: A Supplement to the Summary of National Transportation Statistics," DOT-TSC-OST-75-33, U.S. Department of Transportation, Transportation Systems Center (August 1975).

, "Summary of National Transportation Statistics," DOT-TSC-OST76-11, U.S. Department of Transportation, Transportation Systems Center (June 1976).

General Electric, "The Recovery of Waste Heat Using Rankine Bottoming Cycles as an Effective Means of Fuel Conservation," Space Division, Advanced Energy Programs (27 April 1976). 
Goss, W. P., McGowan, J. G., "Energy Requirements for Passenger Ground Transportation Systems," paper presented at the Intersociety Conference on Transportation, Amherst, Massachusetts, 23-27 September 1973.

Goss, W. P., McGowan, J. G., "Transportation and Energy: A Future Confrontation," Transportation, Vol. 1, No. 3, pp. 265-289 (November 1972).

Gouse, S. W., Jr., Rawal, C. H., "Split Propulsion for High Speed Ground Transport," Carnegie Institute of Technology, American Society of Mechanical Engineers, Rail Transportation Proceedings, papers and discussions from Joint IEEE-ASME Railroad Conference, Jacksonville, Florida, 14-15 March 1972.

Hamilton, S. G., "Railroad Electrification Today," General Electric Company, Railway Management Review, Vol. 74, No. 2, pp. A15-A36 (1974).

Hammitt, A. G., "Aerodynamic Forces on Freight Trains," Vol. 1, "Wind Tunnel Tests of Containers and Trailers on Flatcars," Final Report, FRA/ORD-76-295. I, Andrew G. Hammitt Assoc., U.S. Department of Transportation, Federal Railroad Administration (December 1976).

Hampton, R. N., "Financing Railroad Electrification," Railway Management Review, Vol. 74, No. 2, pp. A78-A81 (1974).

Handy Railroad Atlas of the United States, Rand McNally \& Company, Chicago, New York, San Francisco (1973).

Harley, E. T. et al., "The Management of an Electrified Railroad," Railway Management Review, Vo1. 74, No. 2, pp. A82-A106 (1974).

Harman, R. G., "Fuel in Transport," Traffic Engineering and Control, Vol. 15, No. 10/1, pp. 477-499 (February 1974).

Harris, C.C., Jr., Hille, S. J., "Rail, Truck, or Small Car - Which is the Energy Saver?" Business Horizons, Vol. 17, No. 6, pp. 57-64 (December 1974).

Hay, W. W., Railroad Engineering, Vol. 1 (John Wiley \& Sons, New York, New York, 1953).

R. L. Hines Associates, Inc., "USRA Yard Classification Planning Project: Maximum Throughput and Associated Expenditures in Selected Yards"

(2 January 1975).

Hirst, E., "Energy Consumption for Transportation in the U.S.," ORNLNSF-EP-15, Oak Ridge National Laboratory (March 1972).

Hirst, E., "Energy Intensiveness of Passenger and Freight Transport Modes: 1950-1970," ORNL-NSF-EP-44, Oak Ridge National Laboratory (Apri1 1973). 
Hirst, E., "Energy-Intensiveness of Transportation," ASCE Journal of Transportation Engineering, Vo1. 99, No. TE1, pp. 111-122 (February 1973).

Hirst, E., "Transportation Energy Use and Conservation Potential," Science and Public Affairs, Vol. 29, No. 9 (November 1973).

Hopkins, J. B., "Measurements of Fuel Consumption in Branch-Line Railroad Operations," Preliminary Findings, U.S. Department of Transportation, Transportation Systems Center (March 1975).

, "Railroads and the Environment: Estimation of Fuel Consumption in Rail Transportation. Volume I. Analytical Model," U.S. Department of Transportation, Transportation Systems Center, Federal Railroad Administration, May 1975, DOT-TSC-FRA-75-16-I.

Hopkins, J. B., Newfe1l, A. T., Haze1, M., "Fuel Consumption in Rail Freight Service: Theory and Practice," U.S. Department of Transportation, Transportation Systems Center, paper presented at the 56 th Annual Meeting of The Transportation Research Board, Washington, D.C., 22 January 1977.

Hoppe, C. F., "Evaluation of the WABCO AC Propulsion System," Vol. 1, "CTS/UMTA AC Propulsion Project," UMTA-ON-06-0006-74-3, Cleveland Transit System (September 1974).

Hotte1, H. C., Howard, J. B., New Energy Technology: Some Facts and Assessments (Massachusetts Institute of Technology Press, Cambridge, Massachusetts, 1971).

Huffman, R. A., Walker, J. L., "Rapid Transit System Simulation with Interactive Graphics Display," Transportation Planning and Technology, Vol. 1, pp. 205-217 (1973).

Humphrey, T. J., "Framework for Predicting External Impacts of Railroad Abandonment," DOT-TST-74-78, Massachusetts Institute of Technology, (March 1975).

Interstate Commerce Commission, "Eighty-Seventh Annual Report on Transport Statistics in the United States for the Year Ended December 31, 1973," Bureau of Accounts, Washington, D.C.

, "Financial and Operating Statistics of Class I Railroads for the Six Months Ended June 30, 1973," Statement No. 100, Bureau of Accounts, Washington, D.C.

, "Financial and Operating Statistics of Class I Railroads for the Twelve Months Ended December 31, 1973," Statement No. 100, Bureau of Accounts, Washington, D.C. 
, "Freight Commodity Statistics Class I

Railroads Year Ended December 31, 1974," Bureau of Accounts, Washington, D.C.

, "Portions of 1974 Interstate Commerce Commission Annual Reports from 22 Class I Railroads," Bureau of Accounts, Washington, D.C. (Xerox copies of sections)

,. "Rail Carload Cost Scales: 1973,"

Statement No. ICI-73, Bureau of Accounts, Washington, D.C.

, "Ratios of Empty to Loaded Freight CarMiles by Type of Car and Performance Factors for Way, Through and A11 Trains Combined - Class I Line-Haul Railroads - Calendar Year 1968," Statement No. 6-69, Bureau of Accounts, Washington, D.C. (September 1969).

Janota, M. S., "The Internal Combustion Engine for Rail Traction," Rail Engineering International, Vol. 3, No. 3 (March 1973).

Johansson, A. V., "A New Excitation System for Diese1-Electric Locomotives," paper presented at the Joint IEEE-ASME Railroad Conference, San Francisco, California, 16 April 1975.

Jones, L. W., "Liquid Hydrogen as a Fuel for the Future," Science, Vol. 174, pp. 367-370 (October 1971).

Kahn, A. E., The Economics of Regulation: Principles and Institutions, Vo1. 1 (John Wiley and Sons, New York, New York, 1970).

, The Economics of Regulation: Principles and Institutions, Vo1. 2 (John Wiley and Sons, New York, New York, 1970).

Kaiser Engineers, "Energy Conservation Tradeoff Study for Baltimore Region Rapid Transit System," Report No. 74-25B-RE, Mass Transit Administration, State of Maryland Department of Transportation (March 1974; updated September 1975).

Kalman, G. P., Hafele, B. W., "Feasibility Study of Linear Induction Motor Thrust Boosters for Diesel-Electric Locomotives," DOT-FR-90014, Garrett Corporation, AiResearch Manufacturing Division, 21 March 1969.

Kalra, P., "Dynamic Braking," IEEE Spectrum, Vo1. 12, No. 5, pp. 63-66, (May 1975).

Keeler, T. E., "Railroad Costs, Returns to Scale, and Excess Capacity," The Review of Economics and Statistics, Vo1. 56, No. 2, pp. 201208 (May 1974).

Keller, R., "Gas Turbine Drive for New High Speed Trains," paper presented at the Gas Turbine Conference and Products Show, Houston, Texas, 2-6 March 1975. 
Kibblewhite, G. G., "Progress in Design and Operation of A. C. Locomotives and Multiple-Unit Trains," Institution of Electrical Engineers, Proceedings, Vol. 119, No. 4, pp. 425-430 (April 1972).

Kneafsey, J. T., "Costing in Railroad Operations: A Proposed Methodology Studies in Railroad Operations and Economics - Volume 13," Massachusetts Institute of Technology, Department of Civil Engineering (March 1975).

Krambuh1, J. C., "How to Conserve Fue1 and Lubes," Railway Locomotives and Cars, pp. 34-35, (October/November 1974).

Kumar, S., Dix, R. C., Willis, T., "A Preliminary Study of Fue1 Consumption in Trains Due to Roller Bearing Seal Resistance," Illinois Institute of Technology, Mechanics, Mechanical, and Aerospace Engineering Department (November 1976).

Lang, A. S., Soberman, R. M., Urban Rail Transit: Its Economics and Technology (The M.I.T. Press, Massachusetts Institute of Technology, Cambridge, Massachusetts, 1964).

Lawson, L. J., "Kinetic Energy Storage: A 'New' Propulsion Alternative for Mass Transportation," paper presented at the Intersociety Conference on Transportation, 23-27 September 1973.

Lawson, L. J. et al., "ATA Rail Transit Conference Held in San Francisco, California on April 14 and 16, 1974. Car Equipment Sessions. Papers," American Transit Association (August 1974).

Leilich, R. H., "Study of the Economics of Short Trains," Peat, Marwick, Mitchell and Company (June 1974).

Leilich, R. H. et al., "Energy and Economic Impacts of Projected Freight Transportation Improvements," DOT-TSC-0ST-76-61, Peat, Marwick, Mitchell and Company, Battelle Columbus Laboratories, Transportation Systems Center (November 1976).

Leilich, R. H., Prokopy, J. C., Ruina, D., "Industrial Energy Studies of Ground Freight Transportation," Vo1. 1, DI-14-01-001-1670, Peat, Marwick, Mitchell and Company, Federal Energy Administration (July 1974).

, "Industrial Energy Studies of Ground Freight Transportation," Vol. 2, "Appendices," DI-14-01-001-1670, Peat, Marwick, Mitchell and Company, Federal Energy Administration.

Lenard, M., "The Prediction of Freight Train Fuel Consumption: A Preliminary Report," Working Paper, DOT-FR-54090, The MITRE Corporation, METREK Division, 24 January 1977. 
Lieb, J. G., "A Comparative Analysis of the Energy Consumption for Several Urban Passenger Ground Transportation Systems," Mitre Corporation, Urban Mass Transportation Administration (February 1974).

"Locomotives: Energy-Crisis Asset," Railway Age, Vol. 175, No. 2 (January 1974)

Loebl, A. S., et al., "Transportation Energy Conservation Data Book," 1st Edition, ORNL-5198, Oak Ridge National Laboratory, prepared for the United States Energy Research and Development Administration (October 1976)

Lorentzsen, N. M., "BN Cashes in on the Low-Sulphur Coal Boom," Railway Gazette International, Vol. 130, No. 11, pp. 433-436 (November 1974).

Luthra, S. P., Norain, A., Mathur, H. B. "Bi-Fuel Approach to Burning Ammonia in Diesel Engine," Institution of Engineers (India) Journal, Mechanical Engineering Division, Vol. 53, pp. 64-68 (November 1972).

Lutin, J. M., "Comparison of Energy Savings for Work Trips: An Analysis of Alternative Commuting Patterns for New Jersey," Princeton University, Transportation Program (August 1974).

Lyon, E. C., "Planning for Railway Electrification," Railway Management Review, Vo1. 74, No. 2, pp. A64-A77 (1974).

Malliaris, A. C., Strombotne, R. L., "Demand for Energy by the Transportation Sector and Opportunities for Energy Conservation," U.S. Department of Transportation, Transportation Systems Center, Office of the Secretary, Washington, D.C., paper presented at the Intersociety Conference on Transportation, Denver, Colorado, 23-27 September 1973.

Martin, P. J., Roddin, M. F., "Fue1 Usage for Passenger Transport Between Selected City Pairs," Stanford Research Institute, Menlo Park, California 94025 (14 December 1973).

Mascy, A. C., Paullin, R. L., "Transportation Vehicle Energy Intensities," DOT-TST-13-74-1, NASA Ames Research Center/United States Department of Transportation, Joint Reference Paper, 20 June 1974.

Mays, R. A., Miller, M. P., Schott, G. J., "Intercity Freight Fuel Utilization at Low Package Densities: Airplanes, Express Trains and Trucks," paper presented at the Fifty-Fifth Annual Meeting of the Transportation Research Board, Session \#52, Washington, D.C., 20 January 1976.

Mazziotti, D. F., Meyer, M., "Railroad Abandonment: The Administrative Decision-Making Process," DOT-0S-40019, Institute of Urban and Regional Research, University of Iowa, U.S. Department of Transportation, Office of University Research, Washington, D.C. (June 1974). 
Mazziotti, D. F., Meyer, M. C., Dueker, K. J., "Railroad Abandonment and Re-Use Planning: Relationship with Statewide Transportation Planning and Citizen Participation," Interim Report, TR 33, The Institute of Urban and Regional Research, University of Iowa, U.S. Department of Transportation, Office of University Research, Washington, D.C. (December 1974).

McBrian, R., "New Motive Power Technology," Technological Change and the Railways, The Denver and Rio Grande Western Railroad, pp. 206-220.

McCa11, B. F., "Rails, Energy and Economics," paper presented at the Annual Railway Fuel and Operating Officers Association Meeting, 15 September 1975.

McClean, H. G., "Long-Term Trends in North American Diesel Power," Railway Gazette International, Vol. 129, No. 3, pp. 101-104 (March 1973).

Memmott, F., Scholz, F. S., "Trunk Route Analyses: A Useful Tool for Statewide and Regional Rail Planning," presented at the 55 th Annual Meeting of the Transportation Research Board, Washington, D. C., January 1976.

Moon, A. E., "Guidebook for Planning to Alleviate Urban Railroad Problems," Vo1. 3, DOT-FR-20037, Stanford Research Institute, prepared for U. S. Department of Transportation, Federal Railroad Administration, Federal Highway Administration (August 1974).

Mortimer, N. D., "The Energy Costs of Road and Rail Freight Transport: U. K. 1968," Open University, England (February 1974).

Mutch, J. J., "Transportation Energy Use in the United States: A Statistical History 1955-1971," Rand Corporation Santa Monica, California (December 1973).

National Academy of Sciences, "Optimizing the Use of Materials and Energy in Transportation Construction," Special Report 166, Transportation Research Board, Proceedings of a Conference, 12-14 November 1975.

"New York Subway Tries Out Flywheel Energy Storage," Railway Gazette International, Vol. 131, No. 1, pp.23-24 (January 1975).

"No Easy Answers in the Search for Fuel Economy," Railway Gazette International, Vo1. 131, No. 2, pp. 54-57 (February 1975).

Nouvion, F. F., "Electric or Diesel Traction: The Right Basis for Comparison," Railway Gazette International, Vol. 127, No. 10, pp. 377-380 (October 1971).

The Officia1 Railway Guide, North American Freight Service Edition, National Railway Publication Company, New York, 109th Year, No. 3, (November/December 1976). 
Peat, Marwick, Mitchell and Company, "Profiles of Public Transportation Plans and Programs: An Appendix to the 1974 National Transportation Report," U. S. Department of Transportation, Office of the Secretary, Washington, D. C. (May 1975).

Perry, C. F., Anderson, W., "Recent Experiences with Sulfur in Distillate Type Fuels Burned in U. S. Navy Diesel Engines," paper presented at the Diesel and Gas Engine Power Conference and Exhibit, Houston, Texas, 28 April-2 May 1974.

Petracek, S. J., et al., "Railroad Classification Yard Technology: A Survey and Assessment," DOT-TSC-968, Stanford Research Institute, U. S. Department of Transportation, Transportation Systems Center (July 1976).

Railway Fuel and Operating Officers Association, "Fuel Conservation From An Operating Viewpoint," Compiled by H. C. Eck (1976).

Raposa, R. L., "Energy Demand and Consumption Requirements for SolidState Controlled Linear Induction Motor Propulsion Systems," High Speed Ground Transportation Journal, Vol. 9, No. 1, pp. 345-353, (1975).

Raskin, D., Yutko, R. T., "Energy Storage Propulsion System for Rapid Transit Cars: System Design and Equipment Description," DOT-UT-550, Metropolitan Transportation Authority (NY), NY State Department of Transportation, Urban Mass Transportation Administration, Garrett Corporation (September 1975).

Raush, R. W., et al., "ATA Rail Transit Conference Held in San Francisco, California on April 14 and 16, 1974, Operations Sessions," American Transit Association (August 1974).

Reebie, R. S. et al., "National Intermodal Network Feasibility Study," Vols. 1-4, Part 1, DOT-FR-20065, Reebie Associates, prepared for U.S. Department of Transportation, Federal Railroad Administration (May 1976).

Reebie, R. S. et al., "National Intermodal Network Feasibility Study," Appendices 1-4, Part 2, DOT-FR-20065, Reebie Associates, Peat, Marwick, Mitchell and Company, prepared for U. S. Department of Transportation, Federal Railroad Administration (May 1976).

"Reliability: The New Dimension," Railway Locomotives and Cars, pp. 9-12 (Apri1 1973).

Rice, R. A., "Energy Efficiencies of the Transport Systems," CarnegieMellon University, Society of Automotive Engineers, prepared for Meeting, 8-12 April 1973, and International Automotive Engineering Congress, Detroit, Michigan, 8-12 January 1973. 
, "System Energy and Future Transportation," M. I. T. Technology Review (January 1972).

, "System Energy as a Factor in Considering Future Transportation," paper presented at American Society of Mechanical Engineers Annual Meeting, December 1970.

Roberts, F. S., "Weighted Digraph Models for Energy Use and Air Pollution in Transportation Systems" R-1578-NSF, Rand Corporation (December 1974).

Roberts, P. 0., "Forecasting Freight Flows Using a Disaggregate Freight Demand Mode1," paper presented at the Transportation Research Board Annual Meeting, January 1977.

Roberts, R., "How They Compare: Energy Efficiency of Transport Modes," Modern Railroads, Vol. 30, No. 11, pp. 52-56 (November 1975).

"Romanian Switcher Still Under U. S. Test," Railway Age (25 August 1975).

Ronan, W. J., "Gas "Turbine/Electric Cars in Commuter Service," paper presented at the Symposium on Rapid Transit Vehicles for City Services, 22-23 April 1971.

Ross, B. A., "Electric Energy for Transport in the Immediate Future," Railway Management Review, Vo1. 74, No. 2, pp. A6-A14 (1974).

, "Energy Aspects of Rail Electrication," American Electric Power Service Corporation, Wisconsin University, Madison, The Role of U. S. Railroads in Meeting the Nation's Energy Requirements, Proceedings of the conference held at the University of Wisconsin, 6-8 May 1974.

, "Meeting Tomorrow's Railroad Power Requirements," IEEE Transactions on Power Apparatus and Systems, Vol. 90, No. 2, pp. 393-400 (March 1971).

Roth, R. D., "An Approach to Measurement of Modal Advantage, "American Trucking Associations, Inc., Department of Economics, Washington, D. C. (December 1976).

Sanders, D. B., Reynen, T. A., "Characteristics of Urban Transportation Systems: A Handbook for Transportation Planners," DOT-UR-20019, De Leuw, Cather and Company, U. S. Department of Transportation, Urban Mass Transportation Administration, Federal Highway Administration (May 1974).

Santa Clara County Transit District, Metropolitan Transportation Commission, "Rapid Transit Development Project - (RTDP)," (9 March 1973) 
Sawyer, R., "Gas-Turbine Progress on the Railroads," ASME Journal of Mechanical Engineering, Vol. 94, No. 8, pp. 26-30 (August 1972).

Scott, W. M., "Economics for Positive Traction Control Equipped GP-40 Locomotives," Report No. 132, Technical Research Centre Research and Development, Canadian National Railways (19 May 1976).

Scott, W. M., Skene, R. B., "Positive Traction Wheel Slip Control: Its Development and Performance," paper presented at the Railway Fuel and Operating officers Association Annual Convention, Chicago, Illinois, 28 September 1976.

Scott, W. M., Skene, R. B., Biglow, B. A., "Locomotive Traction Performance Measurement," paper presented at the IEEE-ASME Joint Railroad Conference, San Francisco, California, 15-17 April 1975.

Sebald, A., Herendeen, R., "The Dollar, Energy, and Employment Impacts of Air, Rail, and Automobile Passenger Transportation," University of Illinois, Center for Advanced Computation, Energy Research Group, Urbana, Illinois (September 1974).

Shedd, T., "Main Line Electrification Coming Soon? Part I," Modern Rai1roads, Vol. 26, No. 5, pp. 40-43 (May 1971).

Sloss, J., Humphrey, T. J., Krutter, F. N., "An Analysis and Evaluation of Past Experience in Rationalizing Railroad Networks," DOT-OS-40002, Massachusetts Institute of Technology, prepared for U. S. Department of Transportation, Office of University Research (March 1975).

Smith, D. I., "How to Measure Specific Fuel Consumption - II," Railway Age, pp. 40-42 (23 February 1976).

Society of Automotive Engineers, Inc., "Powerplants for Industrial and Commercial Vehicles: A Look at Tomorrow," SP-270 (April 1965).

Spenny, C. H., "Simulation of Power Collection Dynamics for Simply Supported Power Rail," DOT-TSC-FRA-72-1, U. S. Department of Transportation, Transportation Systems Center, (November 1972).

Staeheli, G. A., "Fuel Conservation," paper presented at the Annual Railway Fuel and Operating Officers Association Meeting, 1974.

, "Fuel Conservation - Energy Conservation," paper presented at the Annual Railway Fuel and Operating Officers Association Meeting, 15 September 1975.

Stickler, J. J., "Evaluation of Noncontact Power Collection Techniques," DOT-TSC-FRA-72-7, U. S. Department of Transportation, Transportation Systems Center (July 1972). 
Storment, J. O., Wood, C. C., Mathis, R. J., "A Study of Fue1 Economy and Emission Reduction Methods for Marine and Locomotive Diesel Engines," DOT-TSC-OST-75-41, U. S. Department of Transportation, Office of the Secretary and U. S. Coast Guard, Washington, D. C. (September 1975).

Sudworth, J. L., Waldron, G. W. J., "The Role of Stored Energy in British Railways," paper presented at Conference on Energy, Europe and the $1980^{\prime} \mathrm{s}$, held in London, England, 6-10 May 1974.

Tassin, Y. M., "Energy and Time Savings Associated with Rapid Ground Transportation Systems," Railway Management Review, Vo1. 74, No. 2, pp. 1-8 (1974).

Tihansky, D. P., "Methods for Estimating the Volume and Energy Demand of Freight Transport," Rand Corporation, Santa Monica, California (December 1972).

Tope, D. W., "Rolling Resistance of Freight Cars," The Tim Ken Company (11 June 1971).

Turbut, G., Spirea, E., "Increase in the Role of the Railways in the Future, As a Result of Decreasing Costs of Transport and Energy Consumption," Rail International, No. 7, pp. 621-625 (July 1975).

"Unit Trains: Utility Acquires Aluminum Cars," Railway Locomotives and Cars, pp. 16-17 (October 1970).

United States Congress, Office of Technology Assessment, "A Review of National Railroad Issues," Washington, D. C. (December 1975).

United States Congress, Office of Technology Assessment, "Energy, the Economy, and Mass Transit," Washington, D. C. (December 1975).

United States Congress, Senate, Committee on Agriculture and Forestry, "Prelude to Legislation to Solve the Growing Crisis in Rural Transportation," Part 1, "Transportation in Rural America: An Analysis of the Current Crisis in Rural Transportation; Part 2: Meeting Rura1 Transportation Needs," The Economic Research Service, U. S. Department of Agriculture, The National Area Development Institute, Lexington, Kentucky, prepared for the 94 th Congress, 1st Session, Washington, D. C. (10 February 1975).

United States Congress, Senate, Committee on Public Works, "Transportation and the New Energy Policies (Part 1)," prepared for the 93rd Congress, 1st Session (11 December 1973).

United States Department of Transportation, "1974 National Transportation Report: Current Performance and Future Prospects," Office of Transportation Planning Analysis, Washington, D. C. (July 1975). 
United States Department of Transportation, Federal Railroad Administration, "A Review of Factors Influencing Railroad Electrification," FRA-OPP-74-01, paper presented at the Third International Electric Vehicle Symposium, Washington, D. C., 20 February 1974.

United States Department of Transportation, Federal Railroad Administration, "1973 Carload Waybill Statistics. Territorial Distribution, Traffic and Revenue by Commodity Classes," Office of Rail Systems Analysis and Program Development, Washington, D. C. (June 1975).

United States Department of Transportation, Federal Railroad Administration, "Proceedings of the llth Annual Railroad Engineering Conference, Cooperative Research Effort Among Railroads, Railroad Associations, Industry and Government," held at Pueblo, Colorado, 23-24 October 1974 .

United States Department of Transportation, Federal Railroad Administration, "Proceedings: Symposium on Economic and Public Policy Factors Influencing Light Density Rail Line Operations, 10-11 January 1973, University of Colorado, Boulder," Washington, D. C. (1973).

United States Department of Transportation, Federal Railroad Administration, "12th Annual Railroad Conference Proceedings, Effect of Heavy Axle Loads on Track," FRA OR\&D 76-243, held at Pueblo, Colorado, 23-24 October 1975 .

United States Department of Transportation, Federal Railroad Administration, Federal Highway Administration, "Report to Congress: RailroadHighway Safety Part II: Recommendations for Resolving the Problem" (August 1972).

United States Department of Transportation, Federal Railroad Administration, The Wisconsin Department of Transportation, "Proceedings: The Role of the U. S. Railroads in Meeting the Nation's Energy Requirements," conference held at the University of Wisconsin, Madison, 6-8 May 1974.

United States Department of Transportation, Secretary of Transportation, "Railroad Abandonments and Alternatives: A Report on Effects Outside the Northeastern Region," Report to the United States Congress, Washington, D. C. (May 1976).

United States Department of Transportation, Transportation Systems Center, "Energy Statistics: A Supplement to the Summary of National Transportation Statistics" (August 1976).

United States Department of Transportation, Transportation Systems Center, "Freight Transportation: A Digest of Technical Papers," Vo1. 1, DOT-TSC-OST-77-68, (28 October 1976).

United States Department of Transportation, Transportation Systems Center, "Research and Development Opportunities for Improved Transportation Energy Usage," DOT-TSC-OST-73-14 (September 1972). 
United States Department of Transportation, Urban Mass Transportation Administration, "Subway Environmenta1 Design Handbook," Vo1. 1,

"Principles and Applications," 2nd Edition, Washington, D. C. (1976).

United States General Accounting Office, U. S. Comptroller General, "Information Available on Estimated Costs to Rehabilitate the Nation's Railroad Track and a Summary of Federal Assistance to the Industry," RED-76-44, Report to Congress, 21 November 1975.

United States Railway Association, "Final System Plan, Volume I (Parts I and II): for Restructuring Railroads in the Northeast and Midwest Region Pursuant to the Regional Rail Reorganization Act of 1973" (26 Ju1y 1975).

United States Railway Association, "Preliminary System Plan, Volume I: for Restructuring Railroads in the Northeast and Midwest Region Pursuant to the Regional Rail Reorganization Act of 1973" (26 February 1975).

Walbridge, E. W., "Per Passenger-Mile Energy Consumption and Costs for Suburban Commuter Service Diese1 Trains," UMTA-IL-11-0006-74-1, University of I1linois, Chicago Circle (August 1974).

"The Way Ahead for the Diesel-Hydraulic," Railway Gazette International, Vo1. 129, No. 3, pp. 105-109 (March 1973).

Westinghouse Electric Corporation, "Electric Power Systems for High Speed Ground Transportation," DOT-9-0025, Transportation Division (August 1969).

Winestone, R. L., "Estimating AMTRAK Ridership," Rail Passenger Programs Division (August 1976).

Wojciechowski, P.H., Dunn, H., "Energy Regeneration and Conversion Efficiency in a Hydraulic Hybrid Propulsion System," High Speed Ground Transportation Journa1, Vo1. 9, No. 1, pp. 383-392 (1975).

Wong, J. Y., "System Energy in High Speed Ground Transportation," High Speed Ground Transportation Journa1, Vol. 9, No. 1, pp. 307-320 (1975).

Yasukawa, S., Todoriki, M. "Calculation of Optimal Train Performance Curves in the UHSGT," Railway Technical Research Institute, Quarterly Report, Vo1. 15, No. 3, pp. 160-161 (September 1974). 